Cochrane Database of Systematic Reviews

\title{
Probiotics for preventing acute otitis media in children (Review)
}

Scott AM, Clark J, Julien B, Islam F, Roos K, Grimwood K, Little P, Del Mar CB

Scott AM, Clark J, Julien B, Islam F, Roos K, Grimwood K, Little P, Del Mar CB. Probiotics for preventing acute otitis media in children.

Cochrane Database of Systematic Reviews 2019, Issue 6. Art. No.: CD012941.

DOI: 10.1002/14651858.CD012941.pub2.

www.cochranelibrary.com 
TABLE OF CONTENTS

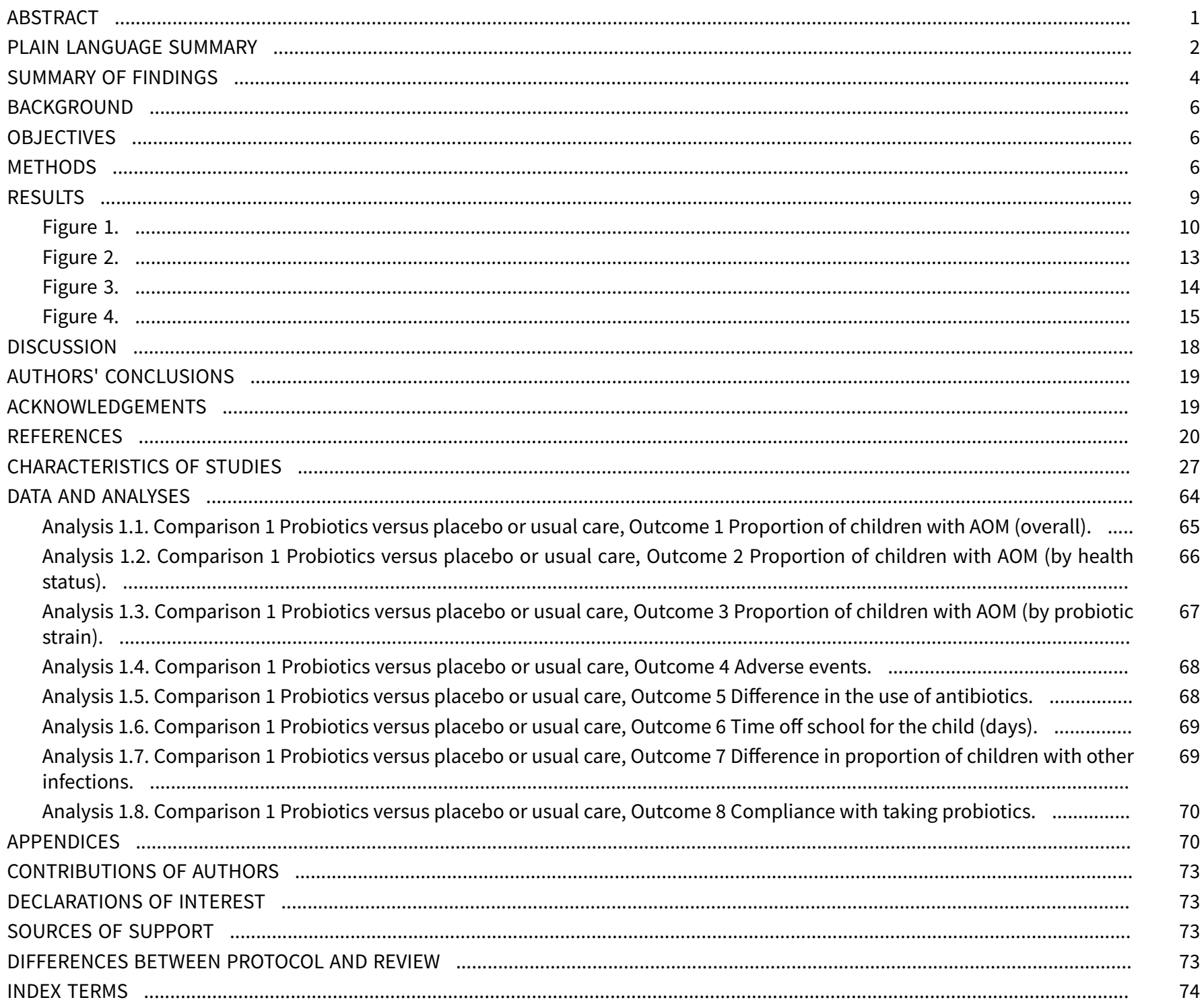


[Intervention Review]

\section{Probiotics for preventing acute otitis media in children}

Anna M Scott ${ }^{1}$, Justin Clark ${ }^{1}$, Blair Julien², Farhana Islam² ${ }^{2}$ Kristian Roos ${ }^{3}$, Keith Grimwood ${ }^{4}$, Paul Little ${ }^{5}$, Chris B Del Mar ${ }^{1}$

${ }^{1}$ Centre for Research in Evidence-Based Practice (CREBP), Bond University, Gold Coast, Australia. ${ }^{2}$ Bond University, Robina, Australia. 3ENT Department, Lundby Hospital, Goteborg, Sweden. ${ }^{4}$ School of Medicine and Menzies Health Institute Queensland, Griffith University and Departments of Infectious Diseases and Paediatrics, Gold Coast Health, Gold Coast, Australia. 5 Primary Care and Population Sciences, Faculty of Medicine, Aldermoor Health Centre, University of Southampton, Southampton, UK

Contact: Anna M Scott, Centre for Research in Evidence-Based Practice (CREBP), Bond University, 14 University Drive, Gold Coast, Queensland, 4229, Australia. ascott@bond.edu.au.

Editorial group: Cochrane Acute Respiratory Infections Group.

Publication status and date: New, published in Issue 6, 2019.

Citation: Scott AM, Clark J, Julien B, Islam F, Roos K, Grimwood K, Little P, Del Mar CB. Probiotics for preventing acute otitis media in children. Cochrane Database of Systematic Reviews 2019, Issue 6. Art. No.: CD012941. DOI: 10.1002/14651858.CD012941.pub2.

Copyright ( 2019 The Cochrane Collaboration. Published by John Wiley \& Sons, Ltd.

\section{A B S T R A C T}

\section{Background}

Acute otitis media (AOM), or acute middle ear infection, is one of the most frequently occurring childhood diseases, and the most common reason given for prescribing antibiotics in this age group. Guidelines often recommend antibiotics as first-line treatment for severe AOM. However, antibiotics also lead to antibiotic resistance, so preventing episodes of AOM is an urgent priority.

\section{Objectives}

To assess the effects of probiotics to prevent the occurrence and reduce the severity of acute otitis media in children.

\section{Search methods}

We searched CENTRAL, PubMed, Embase, and three other databases (October 2018), two trial registers (October 2018), and conducted a backwards and forwards citation analysis (August 2018). We did not apply any language, publication date, or publication status restrictions.

\section{Selection criteria}

Randomised controlled trials (RCTs) of children (aged up to 18 years), comparing probiotics with placebo, usual care, or no probiotic.

\section{Data collection and analysis}

Two review authors independently assessed the eligibility of trials for inclusion and risk of bias of the included trials, and extracted data using pre-piloted data extraction forms. We analysed dichotomous data as either risk ratio (RR) or odds ratios (OR) and continuous data as mean differences (MD).

\section{Main results}

We included 17 RCTs involving 3488 children, of which 16 RCTs were included in the meta-analyses. Of the 16 RCTs that reported the mean age of children, mean age overall was 2.4 years; in 4 RCTs the mean age of children participating in the trial was less than 1 year old; in 2 RCTs the mean age was between 1 and 2 years old; and in 10 RCTs the mean age was older than 2 years. Probiotic strains evaluated by the trials varied, with 11 of the included RCTs evaluating Lactobacillus-containing probiotics, and six RCTs evaluating Streptococcuscontaining probiotics.

The proportion of children (i.e. the number of children in each group) experiencing one or more episodes of AOM during the treatment was lower for those taking probiotics (RR 0.77, 95\% confidence interval (CI) 0.63 to $0.93 ; 16$ trials; 2961 participants; number needed to treat for an additional beneficial outcome (NNTB) = 10; moderate-certainty evidence). 
Post hoc subgroup analysis found that among children not prone to otitis media, a lower proportion of children receiving probiotics experienced AOM (RR 0.64, 95\% Cl 0.49 to 0.84; 11 trials; 2227 participants; NNTB = 9; moderate-certainty evidence). However, among children who were otitis prone, there was no difference between probiotic and comparator groups (RR 0.97, 95\% $\mathrm{Cl} 0.85$ to $1.11 ; 5$ trials; 734 participants; high-certainty evidence). The test for subgroup differences was significant $(P=0.007)$.

None of the included trials reported on the severity of AOM.

The proportion of children experiencing adverse events did not differ between the probiotic and comparator groups (OR $1.54,95 \% \mathrm{Cl} 0.60$ to 3.94 ; 4 trials; 395 participants; low-certainty evidence).

Probiotics decreased the proportion of children taking antibiotics for any infection (RR $0.66,95 \% \mathrm{Cl} 0.51$ to $0.86 ; 8$ trials; 1768 participants; NNTB $=8$; moderate-certainty evidence). Test for subgroup differences (use of antibiotic specifically for AOM, use of antibiotic for infections other than AOM) was not significant.

There was no difference in the mean number of school days lost (MD $-0.95,95 \% \mathrm{Cl}-2.47$ to $0.57 ; 5$ trials; 1280 participants; moderatecertainty evidence). There was no difference between groups in the level of compliance in taking the intervention (RR $1.02,95 \% \mathrm{Cl} 0.99$ to $1.05 ; 5$ trials; 990 participants).

Probiotics decreased the proportion of children having other infections (RR 0.75, 95\% $\mathrm{Cl} 0.65$ to $0.87 ; 11$ trials; 3610 participants; NNTB $=12$; moderate-certainty evidence). Test for subgroup differences (acute respiratory infections, gastrointestinal infections) was not significant.

Probiotic strains trialled and their dose, frequency, and duration of administration varied considerably across studies, which likely contributed to the substantial levels of heterogeneity. Sensitivity testing of funnel plots did not reveal publication bias.

\section{Authors' conclusions}

Probiotics may prevent AOM in children not prone to AOM, but the inconsistency of the subgroup analyses suggests caution in interpreting these results. Probiotics decreased the proportion of children taking antibiotics for any infection. The proportion of children experiencing adverse events did not differ between the probiotic and comparator groups. The optimal strain, duration, frequency, and timing of probiotic administration still needs to be established.

\section{PLAIN LANGUAGE SUMMARY}

\section{Probiotics ('healthy bacteria') for preventing acute middle ear infection in children}

\section{Review question}

Does taking probiotics ('healthy bacteria') prevent children from getting acute middle ear infections?

\section{Background}

Acute middle ear infection is very common in childhood. It is caused by bacteria that travel from the upper part of the throat, through canals (called Eustachian tubes), to the middle ear. Symptoms include fever, earache, and occasionally the eardrum may perforate, discharging pus into the ear canal.

Antibiotics are often prescribed for acute middle ear infection, although they have only a modest effect on reducing symptoms. Moreover, excessive antibiotic use leads to antibiotic resistance, making them less effective for these and other infections. Consequently, preventing acute middle ear infection is highly desirable.

Probiotics are often sold as tablets or powders, as a food ingredient (e.g. in yogurt), and even sprayed directly into the throat. However, it is not yet clear whether they prevent acute middle ear infection. We analysed the scientific evidence to answer this question.

\section{Study characteristics and searches}

We searched and identified 17 randomised controlled trials (studies in which participants are assigned to one of two or more treatment groups using a random method), published before October 2018. All were conducted in Europe, and collectively included 3488 children. Twelve trials included children who were not prone to acute middle ear infections, whilst five trials included children who were prone to such infections.

\section{Key results}

One-third fewer children not prone to acute middle ear infection who took probiotics experienced acute middle ear infections compared to children not taking probiotics. However, probiotics may not benefit children prone to acute middle ear infection. Taking probiotics did not impact on the number of days of school that children missed. None of the studies reported on the impact of probiotics on the severity of acute middle ear infection. There was no difference between the group taking probiotics and the group not taking probiotics in the number of children experiencing adverse events (harms). 


\section{Quality of the evidence}

The quality (or certainty) of the evidence was generally moderate (meaning that further research may change our estimates) or high (further research is unlikely to change our estimates). However, the trials differed in terms of types of probiotics evaluated, how often and for how long they were taken, and how the trial results were reported. 


\begin{tabular}{|c|c|c|c|c|c|c|}
\hline \multicolumn{7}{|c|}{$\begin{array}{l}\text { S U M M A R Y O F F I N D I N G S } \\
\text { Summary of findings for the main comparison. Probiotic compared to placebo for preventing acute otitis media in children }\end{array}$} \\
\hline \multicolumn{7}{|c|}{ Probiotic compared to placebo for preventing acute otitis media in children } \\
\hline \multicolumn{7}{|c|}{$\begin{array}{l}\text { Patient or population: children up to age } 18 \text { years } \\
\text { Setting: community, primary care, and secondary care } \\
\text { Intervention: any probiotic, delivered by any means } \\
\text { Comparison: comparator }\end{array}$} \\
\hline \multirow[t]{2}{*}{ Outcomes } & \multicolumn{2}{|c|}{$\begin{array}{l}\text { Anticipated absolute effects* }(95 \% \\
\mathrm{CI})\end{array}$} & \multirow[t]{2}{*}{$\begin{array}{l}\text { Relative effect } \\
(95 \% \mathrm{Cl})\end{array}$} & \multirow{2}{*}{$\begin{array}{l}\text { № of partici- } \\
\text { pants } \\
\text { (studies) }\end{array}$} & \multirow{2}{*}{$\begin{array}{l}\text { Certainty of } \\
\text { the evidence } \\
\text { (GRADE) }\end{array}$} & \multirow[t]{2}{*}{ Comments } \\
\hline & $\begin{array}{l}\text { Risk with } \\
\text { placebo }\end{array}$ & $\begin{array}{l}\text { Risk with probi- } \\
\text { otic }\end{array}$ & & & & \\
\hline \multirow{2}{*}{$\begin{array}{l}\text { Proportion of chil- } \\
\text { dren with AOM (over- } \\
\text { all) }\end{array}$} & \multicolumn{2}{|c|}{ Study population } & \multirow{2}{*}{$\begin{array}{l}\text { RR } 0.77 \\
(0.63 \text { to } 0.93)\end{array}$} & \multirow{2}{*}{$\begin{array}{l}2961 \\
(16 \mathrm{RCTs})\end{array}$} & \multirow{2}{*}{$\begin{array}{l}\oplus \oplus \oplus \ominus \\
\text { MODERATE } 1\end{array}$} & \multirow{2}{*}{$\begin{array}{l}\text { We conducted a post hoc sensitivity analysis by } \\
\text { health status (children prone to AOM versus chil- } \\
\text { dren not prone to } A O M) \text {. The test for subgroup } \\
\text { differences was significant ( } P=0.007 \text { ). The fol- } \\
\text { low-up duration ranged from } 20 \text { days to } 2 \text { years. }\end{array}$} \\
\hline & 390 per 1000 & $\begin{array}{l}300 \text { per } 1000 \\
(246 \text { to } 362)\end{array}$ & & & & \\
\hline \multirow{2}{*}{$\begin{array}{l}\text { Proportion of chil- } \\
\text { dren with AOM: } \\
\text { children not prone to } \\
\text { AOM }\end{array}$} & \multicolumn{2}{|c|}{ Study population } & \multirow{2}{*}{$\begin{array}{l}\text { RR } 0.64 \\
\text { (0.49 to } 0.84)\end{array}$} & \multirow{2}{*}{$\begin{array}{l}2227 \\
(11 \mathrm{RCTs})\end{array}$} & \multirow{2}{*}{$\begin{array}{l}\oplus \oplus \oplus \odot \\
\text { MODERATE2 }\end{array}$} & \multirow{2}{*}{$\begin{array}{l}\text { The follow-up duration ranged from } 20 \text { days to } 2 \\
\text { years. }\end{array}$} \\
\hline & 295 per 1000 & $\begin{array}{l}189 \text { per } 1000 \\
\text { (145 to } 248)\end{array}$ & & & & \\
\hline \multirow{2}{*}{$\begin{array}{l}\text { Proportion of chil- } \\
\text { dren with AOM: } \\
\text { children prone to } \\
\text { AOM }\end{array}$} & \multicolumn{2}{|c|}{ Study population } & \multirow{2}{*}{$\begin{array}{l}\text { RR } 0.97 \\
\text { (0.85 to } 1.11 \text { ) }\end{array}$} & \multirow{2}{*}{$\begin{array}{l}734 \\
\text { (5 RCTs) }\end{array}$} & \multirow{2}{*}{$\begin{array}{l}\oplus \oplus \oplus \oplus \\
\mathrm{HIGH}\end{array}$} & \multirow{2}{*}{$\begin{array}{l}\text { The follow-up duration ranged from } 20 \text { days to } 2 \\
\text { years. }\end{array}$} \\
\hline & 660 per 1000 & $\begin{array}{l}641 \text { per } 1000 \\
\text { (561 to } 733)\end{array}$ & & & & \\
\hline Severity of AOM & No data & No data & No data & No data & $\mathrm{N} / \mathrm{A}$ & $\begin{array}{l}\text { None of the included studies reported on this } \\
\text { outcome. }\end{array}$ \\
\hline \multirow[t]{2}{*}{ Adverse events } & \multicolumn{2}{|c|}{ Study population } & \multirow{2}{*}{$\begin{array}{l}\text { OR } 1.54 \\
\text { (0.60 to } 3.94)\end{array}$} & \multirow{2}{*}{$\begin{array}{l}395 \\
(4 \mathrm{RCTs})\end{array}$} & \multirow{2}{*}{$\begin{array}{l}\oplus \oplus \odot \odot \\
\text { LOW3 }\end{array}$} & \multirow{2}{*}{$\begin{array}{l}\text { The follow-up duration ranged from } 20 \text { days to } 2 \\
\text { years. }\end{array}$} \\
\hline & 186 per 1000 & $\begin{array}{l}260 \text { per } 1000 \\
(121 \text { to } 474)\end{array}$ & & & & \\
\hline
\end{tabular}




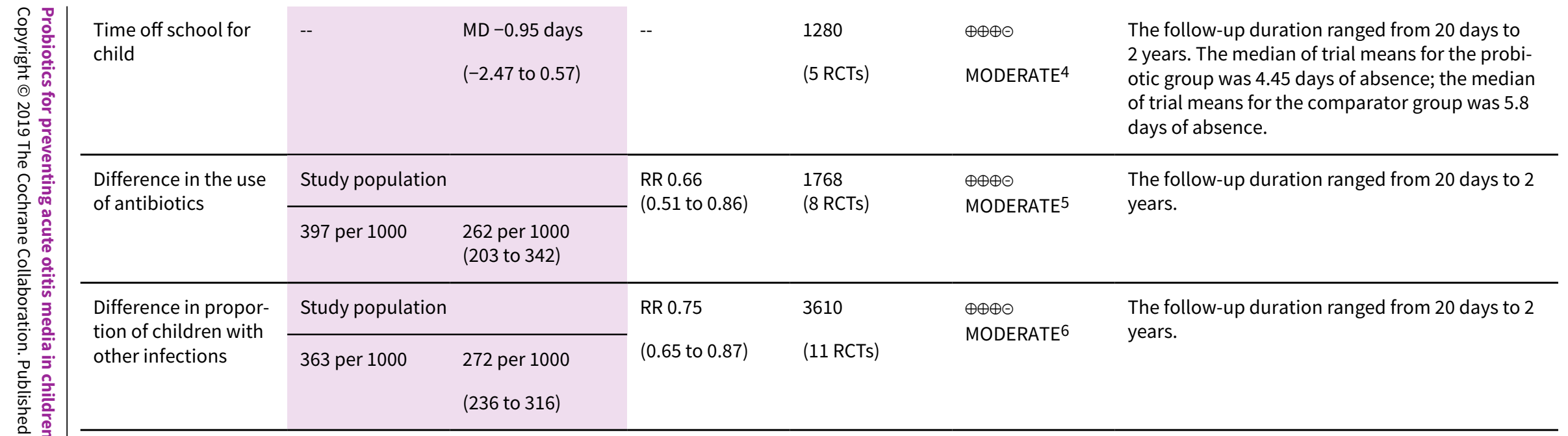

*The risk in the intervention group (and its $95 \%$ confidence interval) is based on the assumed risk in the comparison group and the relative effect of the intervention (and its $95 \% \mathrm{Cl}$ ).

AOM: acute otitis media; Cl: confidence interval; MD: mean difference; N/A: not applicable; OR: odds ratio; RCT: randomised controlled trial; RR: risk ratio

\section{GRADE Working Group grades of evidence}

High certainty: We are very confident that the true effect lies close to that of the estimate of the effect.

Moderate certainty: We are moderately confident in the effect estimate: the true effect is likely to be close to the estimate of the effect, but there is a possibility that it is substantially different.

Low certainty: Our confidence in the effect estimate is limited: the true effect may be substantially different from the estimate of the effect.

Very low certainty: We have very little confidence in the effect estimate: the true effect is likely to be substantially different from the estimate of effect.

1Downgraded one level for substantial heterogeneity $(72 \%)$

2Downgraded one level for moderate/substantial heterogeneity (59\%).

3Downgraded two levels for imprecision, wide confidence intervals, and small number of participants.

4 Downgraded one level for moderate heterogeneity (54\%).

5 Downgraded one level for substantial heterogeneity (70\%).

${ }^{6}$ Downgraded one level for substantial heterogeneity (64\%). 


\section{B A C K G R O U N D}

\section{Description of the condition}

Acute otitis media (AOM) is one of the most common childhood infections. It is characterised by effusion of the middle ear and rapid onset of symptoms such as fever, malaise, ear pain, and, on occasion, otorrhoea (discharge from the ear) (AAP 2013). Although AOM has low mortality, it has a high disease burden (Stool 1989); by two years of age, $70 \%$ of children have had at least one episode of $\mathrm{AOM}$, and $20 \%$ to $30 \%$ of children have experienced three or more episodes (Hatakka 2007b). Globally, the incidence rate (new episodes of AOM per hundred people per year) is estimated at $10.85 \%$ (the equivalent of 709 million cases of AOM annually); the incidence rate varies, from a low of $3.64 \%$ in Central Europe to $43.37 \%$ in central sub-Saharan Africa (Monasta 2012).

Clinical care guidelines for treatment of AOM vary internationally. For mild-moderate cases, 'watchful waiting' has now been adopted in many high-income countries, although this remains infrequent in low-income countries (Tamir 2017). Most guidelines recommend amoxicillin as first-line treatment, with some exceptions: amoxicillin-clavulanate in some high-income countries, penicillin $\mathrm{V}$ in Scandinavian countries, whilst other first-line treatments in low-income countries include trimethoprim-sulphamethoxazole, cephalexin, cloxacillin, and others (Tamir 2017). Accordingly, AOM is one of the main reasons given for prescribing antibiotics in children (Hendley 2002). However, the rates of antibiotic prescription for AOM vary internationally, from $56 \%$ of consultations for AOM in the Netherlands (Akkerman 2005), to 89\% to 95\% in Australia and North America, respectively (Froom 2001; McCullough 2017). Antibiotic use leads to antibiotic resistance, therefore there is increased interest in identifying novel means of preventing AOM, especially since randomised clinical trials of pneumococcal and influenza vaccines have demonstrated limited protective efficacy against AOM (Cohen 2013b; Dagan 2016; Fortanier 2014; Hatakka 2007b; Jefferson 2018; Niittynen 2012).

\section{Description of the intervention}

The World Health Organization (WHO) defines probiotics as live micro-organisms that confer a health benefit on the host when administered in adequate amounts (FAO-WHO 2006). Microorganisms used as probiotics include: Lactobacillus (e.g. L acidophilus, L fermentum), Bifidobacterium (e.g. B bifidum, B lactis), Streptococcus (e.g. S thermophiles) species, and Saccharomyces (e.g. S boulardii) species (Niittynen 2012). Probiotics are available in multiple forms: as tablets or powders or liquid drops (regulated as dietary supplements), as a food ingredient (e.g. yogurt or kefir) (Wang 2016), or directly applied by spray to the throat (Roos 2001b). While probiotics are not currently routinely used in clinical practice, they can be used by adults and children (Wang 2016), and are not generally believed to have harmful effects in healthy, immunocompetent people (Marteau 2002).

\section{How the intervention might work}

Acute otitis media is thought to be caused by pathogenic bacteria entering the middle ear cleft from the nasopharynx via the Eustachian tubes. Probiotics may restore the balance of the normal microbiota (Hatakka 2007b), although the mechanism for this is unclear (Hao 2015); they may stabilise gut microbiota; maintain epithelial cell barrier function; modulate immune function; compete with pathogens for nutrients or adhesion sites on epithelial cell surfaces; produce bacteriocins or other inhibitory substances (Hao 2015; Hatakka 2007b; Niittynen 2012).

\section{Why it is important to do this review}

Concern about antibiotic use leading to increased antibiotic resistance has created interest in alternative managements ( $O$ 'Neill 2014), which include probiotics (Hatakka 2007b). Cochrane Reviews have investigated other interventions for the prevention of otitis media, including xylitol (Azarpazhooh 2016), pneumococcal conjugate vaccines (Fortanier 2014), and influenza vaccines (Norhayati 2017). Another Cochrane Review that addressed probiotics to prevent acute respiratory tract infections did not include trials with AOM on the grounds that otitis-prone children may have immunodeficiencies (Hao 2015).

\section{O B J E C T IVES}

To assess the effects of probiotics to prevent the occurrence and reduce the severity of acute otitis media in children.

\section{METHODS}

\section{Criteria for considering studies for this review \\ Types of studies}

Randomised controlled trials (RCTs), irrespective of study design (e.g. cluster, parallel, cross-over) and publication type (full text, abstract only, unpublished data).

\section{Types of participants}

Children (aged up to 18 years).

We excluded children with the following comorbidities or characteristics: chromosomal and genetic disorders; craniofacial abnormalities, including cleft palate; those taking systemic corticosteroids or with immune deficiency status; and those with cystic fibrosis or primary ciliary dyskinesia.

\section{Types of interventions}

We included trials comparing probiotics with placebo or usual care or no probiotic. The probiotics could be of any composition (e.g. powder, drink, spray). Any co-intervention (including antibiotics) applied to both the intervention and control groups could be used.

\section{Types of outcome measures}

\section{Primary outcomes}

1. Proportion of children with AOM (in each group) (i.e. the number of children experiencing one or more episodes of AOM during the treatment).

2. Severity of AOM.

3. Adverse events (e.g. gastrointestinal side effects).

\section{Secondary outcomes}

1. Median duration of AOM episodes (days).

2. Difference in the use of antibiotics (e.g. dose, duration).

3. Time off school (for the child) (e.g. in days or hours).

4. Time off work (for the parent or carer) (e.g. in days or hours).

5. Difference between groups in hearing loss, if AOM occurs.

6. Serous/secretory otitis media. 
7. Difference in referrals to a specialist (e.g. for glue ear).

8. Difference in other infections (respiratory and gastrointestinal).

9. Compliance with taking probiotics (e.g. measured by pill count or weight of the spray bottle).

10.Quality of life measures (using any validated quality of life measure).

11.Difference in use of other treatments (e.g. differences in dosage of analgesics, decongestants).

\section{Search methods for identification of studies}

\section{Electronic searches}

We searched the following bibliographic databases:

1. Cochrane Central Register of Controlled Trials (CENTRAL; 2018, Issue 9, September), which includes the Cochrane Acute Respiratory Infections Group Specialised Register, in the Cochrane Library (searched 4 October 2018);

2. PubMed (1946 to 4 October 2018);

3. Embase Elsevier (1947 to 4 October 2018);

4. CINAHL EBSCO (Cumulative Index to Nursing and Allied Health Literature, 1982 to 4 October 2018);

5. LILACS (Latin American and Caribbean Health Science Information database, 1982 to 4 October 2018); and

6. Web of Science (1900 to 4 October 2018).

We searched the following trial registries:

1. US National Institutes of Health Ongoing Trials Register ClinicalTrials.gov (www.clinicaltrials.gov) (searched 10 October 2018); and

2. World Health Organization International Clinical Trials Registry Platform (WHO ICTRP) (apps.who.int/trialsearch/) (searched 10 October 2018).

We used the search strategies described in Appendix 1 to search the bibliographic databases. Where appropriate, these were combined with the Cochrane Highly Sensitive Search Strategy for randomised trials: sensitivity and precision-maximising version (2008 revision) (Lefebvre 2011). We did not impose any language, publication date, or publication status restrictions.

We used the search strategies described in Appendix 2 to search ClinicalTrials.gov and the WHO ICTRP to identify published registered trials, as well as ongoing trials.

We conducted a backwards (cited) and forwards (citing) citation analyses on all included trials in Web of Science (28 August 2018). As we identified no additional trials, we did not carry out the use of the similar article feature in PubMed and the shared citation matcher in Web of Science.

\section{Searching other resources}

We contacted experts in the field to identify additional unpublished materials, however as no relevant unpublished completed trials were identified, we did not need to contact trial investigators for unpublished data.

\section{Data collection and analysis}

\section{Selection of studies}

Two review authors (AMS and JC, AMS and FI, or AMS and BJ) independently screened the titles and abstracts identified as a result of the search for potentially relevant trials. We retrieved the full-text study reports/publication of all studies deemed potentially relevant, and two review authors (AMS and JC, AMS and FI, or AMS and $\mathrm{BJ}$ ) independently screened the full texts and identified trials for inclusion, and identified and recorded reasons for exclusion of the ineligible trials. Any disagreements were resolved through discussion or by consulting a third review (CDM) author when necessary. We identified and excluded duplicates and collated multiple reports of the same study so that each study, rather than each report, was the unit of interest in the review. We recorded the selection process in sufficient detail to complete a PRISMA flow diagram and Characteristics of excluded studies table (Moher 2009). We did not impose any language restrictions.

\section{Data extraction and management}

We used a data collection form for study characteristics and outcome data that had been piloted on two trials in the review. Two review authors (AMS and $\mathrm{FI}$, or AMS and BJ) independently extracted the following study characteristics from the included trials.

1. Methods: study location, study design, study objective, study duration.

2. Participants: N, type of participants, mean age, age range, gender, comorbidities, number of previous episodes of otitis media, diagnostic criteria.

3. Interventions: probiotic type, duration, dose, comparison, other permitted interventions (e.g. concomitant analgesics, decongestants), other prohibited interventions (e.g. analgesics, decongestants).

4. Outcomes: primary and secondary outcomes specified and collected, and time points reported.

5. Notes: funding for trial, and notable conflicts of interest of trial authors.

We noted in the Characteristics of included studies table if outcome data were not reported in a useable way. Any disagreements were resolved by consensus or by involving a third review author (CDM). One review author (AMS) transferred data into the Review Manager 5 file (RevMan 2014). We double-checked that data were entered correctly by comparing the data presented in the systematic review with the study reports. A second review author (CDM) also conducted a spot-check of study characteristics for accuracy against the trial report.

\section{Assessment of risk of bias in included studies}

Two review authors (AMS and FI, or AMS and BJ) independently assessed risk of bias for each study using the criteria outlined in the Cochrane Handbook for Systematic Reviews of Interventions (Higgins 2011). Any disagreements were resolved by discussion or by involving another review author (CDM). We assessed risk of bias according to the following domains.

1. Random sequence generation.

2. Allocation concealment. 
3. Blinding of participants and personnel.

4. Blinding of outcome assessment.

5. Incomplete outcome data.

6. Selective outcome reporting.

7. Other bias.

We graded each potential source of bias as high, low, or unclear, and provided a quote from the study report together with a justification for our judgement in the 'Risk of bias' table. We summarised the 'Risk of bias' judgements across different trials for each of the domains listed. When considering treatment effects, we took into account the risk of bias for the trials that contributed to that outcome.

\section{Assessment of bias in conducting the systematic review}

We conducted the review according to our published protocol (Scott 2018), and reported any deviations from it in the Differences between protocol and review section of the review.

\section{Measures of treatment effect}

One review author (AMS) entered the outcome data for each study into the data tables in Review Manager 5 to calculate the treatment effects (RevMan 2014). We analysed dichotomous data as either risk ratio (RR) or odds ratios (OR) and continuous data as mean differences (MD).

We calculated the number needed to treat for an additional beneficial outcome (NNTB) in the following manner: NNTB = 1/ARR, where $A A R=$ absolute risk reduction, that is the absolute difference between the event rate in the untreated (comparator) and treated (probiotic) groups.

We undertook meta-analyses only where this was meaningful, that is if the treatments, participants, and the underlying clinical question were similar enough for pooling to make sense. If metaanalysis was possible, we used a random-effects model due to high heterogeneity of the included trials.

\section{Unit of analysis issues}

We used the participant as the unit of analysis; one cluster-RCT met our inclusion criteria (Stecksen-Blicks 2009), but it reported individual data, permitting the use of participant as the unit of analysis. Nocerino 2017 was a three-armed trial with two probiotics arms. We combined the probiotics arms to form one intervention group for the meta-analysis.

\section{Dealing with missing data}

We intended to contact investigators or study sponsors to verify key study characteristics and to obtain missing numerical outcome data where possible (e.g. when a study was identified as abstract only), however we included no incomplete or abstract-only trials in the review.

Where outcome data for standard deviations were missing, we calculated them from $95 \%$ confidence intervals (where available) according to the methods described in the Cochrane Handbook for Systematic Reviews of Interventions (Higgins 2011), or from the range data (Hozo 2005).

\section{Assessment of heterogeneity}

We used the $1^{2}$ statistic to measure heterogeneity amongst the trials in each analysis. If we identified substantial heterogeneity and there were sufficient data, we reported the heterogeneity and explored possible causes for it by subgroup analysis (e.g. see Analyses 1.1.1, 1.1.2, 1.1.3). We considered an $\mathrm{I}^{2}$ statistic value of $0 \%$ to $40 \%$ as low heterogeneity; $41 \%$ to $60 \%$ as moderate heterogeneity; $61 \%$ to $90 \%$ as substantial heterogeneity; and over $91 \%$ as considerable heterogeneity (Higgins 2011).

\section{Assessment of reporting biases}

As we were able to pool more than 10 trials, we created a funnel plot to explore possible small-study and publication bias.

\section{Data synthesis}

We pooled data from trials we judged to be clinically homogeneous using Review Manager 5 (RevMan 2014). Where three or more trials provided useable data in any single comparison, we performed a meta-analysis. We had expected sizeable heterogeneity in terms of populations, probiotics studied, etc., which materialised, therefore we used the random-effects model. Where the volume of evidence was insufficient to perform a meta-analysis, we reported outcomes in a narrative format.

\section{GRADE and 'Summary of findings' table}

We created a 'Summary of findings' table using the following outcomes: proportion of children with AOM; proportion of children with $A O M$ among children not prone to $A O M$; proportion of children with $\mathrm{AOM}$ among children prone to $\mathrm{AOM}$; severity of $\mathrm{AOM}$; adverse events; time off school; antibiotic use; and proportion of children with other infections. We used the five GRADE considerations (study limitations, consistency of effect, imprecision, indirectness, and publication bias) to assess the quality (certainty) of a body of evidence as it related to the trials that contributed data to the meta-analyses for the prespecified outcomes (Atkins 2004). We used the methods and recommendations described in Section 8.5 and Chapter 12 of the Cochrane Handbook for Systematic Reviews of Interventions (Higgins 2011), employing GRADEpro GDT software (GRADEpro GDT 2015). We justified all decisions to downor upgrade the quality (certainty) of studies using footnotes, and made comments to aid the reader's understanding of the review where necessary.

\section{Subgroup analysis and investigation of heterogeneity}

We conducted the following subgroup analyses:

1. proportion of children with AOM by child's health status (AOMprone versus not);

2. proportion of children with $A O M$ by strain of probiotic (Lactobacillus-containing versus Streptococcus-containing);

3. proportion of children using antibiotics (use for AOM versus use for infections other than AOM); and

4. proportion of children with other infections (acute respiratory infections versus gastrointestinal infections).

We used the $\mathrm{Chi}^{2}$ test to test for subgroup interactions in Review Manager 5 (RevMan 2014). 


\section{Sensitivity analysis}

We did not conduct any sensitivity analyses, as only a single included study had two domains rated as at high risk of bias (Di Pierro 2016).

\section{RES U L T S}

\section{Description of studies}

\section{Results of the search}

We searched six databases (see Electronic searches) and retrieved 1633 records. A backwards (screening of the reference lists) and forwards citation analysis, undertaken in Web of Science on our initial list of included trials, retrieved 952 records for screening, for a total of 2585 records for screening. Our search of two clinical trial registers identified 25 further trials.

After removal of duplicates (from both the search and the citation analysis), a total of 1700 records remained for screening. We excluded 1612 records based on title and abstract. We obtained the full texts of the remaining 88 records. We excluded 69 trials (see Characteristics of excluded studies table). From the 25 clinical trial register results, we identified nine ongoing trials. No trials were awaiting classification.

We included 17 trials reported in 19 references (see Characteristics of included studies table). For a detailed description of our screening process, see the study flow diagram in Figure 1. All included trials came from the original search; the citation analysis and search of trial registries identified no additional trials. 
Figure 1. Study flow diagram.

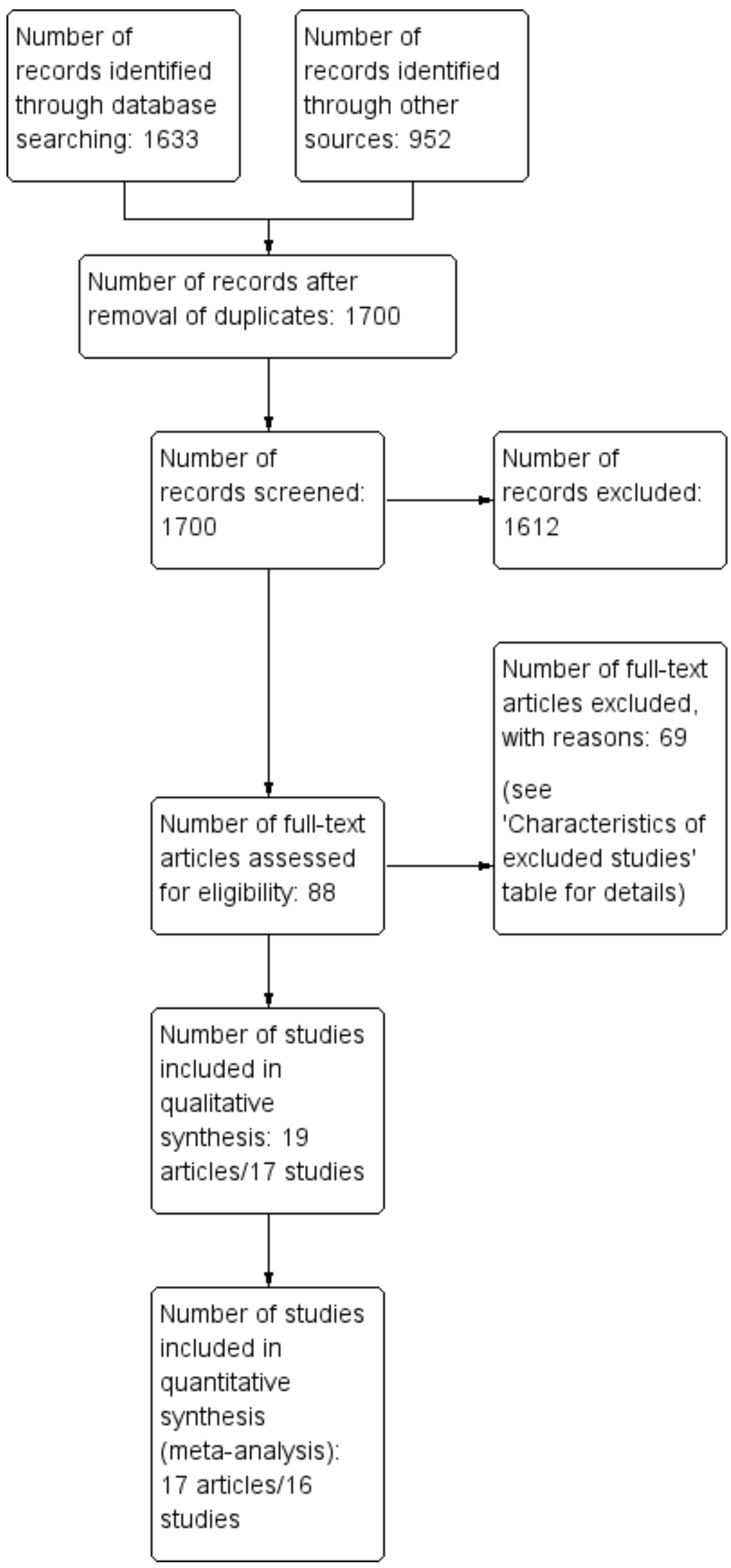




\section{Included studies}

We included 19 references that reported on 17 randomised clinical trials. Two trials, Maldonado 2012; Taipale 2011, also reported two- or three-year follow-up data, respectively (Maldonado 2015; Taipale 2016).

\section{Study design}

Sixteen RCTs had a two-arm parallel design, and one RCT had a three-arm parallel design (Nocerino 2017). Sixteen RCTs randomised by individual, whilst one RCT was a cluster-randomised study, but also reported numbers for individuals (Stecksen-Blicks 2009).

\section{Participants}

All 17 included RCTs involved children. The mean (or median where reported instead) age ranged from one-month-old infants, in Taipale 2011, to 17.5-year-olds, in Di Nardo 2014. The trials included a total of 3488 participants, all of whom were children (aged $<18$ years old).

Five RCTs reported on children prone to otitis (Cohen 2013a; Hatakka 2007a; Marchisio 2015; Roos 2001a; Tano 2002), whilst the remaining RCTs reported on children not prone to otitis. The definition of 'otitis-prone' was not clear and may have involved a subjective element.

All of the included trials were performed in Europe: two in Croatia (Hojsak 2010a; Hojsak 2016); four in Finland (Hatakka 2001a; Hatakka 2007a; Rautava 2009; Taipale 2011/Taipale 2016); one in France (Cohen 2013a); five in Italy (Corsello 2017; Di Nardo 2014; Di Pierro 2016; Marchisio 2015; Nocerino 2017); one in Russia (Karpova 2015); one in Spain (Maldonado 2012/Maldonado 2015); and three in Sweden (Roos 2001a; Stecksen-Blicks 2009; Tano 2002).

\section{Interventions}

Two trials included synbiotics, that is a combination of prebiotic and probiotic (Cohen 2013a; Maldonado 2012/Maldonado 2015); the remaining trials tested probiotics consisting of single or multiple bacterial strains. Eleven RCTs evaluated Lactobacilluscontaining probiotics (Corsello 2017; Di Nardo 2014; Hatakka 2001a; Hatakka 2007a; Hojsak 2010a; Hojsak 2016; Maldonado 2012/Maldonado 2015; Nocerino 2017; Rautava 2009; StecksenBlicks 2009; Taipale 2011/Taipale 2016); six RCTs evaluated Streptococcus-containing probiotics (Cohen 2013a; Di Pierro 2016; Karpova 2015; Marchisio 2015; Roos 2001a; Tano 2002).

The probiotics were administered as powder or drops dissolved in a liquid (e.g. milk or water) in nine RCTs (Cohen 2013a; Corsello 2017; Di Nardo 2014; Hatakka 2001a; Hojsak 2010a; Hojsak 2016; Maldonado 2012/Maldonado 2015; Nocerino 2017; Stecksen-Blicks 2009); as capsule or tablet in four RCTs (Di Pierro 2016; Hatakka 2007a; Rautava 2009; Taipale 2011/Taipale 2016); and as a spray in four RCTs (Karpova 2015; Marchisio 2015; Roos 2001a; Tano 2002).

Duration of administration of the probiotic ranged from 20 days, in Roos 2001a, to two years, in Taipale 2016.

Two-arm trials compared probiotic to placebo (15 RCTs) or to untreated group (one RCT; Di Pierro 2016); one three-arm trial compared two probiotic groups to placebo (Nocerino 2017).

\section{Outcome measures}

\section{Primary outcomes}

Outcome measures were reported in a variety of ways. The primary outcome, proportion of children with AOM, was reported by all 17 trials, most frequently as the number of children with AOM in each group (Cohen 2013a; Corsello 2017; Di Nardo 2014; Hatakka 2001a; Hatakka 2007a; Hojsak 2010a; Hojsak 2016; Karpova 2015; Marchisio 2015; Nocerino 2017; Rautava 2009; Roos 2001a; Taipale 2011/Taipale 2016; Tano 2002), although some trials reported the number of AOM events in each group, Maldonado 2012/Maldonado 2015 , or the mean number of days with otitis media in each group (Stecksen-Blicks 2009).

\section{No trials reported on severity of AOM.}

Fourteen RCTs reported on adverse events, most often narratively. Eight trials stated that no adverse events were reported (Corsello 2017; Di Pierro 2016; Hatakka 2001a; Hojsak 2010a; Hojsak 2016; Maldonado 2012; Nocerino 2017; Stecksen-Blicks 2009); two trials reported the number of events in each group (Cohen 2013a; Tano 2002); and four trials reported the number of children with events in each group (Marchisio 2015; Rautava 2009; Roos 2001a; Taipale 2011/Taipale 2016).

\section{Secondary outcomes}

Only one study reported median duration of AOM episodes (Hatakka 2007a), which reported on the median duration and interquartile range of the AOM episodes in each group.

Five trials reported on difference between groups in the use of antibiotics specifically for AOM (Cohen 2013a; Hojsak 2010a; Karpova 2015; Marchisio 2015; Roos 2001a), either as the number of antibiotic courses in each group, Cohen 2013a, or as the number of children treated with antibiotics for AOM in each group (Hojsak 2010a; Karpova 2015; Marchisio 2015; Roos 2001a). Nine trials reported on difference in the use of antibiotics more generally, for any infection, as the number of antimicrobial treatments or prescriptions per child in each group (Hatakka 2007a; Hojsak 2016; Maldonado 2012); the number of children who received antibiotics in each group (Corsello 2017; Hatakka 2001a; Nocerino 2017; Rautava 2009; Taipale 2011); or the mean number of days with antibiotic treatment (Stecksen-Blicks 2009).

Five trials reported on time off school for the child, as the mean number of days of absence from school or day care (Corsello 2017; Hatakka 2001a; Hojsak 2010a; Hojsak 2016; Stecksen-Blicks 2009).

One study reported on time off work for the parent or carer (Corsello 2017), as the mean number of lost days of work for parents.

None of the included trials reported on difference between groups in hearing loss if AOM occurs.

Two trials reported on serous/secretory otitis media (Rautava 2009; Roos 2001a). One study reported on the number of children in each group with secretory otitis media at their last visit (Roos 2001a), and one reported on the number of children in each group requiring tympanostomies to prevent recurrent AOM or to treat secretory otitis media (Rautava 2009).

None of the included trials reported on difference in referrals to specialists. 
Difference in other infections was reported in terms of reduction in acute respiratory infections and reductions in gastrointestinal (GI) infections. Fifteen trials reported on difference in respiratory infections, as: mean number of respiratory infections or episodes in each group (Cohen 2013a; Di Nardo 2014; Hatakka 2007a; Maldonado 2012/Maldonado 2015; Tano 2002); number of children with respiratory infections (Corsello 2017; Di Pierro 2016; Hatakka 2001a; Hojsak 2010a; Hojsak 2016; Karpova 2015; Nocerino 2017; Rautava 2009; Taipale 2011/Taipale 2016); or the mean number of days with respiratory symptoms (Stecksen-Blicks 2009). Eleven trials reported on difference in GI infections, as: the number of children with GI infections in each group (Cohen 2013a; Corsello 2017; Hojsak 2010a; Hojsak 2016; Nocerino 2017; Rautava 2009; Taipale 2011/Taipale 2016); the number of GI infections in each group (Di Nardo 2014; Maldonado 2012/Maldonado 2015); or the mean number of days with GI symptoms (Hatakka 2001a; StecksenBlicks 2009).

Thirteen trials reported on compliance with taking probiotics, as: the number of capsules eaten (Hatakka 2007a); the number of children complying or not complying with treatment (Cohen 2013a; Hojsak 2010a; Hojsak 2016; Marchisio 2015; Taipale 2011); the percentage of days during which consumption exceeded a prespecified amount (Hatakka 2001a); or narratively, for example by stating that the compliance was "good" or the treatment was "well-received" (Corsello 2017; Di Pierro 2016; Maldonado 2012; Nocerino 2017; Stecksen-Blicks 2009; Taipale 2011).

One study reported on quality of life measures (Hatakka 2001a), which reported a mean total symptom score for both groups (measuring the overall burden of symptoms on a scale of 0 to 9).

Three trials reported on difference in the use of other treatments (Corsello 2017; Karpova 2015; Nocerino 2017), as the number of children consuming corticosteroids and antipyretics, in Corsello 2017 and Nocerino 2017, or the number of prescriptions for corticosteroids, in Karpova 2015, in each group.

\section{Study funding sources}

Funding sources for the included studies are reported in the Characteristics of included studies table.

Two studies did not report funding (Di Pierro 2016; Karpova 2015).

Eight studies were funded at least partially (either financially or in-kind, e.g. by providing formula or probiotic) by manufacturers of probiotic or formula, but the role of the sponsor in the design, analysis, interpretation, or write-up of the study was not stated (Cohen 2013a; Hatakka 2001a; Hatakka 2007a; Hojsak 2016; Maldonado 2012; Marchisio 2015; Stecksen-Blicks 2009; Tano 2002). Three studies reported funding at least partially (either financially or in-kind, e.g. by providing formula or probiotic) by manufacturers of probiotic or formula, and reported at least some sponsor involvement in study design, analysis, interpretation, or write-up (Maldonado 2015; Taipale 2011; Taipale 2016).

One study was funded by non-industry funders, but the role of the sponsor was unclear (Roos 2001a).

Five studies reported funding at least partially by manufacturers and explicitly stated that the funder had no role in the design, analysis, interpretation, or write-up of the study (Corsello 2017; Di Nardo 2014; Hojsak 2010a; Nocerino 2017; Rautava 2009).

\section{Excluded studies}

We excluded 70 trials (Figure 1). The reasons for their exclusion are provided in the Characteristics of excluded studies table.

\section{Risk of bias in included studies}

The overall risk of bias of the included trials (Characteristics of included studies table) is presented graphically in Figure 2 and Figure 3. 
Figure 2. Risk of bias summary: review authors' judgements about each risk of bias item for each included study.

\begin{tabular}{|c|c|c|c|c|c|c|c|}
\hline & 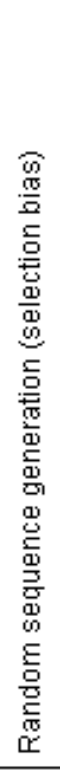 & 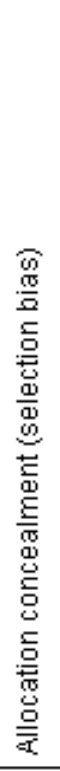 & 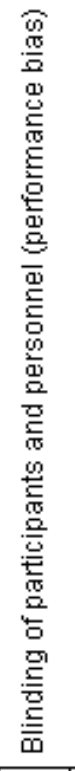 & 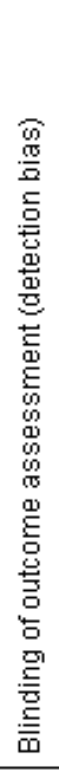 & 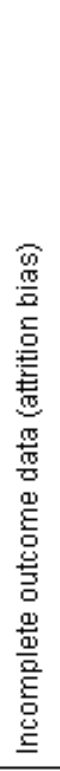 & 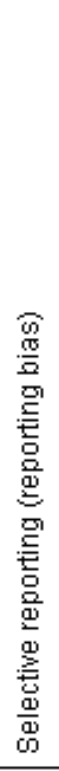 & 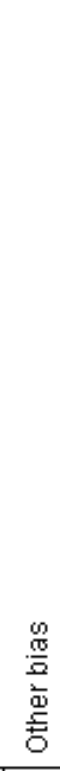 \\
\hline Cohen 2013a & $\odot$ & $?$ & $\odot$ & $?$ & $\odot$ & $?$ & - \\
\hline Corsello 2017 & 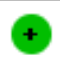 & $?$ & + & + & $\oplus$ & $?$ & + \\
\hline Di Nardo 2014 & + & $\oplus$ & + & + & + & $\oplus$ & + \\
\hline Di Pierro 2016 & + & $?$ & 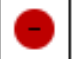 & $?$ & + & + & $\theta$ \\
\hline Hatakka 2001a & $\odot$ & $?$ & + & $?$ & + & + & O \\
\hline Hatakka 2007a & $\oplus$ & $?$ & + & $?$ & + & + & $\odot$ \\
\hline Hojsak 2010a & $\oplus$ & $?$ & + & $\oplus$ & + & + & + \\
\hline Hojsak 2016 & + & + & + & + & + & + & $\odot$ \\
\hline Karpova 2015 & $?$ & $?$ & $?$ & $?$ & + & $?$ & - \\
\hline Maldonado 2012 & + & $?$ & + & + & + & $\oplus$ & - \\
\hline Maldonado 2015 & + & $?$ & $?$ & $?$ & + & + & - \\
\hline Marchisio 2015 & + & $?$ & $\odot$ & $?$ & $\odot$ & $?$ & - \\
\hline Nocerino 2017 & + & + & + & $\oplus$ & + & 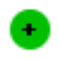 & + \\
\hline Rautava 2009 & + & $?$ & + & $?$ & + & $\oplus$ & $?$ \\
\hline Roos 2001a & + & $?$ & + & $?$ & + & 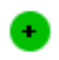 & $?$ \\
\hline Stecksen-Blicks 2009 & + & + & + & $?$ & + & + & - \\
\hline Taipale 2011 & + & $?$ & + & + & + & $\oplus$ & $\odot$ \\
\hline Taipale 2016 & + & $?$ & + & + & + & $\oplus$ & $?$ \\
\hline Tano 2002 & $\odot$ & $?$ & + & $?$ & $\odot$ & $?$ & - \\
\hline
\end{tabular}


Figure 3. Risk of bias graph: review authors' judgements about each risk of bias item presented as percentages across all included studies.

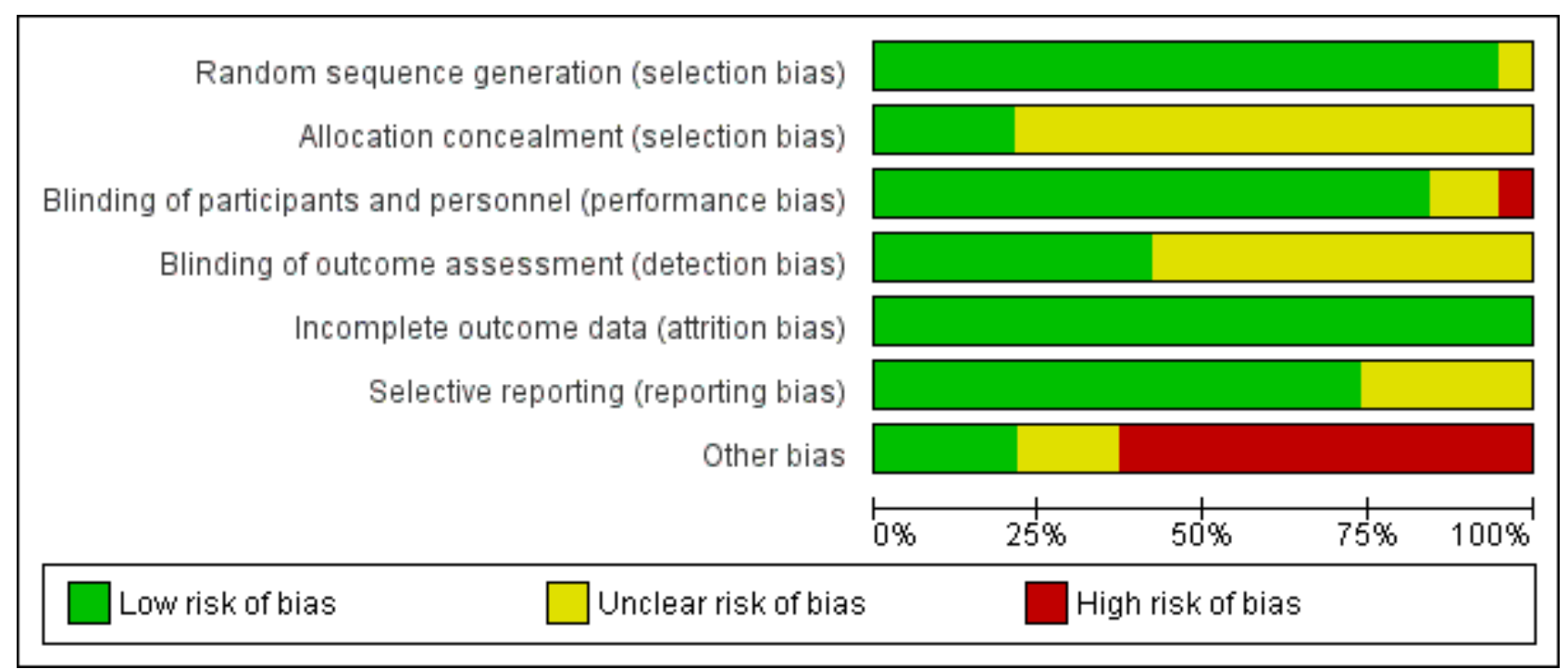

\section{Allocation}

Sixteen trials clearly described random sequence generation (Cohen 2013a; Corsello 2017; Di Nardo 2014; Di Pierro 2016; Hatakka 2001a; Hatakka 2007a; Hojsak 2010a; Hojsak 2016; Maldonado 2012/Maldonado 2015; Marchisio 2015; Nocerino 2017; Rautava 2009; Roos 2001a; Stecksen-Blicks 2009; Taipale 2011/Taipale 2016; Tano 2002). One study was described as randomised, but the method of randomisation was not described, and a table of baseline characteristics to permit evaluation of whether randomisation worked was not provided (Karpova 2015)

Four trials described allocation concealment (Di Nardo 2014; Hojsak 2016; Nocerino 2017; Stecksen-Blicks 2009). The remaining 13 trials did not describe whether allocation was concealed (Cohen 2013a; Corsello 2017; Di Pierro 2016; Hatakka 2001a; Hatakka 2007a; Hojsak 2010a; Karpova 2015; Maldonado 2012/Maldonado 2015; Marchisio 2015; Rautava 2009; Roos 2001a; Taipale 2011/Taipale 2016; Tano 2002).

\section{Blinding}

Fourteen trials were double-blinded (Cohen 2013a; Corsello 2017; Di Nardo 2014; Hatakka 2001a; Hatakka 2007a; Hojsak 2010a; Hojsak 2016; Marchisio 2015; Nocerino 2017; Rautava 2009; Roos 2001a; Stecksen-Blicks 2009; Taipale 2011/Taipale 2016; Tano 2002). One study was double-blinded (Maldonado 2012), but it was not clear whether its three-year follow-up was also double-blinded (Maldonado 2015). One study did not clearly report blinding of participants and personnel (Karpova 2015). One study compared probiotic to no treatment and was thus considered unlikely to be blinded (Di Pierro 2016).

Blinding of outcome assessor occurred in six trials (Corsello 2017; Di Nardo 2014; Hojsak 2010a; Hojsak 2016; Nocerino 2017; Taipale 2011/Taipale 2016). In one study the outcome assessors were blinded (Maldonado 2012), but it was unclear whether this was also the case for the three-year follow-up (Maldonado 2015). Blinding was unclear in the remaining 10 trials (Cohen 2013a; Di Pierro 2016;
Hatakka 2001a; Hatakka 2007a; Karpova 2015; Marchisio 2015; Rautava 2009; Roos 2001a; Stecksen-Blicks 2009; Tano 2002).

\section{Incomplete outcome data}

Sixteen trials reported attrition in both arms with reasons (Cohen 2013a; Di Nardo 2014; Di Pierro 2016; Hatakka 2001a; Hatakka 2007a; Hojsak 2010a; Hojsak 2016; Karpova 2015; Maldonado 2012/Maldonado 2015; Marchisio 2015; Nocerino 2017; Rautava 2009; Roos 2001a; Stecksen-Blicks 2009; Taipale 2011/Taipale 2016; Tano 2002). One study reported the attrition for both arms but did not provide reasons for it (Corsello 2017); however, as the attrition was less than $20 \%$ in both arms, we judged risk of bias to be low.

\section{Selective reporting}

We considered whether the trials reported all of the primary and secondary outcomes specified in their methods sections. We judged 12 trials as at low risk of bias (all prespecified outcomes were reported) (Di Nardo 2014; Di Pierro 2016; Hatakka 2001a; Hatakka 2007a; Hojsak 2010a; Hojsak 2016; Maldonado 2012/Maldonado 2015; Nocerino 2017; Rautava 2009; Roos 2001a; Stecksen-Blicks 2009; Taipale 2011/Taipale 2016). We assessed five trials as at unclear risk of bias for this domain either because one of the outcomes was unreported (Cohen 2013a; Corsello 2017; Karpova 2015), or because it was not clear which outcomes were primary or secondary (Marchisio 2015; Tano 2002).

\section{Other potential sources of bias}

We judged four trials at low risk of other bias (Corsello 2017; Di Nardo 2014; Hojsak 2010a; Nocerino 2017). Three trials were judged at unclear risk of other bias due either to absence of information about or an unclear statement of authors' conflicts of interest (Rautava 2009; Roos 2001a), or failure to report their funding source (Taipale 2016). We assessed 12 trials as at high risk of other bias due to authors' employment with study funder, undeclared conflict of interest, and unstated role of the funder in the study design, analysis, interpretation, and manuscript writing (Cohen 2013a; Di Pierro 2016; Hatakka 2001a; Hatakka 2007a; Hojsak 2016; Karpova 
2015; Maldonado 2012/Maldonado 2015; Marchisio 2015; StecksenBlicks 2009; Taipale 2011; Tano 2002).

\section{Effects of interventions}

See: Summary of findings for the main comparison Probiotic compared to placebo for preventing acute otitis media in children

\section{Primary outcomes}

\section{Proportion of children with AOM}

All 17 RCTs reported on this outcome. Two trials, Maldonado 2012/Maldonado 2015; Stecksen-Blicks 2009, could not be pooled with the other 15 trials. Maldonado 2012/Maldonado 2015 reported the number of AOM events in each group, rather than the number of children with AOM events in each group. The difference between groups in the number of AOM events was not significant. StecksenBlicks 2009 reported the mean number of days with otitis media; the difference between groups was significant and favoured probiotics: 0.5 days (standard deviation (SD) 2.2) in the probiotic group versus 1.0 (SD 2.7) days in the comparator group, $\mathrm{P}=0.003$.
We pooled 16 RCTs in three meta-analyses (Cohen 2013a; Corsello 2017; Di Nardo 2014; Di Pierro 2016; Hatakka 2001a; Hatakka 2007a; Hojsak 2010a; Hojsak 2016; Karpova 2015; Marchisio 2015; Nocerino 2017; Rautava 2009; Roos 2001a; Taipale 2011; Taipale 2016; Tano 2002).

A meta-analysis of 16 RCTs showed that a smaller proportion of children taking probiotics experienced AOM (risk ratio (RR) 0.77 , $95 \%$ confidence interval $(\mathrm{Cl}) 0.63$ to $0.93 ; \mathrm{P}=0.006$; number needed to treat for an additional beneficial outcome (NNTB) $=10 ;\left.\right|^{2}=72 \%$; moderate-certainty evidence; Analysis 1.1).

The funnel plot revealed asymmetry (Figure 4). We explored the asymmetry by removing from the analysis two studies whose standard error was above 0.5 (Di Nardo 2014; Karpova 2015). Their removal restored symmetry to the funnel plot, but only slightly changed the effect estimate (RR $0.78,95 \% \mathrm{Cl} 0.65$ to $0.95 ; \mathrm{I}^{2}=73 \%$; $P=0.01)$.

\section{Figure 4. Funnel plot of comparison: 1 Probiotics versus placebo or usual care, outcome: 1.1 Proportion of children with AOM (overall).}

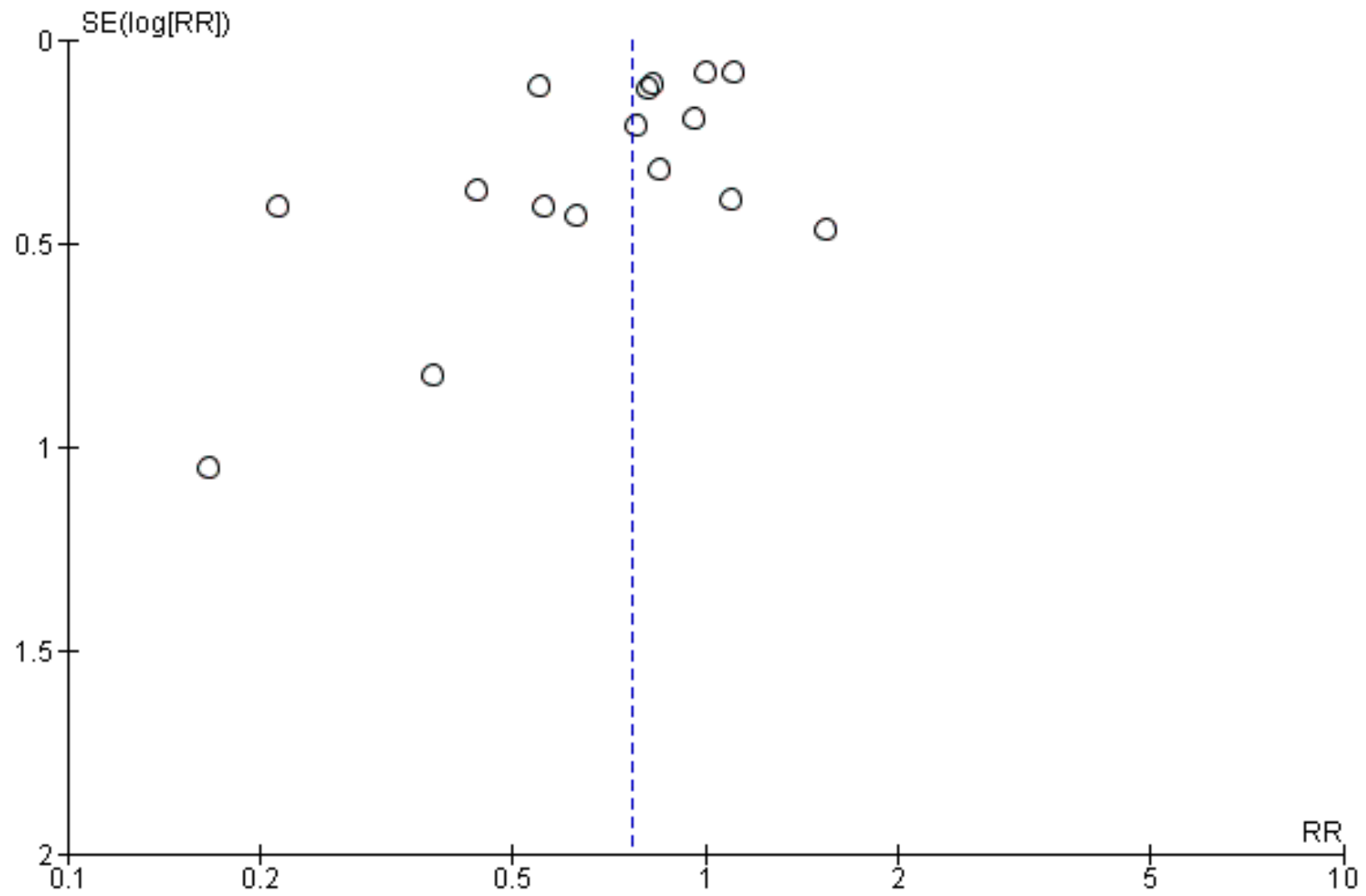

A meta-analysis subgrouping the trials into those that included children who were otitis-prone, Cohen 2013a; Hatakka 2007a; Marchisio 2015; Roos 2001a; Tano 2002, and those that included children who were not otitis-prone, Corsello 2017; Di Nardo 2014; Di Pierro 2016; Hatakka 2001a; Hojsak 2010a; Hojsak 2016; Karpova 2015; Nocerino 2017; Rautava 2009; Taipale 2011/Taipale 2016, was not pre-planned but was possible due to sufficient data. The meta-analysis showed no significant difference between probiotics and comparator for otitis-prone children (RR $0.97,95 \% \mathrm{Cl} 0.85$ to $\left.1.11 ; 1^{2}=32 \% ; P=0.64\right)$. Children who were not prone to otitis media, however, benefited from probiotics, as a smaller proportion experienced $\mathrm{AOM}$ (RR $0.64,95 \% \mathrm{Cl} 0.49$ to $0.84 ; 12=59 \% ; \mathrm{P}=$ 0.001 ; NNTB $=9$; Analysis 1.2; Summary of findings for the main 
comparison). The test for subgroup differences was significant $(\mathrm{P}=$ $0.007)$.

A meta-analysis subgrouping the trials into those that evaluated Lactobacillus-containing probiotics, Corsello 2017; Di Nardo 2014; Hatakka 2001a; Hatakka 2007a; Hojsak 2010a; Hojsak 2016; Nocerino 2017; Rautava 2009; Taipale 2011/Taipale 2016; Tano 2002, and those that evaluated Streptococcus-containing probiotics, Cohen 2013a; Di Pierro 2016; Karpova 2015; Marchisio 2015; Roos 2001a; Tano 2002, showed that Lactobacillus-containing probiotics significantly decreased the proportion of children with AOM (RR 0.72, 95\% Cl 0.54 to $0.98 ; \mathrm{I}^{2}=72 \% ; \mathrm{P}=0.04$; NNTB = 13), but this was not the case for Streptococcus-containing probiotics (RR $0.78,95 \% \mathrm{Cl} 0.60$ to $\left.1.02 ; \mathrm{I}^{2}=74 \% ; \mathrm{P}=0.07\right)$. The test for subgroup differences was not significant $(P=0.70)$ (Analysis 1.3).

\section{Severity of $A O M$}

None of the included trials reported on the severity of AOM.

\section{Adverse events}

Fourteen trials reported on adverse events.

Eight trials reported on adverse events narratively, all stating that no adverse events were reported (Corsello 2017; Di Pierro 2016; Hatakka 2001a; Hojsak 2010a; Hojsak 2016; Maldonado 2012; Nocerino 2017; Stecksen-Blicks 2009).

Two trials reported the number of adverse events in the probiotic and comparator groups (Cohen 2013a; Tano 2002). Cohen 2013a reported five adverse events (lack of appetite for milk, regurgitation, dry skin, chronic diarrhoea, and abdominal pain) as likely to have been related to the study; four were in the probiotic group and one was in the comparator group, although it was unclear which event occurred in which group. Tano 2002 reported the following adverse events: rhinitis, cough, rash, nosebleed, and vomiting. The total number of adverse events in the placebo group $(n=5)$ was higher than in the probiotic group $(n=4), P$ values were not reported.

Four trials reported on the number of children with adverse events in each group (Marchisio 2015; Rautava 2009; Roos 2001a; Taipale 2011/Taipale 2016). As data from Taipale 2016 reiterate data from Taipale 2011, this study was not pooled in order to avoid doublecounting; the remaining trials were pooled. The results showed no significant difference between groups in the number of children with adverse events (odds ratio (OR) $1.54,95 \% \mathrm{Cl} 0.60$ to $3.94 ; \mathrm{P}=$ 0.37 ; low-certainty evidence; Analysis 1.4 ; Summary of findings for the main comparison).

\section{Secondary outcomes}

\section{Median duration of AOM episodes}

One trial reported on the median duration of AOM episodes (Hatakka 2007a), finding that the median duration of an AOM episode among children taking probiotics was 5.6 days (interquartile range (IQR) 3.5 to 9.4 days), whilst among children taking placebo it was 6.0 days (IQR 4.0 to 10.5 days). The difference between groups was not significant.

\section{Difference in the use of antibiotics}

Eight trials reported data that could be pooled (Corsello 2017; Hatakka 2001a; Hojsak 2016; Karpova 2015; Marchisio 2015;
Nocerino 2017; Rautava 2009; Taipale 2011); the pooled data overall favoured the probiotic group (RR $0.66,95 \% \mathrm{Cl} 0.51$ to $0.86 ; \mathrm{P}=$ $0.002 ;$ NNTB $=8 ; 1^{2}=70 \%$; moderate-certainty evidence; Analysis 1.5; Summary of findings for the main comparison).

There were sufficient data to perform subgroup analyses that were not prespecified in the protocol: use of antibiotics for AOM specifically, and use of antibiotics more generally. However, the test for subgroup differences was not significant $(P=0.96)$.

Difference between groups in the use of antibiotics was reported specifically for AOM as either the number of antibiotic courses for AOM in each group, in Cohen 2013a, or as the number of children treated with antibiotics for AOM, in Hojsak 2010a; Karpova 2015; Marchisio 2015; Roos 2001a. We pooled the data from the latter studies, excepting the Roos 2001a study, where antibiotics were part of the intervention in both groups. Pooled data showed no difference between groups ( $R R 0.63,95 \% \mathrm{Cl} 0.30$ to $1.32 ; \mathrm{P}=0.22 ; \mathrm{I}^{2}$ $=58 \%$; moderate-certainty evidence). Data from Cohen 2013a were not pooled but showed no significant difference between groups in the number of antibiotic courses ( 242 courses per 112 children in the probiotic group versus 226 courses per 112 children in the comparator group; $\mathrm{P}=0.45$; Analysis 1.5 )

Nine trials reported the difference in the use of antibiotics for any infection (other than AOM), as follows: the number of antimicrobial treatments or prescriptions per child (Hatakka 2007a; Hojsak 2016; Maldonado 2012); the number of children who received antibiotics in each group (Corsello 2017; Hatakka 2001a; Nocerino 2017; Rautava 2009; Taipale 2011); or the mean number of days with antibiotic treatment in each group (Stecksen-Blicks 2009). Data on the number of children receiving antibiotics in each group were pooled, and favoured the probiotic group (RR $0.65,95 \% \mathrm{Cl} 0.45$ to $0.92 ; \mathrm{P}=0.01 ; \mathrm{NNTB}=6 ; \mathrm{I}^{2}=77 \%$; moderate-certainty evidence; Analysis 1.5). The studies that could not be pooled all showed no significant difference in the use of antibiotics between probiotic and comparator groups (Hatakka 2007a; Hojsak 2016; Maldonado 2012; Stecksen-Blicks 2009).

However, it is worth noting that effect size estimates for the two subgroups (use of antibiotic for AOM, use of antibiotic for infections other than AOM) are very similar, so it is possible that the nonsignificant finding for the former is due to underpowering.

\section{Time off school for the child}

Five trials reported on the mean number of days of children's absence from school or day care in each group (Corsello 2017; Hatakka 2001a; Hojsak 2010a; Hojsak 2016; Stecksen-Blicks 2009). Pooled data showed the difference between groups was not significant (mean difference (MD) -0.95 days, $95 \% \mathrm{Cl}-2.47$ to 0.57 ; $\mathrm{P}=0.22 ; \mathrm{I}^{2}=54 \%$; Analysis 1.6).

\section{Time off work for the parent or carer}

One trial reported on time off work for the child's parent or carer (Corsello 2017). The mean number of lost workdays was significantly lower in the probiotic group ( 0.6 days, $95 \% \mathrm{Cl} 0.2$ to 1.0) than in the comparator group ( 3.3 days, $95 \% \mathrm{Cl} 1.1$ to 5.5 ).

\section{Difference between groups in hearing loss, if AOM occurs}

None of the included trials reported on the difference between groups in hearing loss. 


\section{Serous/secretory otitis media}

Two trials reported on this outcome, one directly, Roos 2001a, and one indirectly, Rautava 2009.

Roos 2001a reported on the number of children with secretory otitis media at last study visit, finding that fewer children in the probiotic group had serous otitis media (19\% versus $27 \%$ ). Rautava 2009 reported on rates of tympanostomy that were performed to either prevent recurrent AOM or to treat secretory otitis media: $0 \%$ of children in the probiotic group and $10 \%$ in the comparator group required tympanostomy, but the difference was not significant $(\mathrm{P}=$ 0.07).

\section{Difference in referrals to a specialist}

None of the included trials reported on referrals to a specialist.

\section{Difference in other infections}

Overall, a smaller proportion of children in the probiotic group had infections (RR $0.75,95 \% \mathrm{Cl} 0.65$ to 0.87 ; $\mathrm{P}<0.001$; NNTB $=12 ; 1^{2}=$ $64 \%$; Analysis 1.7; Summary of findings for the main comparison).

There were sufficient data to perform the following subgroup analyses not prespecified in the protocol: reduction in acute respiratory infections and reduction in $\mathrm{Gl}$ infections.

Fifteen trials reported on difference in acute respiratory infections, as follows: mean number of days with respiratory symptoms in each group (Stecksen-Blicks 2009); mean number of respiratory infections or episodes in each group (Cohen 2013a; Di Nardo 2014; Hatakka 2007a; Maldonado 2012/Maldonado 2015; Tano 2002); or number of children with respiratory infections in each group (Corsello 2017; Di Pierro 2016; Hatakka 2001a; Hojsak 2010a; Hojsak 2016; Karpova 2015; Nocerino 2017; Rautava 2009; Taipale 2011/Taipale 2016).

The mean number of days with respiratory symptoms was lower in the comparator group than in the probiotic group ( 9.8 days versus 15.4 days, respectively) (Stecksen-Blicks 2009).

The mean number of respiratory infections or episodes in each group was either not significantly different between groups, Cohen 2013a; Hatakka 2007a; Maldonado 2015; Tano 2002, or significantly lower among children in the probiotic group, Di Nardo 2014; Maldonado 2012.

Data for the number of children with respiratory infections in each group were pooled, showing that a smaller proportion of children in the probiotic group had respiratory infections (RR $0.74,95 \% \mathrm{Cl} 0.62$ to $0.88 ; \mathrm{P}<0.001 ; \mathrm{NNTB}=11 ; \mathrm{I}^{2}=70 \%$; moderate-certainty evidence; Analysis 1.7) (Corsello 2017; Di Pierro 2016; Hatakka 2001a; Hojsak 2010a; Hojsak 2016; Karpova 2015; Nocerino 2017; Rautava 2009; Taipale 2011/Taipale 2016).

Eleven trials reported on difference in $\mathrm{Gl}$ infections, as follows: mean number of days with GI symptoms in each group (Hatakka 2001a; Stecksen-Blicks 2009); number of GI infections in each group (Di Nardo 2014; Maldonado 2012/Maldonado 2015); or number of children with GI infections (Cohen 2013a; Corsello 2017; Hojsak 2010a; Hojsak 2016; Nocerino 2017; Rautava 2009; Taipale 2011/Taipale 2016).

Probiotics for preventing acute otitis media in children (Review)

Copyright (c) 2019 The Cochrane Collaboration. Published by John Wiley \& Sons, Ltd.
In one trial the mean number of days with GI symptoms did not differ significantly between groups (Hatakka 2001a), whilst in another trial, it was lower in the control group (1.1, SD 1.8) than in the probiotic group (1.7, SD 2.3) (intracluster coefficient 0.16) (Stecksen-Blicks 2009).

In one trial the number of $\mathrm{Gl}$ infections in each group did not differ significantly between groups (Di Nardo 2014). In another trial there were significantly more $\mathrm{Gl}$ events in the probiotic group than in the control group (incidence rate decrease $46 \%, P=0.032$ ) (Maldonado 2012), but not in the three-year follow-up $(P=0.947)$ (Maldonado 2015).

Data for studies that reported the number of children with GI infections in each group were pooled (Cohen 2013a; Corsello 2017; Hojsak 2010a; Hojsak 2016; Nocerino 2017; Rautava 2009; Taipale 2011/Taipale 2016), showing no difference between groups in the proportion of children with $\mathrm{Gl}$ infections (RR $0.78,95 \% \mathrm{Cl} 0.57$ to $1.06 ; \mathrm{P}=0.11 ; 1^{2}=61 \%$; moderate-certainty evidence; Analysis 1.7).

Test for subgroup differences was not significant $(P=0.76)$.

\section{Compliance with taking probiotics}

Thirteen trials reported compliance with taking probiotics. Six trials reported on this outcome narratively, all stating that compliance was "good" or that the treatment was "well-received" (Corsello 2017; Di Pierro 2016; Maldonado 2012; Nocerino 2017; StecksenBlicks 2009; Taipale 2011). One trial reported on the percentage of capsules consumed (Hatakka 2007a), which was $96 \%$ in both groups. One trial reported the percentage of days during which consumption exceeded a prespecified amount (Hatakka 2001a), which was $60 \%$ in both groups. Five trials reported on the number of children complying or not complying with treatment (Cohen 2013a; Hojsak 2010a; Hojsak 2016; Marchisio 2015; Taipale 2016), permitting the pooling of data. Pooled data showed no significant difference between groups in compliance (RR $1.02,95 \% \mathrm{Cl} 0.99$ to $1.05 ; \mathrm{P}=0.21 ; \mathrm{I}^{2}=0 \%$; Analysis 1.8 ).

\section{Quality of life measures}

Hatakka 2001a reported on quality of life using the total symptom score (defined as a measure of the overall symptom burden, which consisted of the sum of all of the recorded symptoms ranging from 0 to 9). The difference between groups was not significant, with a mean unadjusted score of 34 in the probiotic group $(95 \% \mathrm{Cl} 30$ to 39 ) and 40 in the control group ( $95 \% \mathrm{Cl} 35$ to 46$), P=0.10$. Mean ageadjusted scores also did not differ significantly: the mean score was 36 for the probiotic group $(95 \% \mathrm{Cl} 32$ to 40$)$ and 39 for the control group ( $95 \% \mathrm{Cl} 34$ to 44$), \mathrm{P}=0.36$.

\section{Difference in use of other treatments}

Three trials reported on the difference between groups in the use of other treatments (Corsello 2017; Karpova 2015; Nocerino 2017).

Corsello 2017 reported a significantly lower use of antipyretics $(P=0.044)$ and corticosteroids $(P=0.027)$ in the probiotic group compared to the placebo group.

Nocerino 2017 reported a significantly lower use of antipyretics in one probiotic group (rice with Lactobacillus paracasei CBA L74, P $=0.001$ ) and lower use of antipyretics in another probiotic group (milk with Lactobacillus paracasei CBA L74, $\mathrm{P}=0.058$ ) than in placebo. The study authors also reported a significantly lower use 
of corticosteroids in one probiotic group (milk with Lactobacillus paracasei, $\mathrm{P}=0.001$ ) and lower use of corticosteroids in another probiotic group (rice with Lactobacillus paracasei, $\mathrm{P}=0.07$ ) than in placebo.

Karpova 2015 reported that $47 \%$ children in the probiotic group, compared to $93 \%$ in the control group, had prescriptions of intranasal corticosteroids (however, an inclusion criterion of this study was children with signs of chronic adenoiditis).

\section{DISCUSSION}

\section{Summary of main results}

This review suggests that probiotics prevent AOM, the primary outcome, by a clinically important amount. However, a subgroup analysis (not planned a priori) suggests that this effect was evident only in children who were not otitis-prone; the effect was not observed for otitis-prone children (as defined by studies themselves, and it is worth noting that the definition was not always clear and may have involved a subjective element). This is consistent with results from clinical trials of pneumococcal conjugate vaccines, which found a modest benefit for those already at low risk of AOM, but no protective effect for those with established recurrent disease, including otitis-prone children (Fortanier 2014). These findings may be due to clinical, pathological, and particularly immunological differences between children who are otitis-prone and those who are not otitis-prone (Pichichero 2016; Xu 2016).

Alternatively, there may be a methodological effect from increased bias, such as publication bias, of trials of children not prone to otitis media. Testing for publication bias by funnel plot does not support this, but statistical methods for determining publication bias are notoriously insensitive (Higgins 2011).

Another possibility is that any intervention effect is underreported: diagnosis of AOM is notoriously difficult and frequently relies upon subjective clinical judgement (Pirozzo 2000). Some RCTs of interventions for AOM require special training in the diagnosis of AOM for participating clinicians, since overdiagnosis of AOM would decrease the intervention effect (Hoberman 2016). This is also problematic where allocation concealment and blinding of outcomes are incomplete, which even subconsciously risks influencing diagnostic behaviour, resulting in a potential misclassification bias.

However, efficacy was supported by some secondary outcomes: decreased infections other than AOM (for acute respiratory infections if not $\mathrm{Gl}$ infections) and overall decreased antibiotic use (although unexpectedly for infections other than AOM, but not for AOM itself). Nevertheless, given the considerable variation in the probiotic strains trialled, their frequency, and duration of administration across studies, the optimal regimen is currently unclear. Further large and well-conducted RCTs, testing a range of probiotic strains and administration regimens (frequency, dose, duration), as well as collecting data on outcomes for which there is currently very limited evidence (e.g. severity of AOM, duration of AOM episodes, need for antibiotics, time off work for carer, hearing loss, referrals to specialists, and quality of life) may therefore help to resolve doubts about the real effectiveness of probiotics.

The pooled results found no consistent increase in adverse effects.

\section{Overall completeness and applicability of evidence}

We searched six distinct databases with no language restriction and searched trials registers, supplemented by forward- and backward-searching of cited works. However, we did not contact authors for additional research, nor did we handsearch conference proceedings, partly because there are no obvious conference candidates for this.

The volume of evidence varied considerably among the outcomes. There was sufficient evidence to perform meta-analyses for two of the primary outcomes (proportion of children with AOM and adverse events), but none of the included studies reported on the primary outcome severity of AOM.

The volume of evidence varied for the secondary outcomes. There was sufficient evidence to perform meta-analyses for four secondary outcomes (difference in the use of antibiotics, time off school for the child, difference in other infections, compliance with taking probiotics). Seven of the secondary outcomes were not meta-analysable. This was due to variability of reporting (difference in use of other treatments outcome) or paucity of evidence (two trials reported on the serous/secretory otitis media outcome; one trial reported on each of the following outcomes: median duration of AOM episodes, time off work for parent/carer, quality of life). No trials reported on referrals to specialist or difference in hearing loss between groups.

\section{Quality of the evidence}

We assessed the quality (certainty) of the evidence as moderate for most of the outcomes reported in the Summary of findings for the main comparison, including: proportion of children with AOM overall, proportion of children with AOM among children not prone to AOM, antibiotic use, and proportion of children with other infections. We assessed the quality of the evidence for one outcome - proportion of children with AOM among children who were prone to AOM - as high. No studies reported on the severity of $\mathrm{AOM}$, therefore no quality of evidence rating was assigned. Risk of bias among the included studies was mostly related to allocation concealment, blinding of outcomes, and conflicts of interest and unclear role of funders in the trials.

\section{Potential biases in the review process}

Both clinical heterogeneity (especially from the disparate probiotic strains) and statistical heterogeneity confirmed our protocoldeclared use of random-effects model analysis to avoid making inappropriate assumptions about the trials testing similar interventions. Heterogeneity was the principal reason for marking down the certainty of the evidence in the GRADE assessment (Summary of findings for the main comparison).

Biases could have arisen due to differences between the protocol and the systematic review (see the Differences between protocol and review section), in particular from: the broadening of the population (from children diagnosed with AOM to any children); omission of three of the prespecified subgroup analyses (one due to broadening of the population, two due to paucity of evidence); two subgroup analyses performed due to unanticipated availability of data (difference in the use of antibiotics, reduction in other infections). We did not perform sensitivity analysis (as only one included study was rated as having two domains at high risk of bias); the primary outcome was originally specified as incidence of 
AOM, but was reported as proportion of children with AOM (due to variation in time points at which studies reported the outcome); and several outcomes had to be omitted, whilst others were added to the Summary of findings for the main comparison due to paucity or availability of evidence, respectively.

\section{Agreements and disagreements with other studies or reviews}

A previous systematic review found some evidence (in 4 out of 14 RCTs) for efficacy of probiotics as prophylaxis against the symptoms, but not the incidence, of acute respiratory tract infections in 3764 adults and children (Vouloumanou 2009). No meta-analysis was undertaken due to perceived heterogeneity of the interventions, populations, and diseases. A more recent systematic review and meta-analysis of 15 RCTs restricted to 5121 children also found evidence for a preventive reduction in the duration of acute respiratory tract infections (including AOM as a secondary outcome) in three of the trials, by about 0.75 of a day per year (Laursen 2018). (The authors were able to extract unpublished AOM-specific data from their own RCT, which was one of the trials included in the meta-analysis, Laursen 2017b).

It thus seems that our review is in accordance with this older literature.

\section{AUTHORS' CONCLUSIONS}

\section{Implications for practice}

A range of different probiotics may provide protection against acute otitis media (AOM) in children not prone to AOM, although it is possible that this effect is due to a bias not detected by our methods (such as publication bias, to account for the unexpected finding of better efficacy for non-otitis-prone children than otitis-prone ones, notwithstanding several biologically plausible explanations).

Many uncertainties remain about the use of probiotics to protect children from AOM: not just the concern that this is not a real effect (from bias distortion), but also about the nature of the intervention (can standard preparations of the probiotic be sourced for wholesale clinical practice), and a persistent concern that there may be insufficient data about safety from long-term observational trials (even though some trial data suggest they are safe in immunocompetent people) (Cohen 2018).
Uncertainties about the optimal strain, as well as the duration, frequency, and timing of probiotics administration, hamper the interpretation of results.

\section{Implications for research}

There is a clear need for more, and larger, well-conducted randomised controlled trials to test readily available probiotic preparations for AOM. Those randomised controlled trials should evaluate a variety of probiotic strains, as well as the duration, frequency, and timing of probiotic administration, as the optimal regimen is currently unclear. There is also either a paucity or an absence of evidence on the impact of probiotics on severity of AOM, median duration of AOM episodes, need for use of antibiotics, antimicrobial resistance, time off work for parent or carer, hearing loss, referrals to specialists, and quality of life (using validated tools). Uniform reporting of outcomes is crucial - for example reporting of antibiotic use varied significantly (e.g. as number of antibiotic courses, per cent of participants taking antibiotics, mean number of antibiotics prescriptions, days with antibiotic treatment, etc.), limiting its interpretive value. Finally, identifying children most likely to benefit from probiotics is an important research goal. This might include determining whether probiotics administered from shortly after birth protect high-risk (e.g. Indigenous) infants from AOM during the first years of life.

\section{ACKNOWLEDGEMENTS}

The authors would like to acknowledge and thank the authors of Crosby 2004, whose withdrawn protocol partly informed development of a re-developed protocol for this topic. Parts of the Background are based on a Cochrane Review by Venekamp 2015. One of the current authors (CDM) of this review is also an author on Crosby 2004 and Venekamp 2015. The Methods section of this protocol is based on a standard template developed by the Cochrane Airways Group and adapted by the Cochrane Acute Respiratory Infections Group. We wish to thank the following people for commenting on the draft of this protocol: Catherine Marshall, Jenny Negus, Roderick Venekamp, Tal Marom, Robert Ware, and Zulfiqar Bhutta. We wish to thank the following people for peer-reviewing the draft of this review: Roderick Venekamp, Daniel Merenstein, Rob Ware, Esther Martin, Janet Waddell, and An De Sutter. We also wish to thank Mark Jones for his statistical advice. 


\section{R E F E R E N C E S}

\section{References to studies included in this review}

\section{Cohen 2013a \{published data only\}}

Cohen R, Martin E, de La Rocque F, Thollot F, Pecquet S, Werner A, et al. Probiotics and prebiotics in preventing episodes of acute otitis media in high-risk children: a randomized, double-blind, placebo-controlled study. Pediatric Infectious Disease Journal 2013;32(8):810-4.

\section{Corsello 2017 \{published data only\}}

Corsello G, Carta M, Marinello R, Picca M, De Marco G, Micillo M, et al. Preventive effect of cow's milk fermented with Lactobacillus paracasei CBA L74 on common infectious diseases in children: a multicenter randomized controlled trial. Nutrients 2017;9:7. [DOI: 10.3390/nu9070669]

\section{Di Nardo 2014 \{published data only\}}

Di Nardo G, Oliva S, Menichella A, Pistelli R, De Biase RV, Patriarchi F, et al. Lactobacillus reuteri ATCC55730 in cystic fibrosis. Journal of Pediatric Gastroenterology and Nutrition 2014;58(1):81-6.

\section{Di Pierro 2016 \{published data only\}}

Di Pierro F, Colombo M, Giuliani MG, Danza ML, Basile I, Bollani T, et al. Effect of administration of Streptococcus salivarius K12 on the occurrence of streptococcal pharyngotonsillitis, scarlet fever and acute otitis media in 3 years old children. European Review for Medical and Pharmacological Sciences 2016;20(21):4601-6.

\section{Hatakka 2001a \{published data only\}}

Hatakka K, Savilahti E, Ponka A, Meurman JH, Poussa T, Nase L, et al. Effect of long term consumption of probiotic milk on infections in children attending day care centres: double blind, randomised trial. BMJ 2001;322(7298):1327.

\section{Hatakka 2007a \{published data only\}}

Hatakka K, Blomgren K, Pohjavuori S, Kaijalainen T, Poussa T, Leinonen M, et al. Treatment of acute otitis media with probiotics in otitis-prone children - a double-blind, placebo-controlled randomised study. Clinical Nutrition 2007;26(3):314-21.

\section{Hojsak 2010a \{published data only\}}

Hojsak I, Snovak N, Abdovic S, Szajewska H, Misak Z, Kolacek S. Lactobacillus GG in the prevention of gastrointestinal and respiratory tract infections in children who attend day care centers: a randomized, double-blind, placebo-controlled trial. Clinical Nutrition 2010;29(3):312-6.

\section{Hojsak 2016 \{published data only\}}

Hojsak I, Mocic Pavic A, Kos T, Dumancic J, Kolacek S. Bifidobacterium animalis subsp. lactis in prevention of common infections in healthy children attending day care centers randomized, double blind, placebo-controlled study. Clinical Nutrition 2016;35(3):587-91.
Karpova 2015 \{published data only\}

Karpova EP, Karpycheva IE, Tulupov DA. Prophylaxis of chronic adenoiditis in the children. Vestnik Otorinolaringologii 2015;80(6):43-5.

\section{Maldonado 2012 \{published data only\}}

Maldonado J, Canabate F, Sempere L, Vela F, Sanchez AR, Narbona E, et al. Human milk probiotic Lactobacillus fermentum CECT5716 reduces the incidence of gastrointestinal and upper respiratory tract infections in infants. Journal of Pediatric Gastroenterology and Nutrition 2012;54(1):55-61.

\section{Maldonado 2015 \{published data only\}}

Maldonado LJA, Gil-Campos M, Maldonado J, López-Huertas E, Flores-Rojas K, Valero AD, et al. Long-term safety of early consumption of Lactobacillus fermentum CECT5716: a 3-year follow-up of a randomized controlled trial. Pharmacological Research 2015;95-6:12-9.

\section{Marchisio 2015 \{published data only\}}

Marchisio P, Santagati M, Scillato M, Baggi E, Fattizzo M, Rosazza C, et al. Streptococcus salivarius 24SMB administered by nasal spray for the prevention of acute otitis media in otitisprone children. European Journal of Clinical Microbiology \& Infectious Diseases 2015;34(12):2377-83.

Nocerino 2017 \{published data only\}

Nocerino R, Paparo L, Terrin G, Pezzella V, Amoroso A, Cosenza $L$, et al. Cow's milk and rice fermented with Lactobacillus paracasei CBA L74 prevent infectious diseases in children: a randomized controlled trial. Clinical Nutrition 2017;36(1):118-25

Rautava 2009 \{published data only\}

Rautava S, Salminen S, Isolauri E. Specific probiotics in reducing the risk of acute infections in infancy - a randomised, doubleblind, placebo-controlled study. British Journal of Nutrition 2009;101(11):1722-6.

Roos 2001a \{published data only\}

Roos K, Hakansson EG, Holm S. Effect of recolonisation with "interfering" alpha streptococci on recurrences of acute and secretory otitis media in children: randomised placebo controlled trial. BMJ 2001;322(7280):210-2.

\section{Stecksen-Blicks 2009 \{published data only\}}

Stecksen-Blicks C, Sjostrom I, Twetman S. Effect of longterm consumption of milk supplemented with probiotic lactobacilli and fluoride on dental caries and general health in preschool children: a cluster-randomized study. Caries Research 2009;43(5):374-81.

Taipale 2011 \{published data only\}

Taipale T, Pienihakkinen K, Isolauri E, Larsen C, Brockmann E, Alanen $P$, et al. Bifidobacterium animalis subsp. lactis BB-12 in reducing the risk of infections in infancy. British Journal of Nutrition 2011;105(3):409-16. 
Taipale 2016 \{published data only\}

Taipale TJ, Pienihakkinen K, Isolauri E, Jokela JT, Soderling EM. Bifidobacterium animalis subsp. lactis BB-12 in reducing the risk of infections in early childhood. Pediatric Research 2016;79:65-9.

Tano 2002 \{published data only\}

Tano K, Hakansson EG, Holm SE, Hellstrom S. A nasal spray with alpha-haemolytic streptococci as long term prophylaxis against recurrent otitis media. International Journal of Pediatric Otorhinolaryngology 2002;62(1):17-23.

\section{References to studies excluded from this review}

\section{Agustina 2012 \{published data only\}}

Agustina R, Kok FJ, van de Rest O, Fahmida U, Firmansyah A, Lukito W, et al. Randomized trial of probiotics and calcium on diarrhea and respiratory tract infections in Indonesian children. Pediatrics 2012;129(5):e1155-64.

\section{Ahanchian 2016 \{published data only\}}

Ahanchian H, Jafari SA, Ansari E, Ganji T, Kiani MA, Khalesi M, et al. A multi-strain Synbiotic may reduce viral respiratory infections in asthmatic children: a randomized controlled trial. Electron Physician 2016;8(9):2833-9.

\section{Arvola 1999 \{published data only\}}

Arvola T, Laiho K, Torkkeli S, Mykkanen H, Salminen S, Maunula L, et al. Prophylactic Lactobacillus GG reduces antibiotic-associated diarrhea in children with respiratory infections: a randomized study. Pediatrics 1999;104(5):e64.

\section{Aryayev 2012 \{published data only\}}

Aryayev ML, Bredeleva NK, Kononenko NA, Kukushin VN, Ignatenko AS, Ignatenko MI, et al. Experience of probiotic EcN-suspension use in preterm newborn infants for immunity improvement. First results of an ongoing study. Monatsschrift fur Kinderheilkunde 2012;160:76-7.

\section{Auinger 2013 \{published data only\}}

Auinger A, Riede L, Bothe G, Busch R, Gruenwald J. Yeast (1,3)$(1,6)$-beta-glucan helps to maintain the body's defence against pathogens: a double-blind, randomized, placebo-controlled, multicentric study in healthy subjects. European Journal of Nutrition 2013;52(8):1913-8.

\section{Bellomo 1980 \{published data only\}}

Bellomo G, Mangiagle A, Nicastro L, Frigerio G. A controlled double-blind study of SF68 strain as a new biological preparation for the treatment of diarrhoea in pediatrics. Current Therapeutic Research 1980; Vol. 28:927-36.

\section{Cáceres 2010 \{published data only\}}

Cáceres P, Montes S, Vega N, Cruchet S, Brunser O, Gotteland M. Effects of Lactobacillus rhamnosus HNO01 on acute respiratory infections and intestinal secretory IgA in children. Journal of Pediatric Infectious Diseases 2010;5(4):353-62.

\section{Canani 2016 \{published data only\}}

Canani RB, Corsello G, Nocerino R, Carta M, Marinello R, Picca M, et al. Effect of fermented milk with Lactobacillus paracasei CBA 174 on gastrointestinal and respiratory infections in children: multicenter randomized controlled trial. Digestive and Liver Disease 2016;48:E280-1.

\section{Cazzola 2010 \{published data only\}}

Cazzola M, Pham-Thi N, Kerihuel JC, Durand H, Bohbot S. Efficacy of a synbiotic supplementation in the prevention of common winter diseases in children: a randomized, doubleblind, placebo-controlled pilot study. Therapeutic Advances in Respiratory Disease 2010;4(5):271-8.

Cobo 2006 \{published data only\}

Cobo Sanz JM, Mateos JA, Munoz Conejo A. Effect of Lactobacillus casei on the incidence of infectious conditions in children [Efecto de Lactobacillus casei sobre la incidencia de procesos infeeciosos en niñios/as]. Nutricion Hospitalaria 2006;21(4):547-51.

\section{Collet 1993 \{published data only\}}

Collet JP, Ducruet T, Kramer MS, Haggerty J, Floret D, Chomel JJ, et al. Stimulation of nonspecific immunity to reduce the risk of recurrent infections in children attending day-care centers. Pediatric Infectious Disease Journal 1993;12(8):648-52.

\section{Corsello 2016 \{published data only\}}

Corsello G, Nocerino R, Carta M, Mariniello R, Picca M, Marco G, et al. Effect of fermented milk with Lactobacillus paracasei CBA L74 on gastrointestinal and respiratory infections in children: multicenter randomized controlled trial. Digestive and Liver Disease 2016; Vol. 62:650.

\section{Coulthard 2004 \{published data only\}}

Coulthard MG, Mellis CM. A nasal spray with alpha-haemolytic streptococci as long term prophylaxis against recurrent otitis media. Medical Journal of Australia 2004; Vol. 181, issue 10:556-7.

\section{Crawford 2015 \{published data only\}}

Crawford P, Clauson E. Probiotics for the prevention of upper respiratory tract infections. American Family Physician 2015;92(7):573.

\section{Dekker 2017 \{published data only\}}

Dekker J, Xu L, Hong Q, Xiaoyang S. Bifidobacterium animalis subsp. lactis HN019 protects against respiratory tract infections in Chinese infants. Journal of Pediatric Gastroenterology and Nutrition 2017; Vol. 64:760.

\section{Di Pierro 2012 \{published data only\}}

Di Pierro F, Donato G, Fomia F, Adami T, Careddu D, Cassandro C, et al. Preliminary pediatric clinical evaluation of the oral probiotic Streptococcus salivarius K12 in preventing recurrent pharyngitis and/or tonsillitis caused by Streptococcus pyogenes and recurrent acute otitis media. International Journal of General Medicine 2012;5:991-6. 
Garaiova 2015 \{published data only\}

Garaiova I, Muchova J, Nagyova Z, Wang D, Li JV, Orszaghova Z, et al. Probiotics and vitamin $C$ for the prevention of respiratory tract infections in children attending preschool: a randomised controlled pilot study. European Journal of Clinical Nutrition 2015;69(3):373-9.

\section{Gerasimov 2012 \{published data only\}}

Gerasimov S, Cycura O. Role of probiotics in attenuation of acute respiratory tract infections in preschool and primary school children. European Respiratory Journal 2012;40:Abstract number: 1641.

\section{Gerasimov 2016 \{published data only\}}

Gerasimov SV, Ivantsiv VA, Bobryk LM, Tsitsura OO, Dedyshin LP, Guta NV, et al. Role of short-term use of L. acidophilus DDS-1 and $B$. lactis UABLA-12 in acute respiratory infections in children: a randomized controlled trial. European Journal of Clinical Nutrition 2016;70(4):463-9.

\section{Gonchar 2015 \{published data only\}}

Gonchar NV, Suvorov AN, Maryshev VP, Sorokina TM, Churkova TV, Kharit SM. Probiotics, nutritional status and resistance to respiratory infections in infants. Eksperimentalnaija i Klinicheskaija Gastroenterologija 2015;1(1):48-54.

\section{Guillemard 2010 \{published data only\}}

Guillemard E, Tanguy J, Flavigny A, de la Motte S, Schrezenmeir J. Effects of consumption of a fermented dairy product containing the probiotic Lactobacillus casei DN-114 001 on common respiratory and gastrointestinal infections in shift workers in a randomized controlled trial. Journal of the American College of Nutrition 2010;29(5):455-68.

\section{Gutierrez-Castrellon 2014 \{published data only\}}

Gutierrez-Castrellon P, Lopez-Velazquez G, Diaz-Garcia L, Jimenez-Gutierrez C, Mancilla-Ramirez J, Estevez-Jimenez J, et al. Diarrhea in preschool children and Lactobacillus reuteri: a randomized controlled trial. Pediatrics 2014;133(4):e904-9.

\section{Hatakka 2001b \{published data only\}}

Hatakka K, Savilahti E, Ponka A, Meurman JH, Poussa T, Nase L, et al. Magic bullet milk?. Forschende Komplementarmedizin und Klassische Naturheilkunde 2001; Vol. 8, issue 6:390.

\section{He 2005 \{published data only\}}

He M, Yang YX, Han H, Men JH, Bian LH, Wang GD. Effects of yogurt supplementation on the growth of preschool children in Beijing suburbs. Biomedical and Environmental Sciences 2005;18(3):192-7.

\section{Hojsak 2009a \{published data only\}}

Hojsak I, Abdovic S, Kolacek S. Lactobacillus GG in the prevention of gastrointestinal and respiratory tract infections in children attending day care centres: a randomised, placebo-controlled, double-blind study. Journal of Pediatric Gastroenterology and Nutrition 2009;48:E71-2.

\section{Hojsak 2009b \{published data only\}}

Hojsak I, Abdovic S, Szajewska H, Kolacek S. Lactobacillus GG in the prevention of nosocomial gastrointestinal and respiratory tract infections: a randomised, placebo-controlled, doubleblind study. Journal of Pediatric Gastroenterology and Nutrition 2009;48:E85-6.

\section{Hojsak 2010b \{published data only\}}

Hojsak I, Abdovic S, Szajewska H, Milosevic M, Krznaric Z, Kolacek S. Lactobacillus GG in the prevention of nosocomial gastrointestinal and respiratory tract infections. Pediatrics 2010;125(5):e1171-7.

\section{Hojsak 2015 \{published data only\}}

Hojsak I, Tokic Pivac V, Mocic Pavic A, Pasini AM, Kolacek S. Bifidobacterium animalis subsp. lactis fails to prevent common infections in hospitalized children: a randomized, double-blind, placebo-controlled study. American Journal of Clinical Nutrition 2015;101(3):680-4.

\section{ISCTRN 2004 \{published data only\}}

ISRCTN53286030. A controlled trial of probiotics in the prevention of episodes of otitis media in general practice. http://www.isrctn.com/ISRCTN53286030 (date applied 30/09/2004).

\section{Ito 2017 \{published data only\}}

Ito M, Yumiko M, Ken K, Toshimitsu K, Haruo T, Noboru Y, et al. Randomized controlled trial of juzen-taiho-to in children with recurrent acute otitis media. Auris Nasus Larynx 2017;44(4):390-7.

\section{Jespersen 2015 \{published data only\}}

Jespersen L, Tarnow I, Eskesen D, Morberg CM, Michelsen B, Bugel S, et al. Effect of Lactobacillus paracasei subsp. paracasei, L. casei 431 on immune response to influenza vaccination and upper respiratory tract infections in healthy adult volunteers: a randomized, double-blind, placebo-controlled, parallel-group study. American Journal of Clinical Nutrition 2015;101(6):1188-96.

\section{Kaplan 1968 \{published data only\}}

Kaplan M, Fischgrund A, Dobrowolski B. Therapeutic effectiveness and clinical tolerance in children of a medication combining in the same preparation of a tetracycline base with lyophilized lactobacillus. Semaine des Hospitaux 1968;44(28):1889-93.

\section{Kloster 2008 \{published data only\}}

Kloster Smerud H, Ramstad Kleiveland C, Roll Mosland A, Grave G, Birkeland S-E. Effect of a probiotic milk product on gastrointestinal and respiratory infections in children attending day-care. Microbial Ecology in Health and Disease 2008; Vol. 20, issue 2:80-5.

\section{Kukkonen 2008 \{published data only\}}

Kukkonen K, Savilahti E, Haahtela T, Juntunen-Backman K, Korpela R, Poussa $T$, et al. Long-term safety and impact on infection rates of postnatal probiotic and prebiotic (synbiotic) treatment: randomized, double-blind, placebo-controlled trial. Pediatrics 2008;122(1):8-12. 
Kumpu 2012 \{published data only\}

Kumpu M, Kekkonen RA, Kautiainen H, Jarvenpaa S, Kristo A, Huovinen $\mathrm{P}$, et al. Milk containing probiotic Lactobacillus rhamnosus GG and respiratory illness in children: a randomized, double-blind, placebo-controlled trial. European Journal of Clinical Nutrition 2012;66(9):1020-3.

\section{Kumpu 2013 \{published data only\}}

Kumpu M, Lehtoranta L, Roivainen M, Ronkko E, Ziegler T, Soderlund-Venermo M, et al. The use of the probiotic Lactobacillus rhamnosus $G G$ and viral findings in the nasopharynx of children attending day care. Journal of Medical Virology 2013;85(9):1632-8

\section{Laursen 2017a \{published data only\}}

Laursen RP, Larnkjaer A, Ritz C, Hauger H, Michaelsen KF, Molgaard C. Probiotics and child care absence due to infections: a randomized controlled trial. Pediatrics 2017;140:2. [DOI: 10.1542/peds.2017-0735]

\section{Lehtoranta 2012 \{published data only\}}

Lehtoranta L, Soderlund-Venermo M, Nokso-Koivisto J, Toivola $\mathrm{H}$, Blomgren $\mathrm{K}$, Hatakka $\mathrm{K}$, et al. Human bocavirus in the nasopharynx of otitis-prone children. International Journal of Pediatric Otorhinolaryngology 2012;76(2):206-11.

\section{Li 2014 \{published data only\}}

Li F, Jin X, Liu B, Zhuang W, Scalabrin D. Follow-up formula consumption in 3- to 4-year-olds and respiratory infections: an RCT. Pediatrics 2014;133(6):e1533-40.

\section{Lin 2009 \{published data only\}}

Lin JS, Chiu YH, Lin NT, Chu CH, Huang KC, Liao KW, et al. Different effects of probiotic species/strains on infections in preschool children: a double-blind, randomized, controlled study. Vaccine 2009;27(7):1073-9.

\section{Luoto 2014 \{published data only\}}

Luoto R, Ruuskanen O, Waris M, Kalliomaki M, Salminen S, Isolauri E. Prebiotic and probiotic supplementation prevents rhinovirus infections in preterm infants: a randomized, placebocontrolled trial. Journal of Allergy and Clinical Immunology 2014;133(2):405-13.

\section{Maldonado 2010 \{published data only\}}

Maldonado J, Lara-Villoslada F, Sierra S, Sempere L, Gomez M, Rodriguez JM, et al. Safety and tolerance of the human milk probiotic strain Lactobacillus salivarius CECT5713 in 6-monthold children. Nutrition 2010;26(11-2):1082-7.

\section{Maldonado 2011 \{published data only\}}

Maldonado J, Canabate F, Sempere L, Vela F, Sanchez AR, Narbona E, et al. A follow-on formula with the probiotic lactobacillus fermentum CECT5716 decreases the incidence of respiratory and gastrointestinal infections: a randomized controlled trial. Journal of Pediatric Gastroenterology and Nutrition 2011; Vol. 52:E63-4.

\section{Marchisio 2010 \{published data only\}}

Marchisio P, Esposito S, Bianchini S, Desantis C, Galeone C, Nazzari E, et al. Effectiveness of a propolis and zinc solution in preventing acute otitis media in children with a history of recurrent acute otitis media. International Journal of Immunopathology and Pharmacology 2010;23(2):567-75.

\section{Marchisio 2016 \{published data only\}}

Marchisio P, Esposito S, Principi N. The evidence for applying Streptococcus salivarius 24SMB by nasal spray for preventing recurrent acute otitis media. European Journal of Clinical Microbiology and Infectious Diseases 2016;35(11):1889-90.

\section{Marchisio 2017 \{published data only\}}

Marchisio P, Santagati M, Stefani S, Esposito S, Principi N. Topical intranasal bacteriotherapy: experience in acute otitis media. Italian Journal of Pediatrics 2017; Vol. 43, issue Suppl 1:no pagination.

\section{Marogna 2014 \{published data only\}}

Marogna M, Braidi C, Colombo C, Colombo F, Palumbo L, Compalati E. Sublingual allergoid immunotherapy for mites in the prevention of recurrent respiratory infections: a prospective real life study. Allergy 2014; Vol. 69:509.

\section{Marseglia 2007 \{published data only\}}

Marseglia GL, Tosca M, Cirillo I, Licari A, Leone M, Marseglia A, et al. Efficacy of Bacillus clausii spores in the prevention of recurrent respiratory infections in children: a pilot study. Therapeutic and Clinical Risk Management 2007;3(1):13-7.

\section{Merenstein 2010 \{published data only\}}

Merenstein D, Murphy M, Fokar A, Hernandez RK, Park H, Nsouli $\mathrm{H}$, et al. Use of a fermented dairy probiotic drink containing Lactobacillus casei (DN-114 001) to decrease the rate of illness in kids: the DRINK study. A patient-oriented, doubleblind, cluster-randomized, placebo-controlled, clinical trial. European Journal of Clinical Nutrition 2010;64(7):669-77.

\section{Mizgier 2013 \{published data only\}}

Mizgier Ml, Brignardello J, Morales P, Carvallo C, Cires MJ, Cruchet $\mathrm{S}$, et al. Effect of the administration of a milk product containing a heat-treated probiotic and a prebiotic in preschool children. Annals of Nutrition and Metabolism 2013; Vol. 63, issue Suppl 1:1665.

\section{Nocerino 2014 \{published data only\}}

Nocerino R, Paparo L, Maddalena Y, Caprio S, Amato F, Pezzella $\mathrm{V}$, et al. Novel dietary products derived by fermentation of cow milk and rice with Lactobacillus paracasei cbal74 prevent gastrointestinal and respiratory tract infections in young children: a prospective randomized controlled trial. Digestive and Liver Disease 2014; Vol. 46:e82.

\section{Nocerino 2016 \{published data only\}}

Nocerino R, Corsello G, Carta M, Marinello R, Picca M, De Marco G, et al. Effect of fermented milk with Lactobacillus paracasei CBA L74 on gastrointestinal and respiratory infections in children: multicenter randomized controlled trial. Allergy 2016;71:425.

\section{Pitkaranta 2003 \{published data only\}}

Pitkaranta A, Hatakka K, Blomgren K, Pohjavuori S, Korpela R. Probiotics in prevention of acute otitis media in otitis prone 
children. Recent Advances In Otitis Media: Proceedings of the Eighth International Symposium; 2003 June 3-7;Marriott Harbor Beach Ft. Lauderdale, Florida. Pmph USA Ltd, 2003. [ISBN 13: 9781550092790 ]

\section{Prodeus 2016 \{published data only\}}

Prodeus A, Niborski V, Schrezenmeir J, Gorelov A, Shcherbina A, Rumyantsev A. Fermented milk consumption and common infections in children attending day-care centers: a randomized trial. Journal of Pediatric Gastroenterology and Nutrition 2016;63(5):534-43.

\section{Puccio 2007 \{published data only\}}

Puccio G, Cajozzo C, Meli F, Rochat F, Grathwohl D, Steenhout P. Clinical evaluation of a new starter formula for infants containing live Bifidobacterium longum BL999 and prebiotics. Nutrition 2007;23(1):1-8.

\section{Ringel-Kulka 2015 \{published data only\}}

Ringel-Kulka T, Kotch JB, Jensen ET, Savage E, Weber DJ. Randomized, double-blind, placebo-controlled study of synbiotic yogurt effect on the health of children. Journal of Pediatrics 2015;166(6):1475-81.e1-3.

\section{Río 2002 \{published data only\}}

Río ME, Zago BL, Garcia H, Winter L. The nutritional status change the effectiveness of a dietary supplement of lactic bacteria on the emerging of respiratory tract diseases in children [El estado nutricional modifica la efectividad de un suplemento dietario de bacterias lácticas sobre la aparición de patologías de vías respiratorias en niños]. Archivos Latinoamericanos de Nutricion 2002;52(1):29-34.

\section{Rivero 2004 \{published data only\}}

Rivero M, Roca A, Chifre R, Conde M, Rodriguez M, Santamaria A, et al. Effect of a new infant formula enriched with prebiotics, probiotics, nucleotides and LC-PUFAs on infants recovery after an infection. Journal of Pediatric Gastroenterology and Nutrition 2004;39(Suppl 1):S522.

\section{Sazawal 2004 \{published data only\}}

Sazawal S, Dhingra U, Sarkar A, Dhingra P, Deb S, Marwah $D$, et al. Efficacy of milk fortified with a probiotic Bifidobacterium lactis HN019 (DR-10 (TM)) and prebiotic galacto-oligosaccharides in prevention of morbidity - a community based double masked randomized trial. PLOS ONE 2004;5(8):e12164.

\section{Sazawal 2010 \{published data only\}}

Sazawal S, Dhingra U, Hiremath G, Sarkar A, Dhingra P, Dutta A, et al. Prebiotic and probiotic fortified milk in prevention of morbidities among children: community-based, randomized, double-blind, controlled trial. PLOS One 2010;5(8):e12164.

\section{Schrezenmeir 2004 \{published data only\}}

Schrezenmeir J, Heller K, McCue M, Llamas C, Lam W, Burow H, et al. Benefits of oral supplementation with and without synbiotics in young children with acute bacterial infections. Clinical Pediatrics 2004;43(3):239-49.
Skovbjerg 2009 \{published data only\}

Skovbjerg S, Roos K, Holm SE, Grahn Hakansson E, Nowrouzian F, Ivarsson M, et al. Spray bacteriotherapy decreases middle ear fluid in children with secretory otitis media. Archives of Disease in Childhood 2009;94(2):92-8.

Smith 2016 \{published data only\}

Smith TD, Watt H, Gunn L, Car J, Boyle RJ. Recommending oral probiotics to reduce winter antibiotic prescriptions in people with asthma: a pragmatic randomized controlled trial. Annals of Family Medicine 2016;14(5):422-30.

\section{Stojkovic 2016 \{published data only\}}

Stojkovic A, Simovic A, Bogdanovic Z, Bankovic D, Poskurica M. Clinical trial/experimental study (consort compliant): optimal time period to achieve the effects on synbiotic-controlled wheezing and respiratory infections in young children. Serbian Archives of Medicine 2016;144(1-2):38-45.

\section{Timby 2015 \{published data only\}}

Timby N, Hernell O, Vaarala O, Melin M, Lönnerdal B, Domellöf M. Infections in infants fed formula supplemented with bovine milk fat globule membranes. Journal of Pediatric Gastroenterology and Nutrition 2015;60(3):384-9.

\section{Vlieger 2009 \{published data only\}}

Vlieger AM, Robroch A, Van Buuren S, Kiers J, Rijkers G, Benninga MA, et al. Tolerance and safety of Lactobacillus paracasei ssp. paracasei in combination with Bifidobacterium animalis ssp. lactis in a prebiotic-containing infant formula: a randomised controlled trial. British Journal of Nutrition 2009;102(6):869-75.

\section{Weizman 2006 \{published data only\}}

Weizman Z, Alsheikh A. Safety and tolerance of a probiotic formula in early infancy comparing two probiotic agents: a pilot study. Journal of the American College of Nutrition 2006;25(5):415-9.

\section{West 2008 \{published data only\}}

West CE, Gothefors L, Granström M, Käyhty H, Hammarström MLKC, Hernell O. Effects of feeding probiotics during weaning on infections and antibody responses to diphtheria, tetanus and Hib vaccines. Pediatric Allergy and Immunology 2008;19(1):53-60.

\section{Wright 2009 \{published data only\}}

Wright A, Hawkins CH, Änggård EE, Harper DR. A controlled clinical trial of a therapeutic bacteriophage preparation in chronic otitis due to antibiotic-resistant Pseudomonas aeruginosa; a preliminary report of efficacy. Clinical Otolaryngology 2009;34(4):349-57.

\section{References to ongoing studies}

\section{ACTRN12618000130268 \{published data only\}}

ACTRN12618000130268. Effect of a probiotic on Otitis media (ear infections) and Upper Respiratory Tract Infections amongst 6-24 month old children [A randomised placebo controlled trial of the effect of BLIS probiotic, S. salivarius (K12) on Otitis 
media (ear infections) and Upper Respiratory Tract Infections amongst 6-24 month old children, as measured by medical record events]. https://www.anzctr.org.au/Trial/Registration/ TrialReview.aspx?id=374076 (date submitted 21/12/2017).

\section{EUCTR2017-000820-83-FI \{published data only\}}

EUCTR2017-000820-83-FI. An Open Label Extension Study of GBT440 Administered Orally to Patients with Sickle Cell Disease Who Have Participated in GBT440 Clinical Trials [An Open Label Extension Study of GBT440 Administered Orally to Patients with Sickle Cell Disease Who Have Participated in GBT440 Clinical Trials]. https://www.clinicaltrialsregister.eu/ctr-search/ trial/2017-004045-25/NL (date on which the record was first entered 2018-01-16).

\section{ISRCTN53286030 \{published data only\}}

ISRCTN53286030. A controlled trial of Probiotics in the prevention of episodes of otitis media in general practice $[A$ controlled trial of Probiotics in the prevention of episodes of otitis media in general practice]. http://www.isrctn.com/ ISRCTN53286030 (date applied 30/09/2004).

\section{NCT01724203 \{published data only\}}

NCT01724203. Effect of 12-week Probiotic Supplementation on Bacterial and Viral Infections in Infants Aged 6 to 12 Months [Effect of 12-week Probiotic Supplementation on Bacterial and Viral Infections in Infants Aged 6 to 12 Months: a Double-blind, Randomized, Placebo-controlled Study]. https://clinicaltrials.gov/ct2/show/NCT01724203 (first posted November 9, 2012).

\section{NCT01909128 \{published data only\}}

NCT01909128. Fermented Milk and Fermented Rice on the Appearance of Respiratory and Gastrointestinal Symptoms [Fermented Milk and Fermented Rice on the Appearance of Respiratory and Gastrointestinal Symptoms]. https:// clinicaltrials.gov/ct2/show/NCT01909128 (first posted July 26, 2013).

\section{NCT02221687 \{published data only\}}

NCT02221687. The Combiotic-Study (GOLFIII) [Evaluation of the Efficacy and Safety of an Infant Formula Containing Synbiotics and Its Effects on the Incidence of Infectious Diseases in the Infant Gut : a Double-blind, Randomized, Controlled Interventional Study]. https://clinicaltrials.gov/ct2/show/ NCT02221687 (first posted August 20, 2014).

\section{NCT02802059 \{published data only\}}

NCT02802059. E. Coli Nissle 1917 - Suspension for Infection Prophylaxis (RONi) [E. Coli Nissle 1917 - Suspension for Infection Prophylaxis]. https://clinicaltrials.gov/ct2/show/NCT02802059 (first posted June 16, 2016).

\section{NCT03516409 \{published data only\}}

NCT03516409. Bio-Kult Infantis ${ }^{\circledR}$ in AAD Prevention in Infants [Efficacy of a Synbiotic Product (Probiotics + Prebiotics) in the Prevention of Antibiotics-associated Diarrhoea (AAD) in Infants. A Multicenter, Double Blind, Parallel Group, Placebo Controlled, Randomized Study]. https://clinicaltrials.gov/ct2/ show/NCT03516409 (first posted May 4, 2018).
NCT03614117 \{published data only\}

NCT03614117. Effect of a New Probiotic Strain on Recurrent Acute Otitis Media in Children (PROMAR) (PROMAR) [A Randomized, Double-blind, Placebo-controlled Study to Evaluate the Effect of a Probiotic on Recurrent Acute Otitis Media (rAOM) in Children]. https://clinicaltrials.gov/ct2/show/ NCT03614117 (first posted August 3, 2018).

\section{Additional references \\ AAP 2013}

American Academy of Pediatrics (AAP). Clinical practice guidelines: diagnosis and management of acute otitis media. Pediatrics 2013;131(3):e964-99.

\section{Akkerman 2005}

Akkerman AE, Kuyvenhoven MM, van der Wouden JC, Verhij TJM. Analysis of under- and overprescribing of antibiotics in acute otitis media in general practice. Journal of Antimicrobial Chemotherapy 2005;56:569-74.

\section{Atkins 2004}

Atkins D, Best D, Briss PA, Eccles M, Falck-Ytter Y, Flottorp S, et al. GRADE Working Group. Grading quality of evidence and strength of recommendations. BMJ 2004;328(7454):1490.

\section{Azarpazhooh 2016}

Azarpazhooh A, Lawrence HP, Shah PS. Xylitol for preventing acute otitis media in children up to 12 years of age. Cochrane Database of Systematic Reviews 2016, Issue 8. [DOI: 10.1002/14651858.CD007095.pub3]

\section{Cohen 2013b}

Cohen R, Martin E, de la Rocque F, Thollot F, Pecquet S, Werner A, et al. Probiotics and prebiotics in preventing episodes of acute otitis media in high-risk children: a randomized double-blind, placebo-controlled study. Pediatric Infectious Disease Journal 2013;32(8):810-4.

\section{Cohen 2018}

Cohen PA. Probiotic safety - no guarantees. JAMA Internal Medicine 2018;178(12):1577-8. [DOI: 10.1001/ jamainternmed.2018.5403]

\section{Dagan 2016}

Dagan R, Pelton S, Bakaletz L, Cohen R. Prevention of early episodes of otitis media by pneumococcal vaccines might reduce progression to complex disease. Lancet Infectious Diseases 2016;16(4):480-92.

\section{FAO-WHO 2006}

Food, Agriculture Organization of the United Nations. World Health Organization (FAO-WHO). Probiotics in food: health and nutritional properties and guidelines for evaluation. www.fao.org/3/a-a0512e.pdf (accessed 7 March 2017).

\section{Fortanier 2014}

Fortanier AC, Venekamp RP, Boonacker CWB, Hak E, Schilder AGM, Sanders EAM, et al. Pneumococcal conjugate vaccines for preventing otitis media. Cochrane 
Database of Systematic Reviews 2014, Issue 4. [DOI:

10.1002/14651858.CD001480.pub4]

\section{Froom 2001}

Froom J, Culpepper L, Green LA, de Melker RA, Grob P, Heeren T, et al. A cross-national study of acute otitis media: risk factors, severity, and treatment at initial visit. Report from the International Primary Care Network (IPCN) and the Ambulatory Sentinel Practice Network (ASPN). Journal of the American Board of Family Practice 2001;14:406-17.

\section{GRADEpro GDT 2015 [Computer program]}

McMaster University (developed by Evidence Prime). GRADEpro GDT. Hamilton (ON): McMaster University (developed by Evidence Prime), 2015.

\section{Hao 2015}

Hao Q, Dong BR, Wu T. Probiotics for preventing acute upper respiratory tract infections. Cochrane Database of Systematic Reviews 2015, Issue 2. [DOI: 10.1002/14651858.CD006895.pub3]

\section{Hatakka 2007b}

Hatakka K, Blomgren K, Pohjavuori S, Kaijalainen T, Poussa T, Leinonen M, et al. Treatment of acute otitis media with probiotics in otitis-prone children - a double-blind, placebocontrolled randomised study. Clinical Nutrition 2007;26:314-21.

\section{Hendley 2002}

Hendley JO. Otitis media. New England Journal of Medicine 2002;347(15):1169-74.

\section{Higgins 2011}

Higgins JP, Green S, editor(s). Cochrane Handbook for Systematic Reviews of Interventions Version 5.1.0 (updated March 2011). The Cochrane Collaboration, 2011. Available from handbook.cochrane.org.

\section{Hoberman 2016}

Hoberman A, Paradise JL, Rockette HE, Kearney DH, Bhatnagar S, Shope TR, et al. Shortened antimicrobial treatment for acute otitis media in young children. New England Journal of Medicine 2016;375(25):2446-56.

\section{Hozo 2005}

Hozo SP, Djulbegovic B, Hozo I. Estimating the mean and variance from the median, range, and the size of a sample. $B M C$ Medical Research Methodology 2005;5(13):1-10.

\section{Jefferson 2018}

Jefferson T, Rivetti A, Di Pietrantonj C, Demicheli V. Vaccines for preventing influenza in healthy children. Cochrane Database of Systematic Reviews 2018, Issue 2. [DOI: 10.1002/14651858.CD004879.pub5]

\section{Laursen 2017b}

Laursen RP, Larnkjaer A, Ritz C, Hauger H, Michaelsen KF, Moelgaard C. Probiotics and child care absence due to infections: a randomised controlled trial. Paediatrics 2017;140(2):e20170735.

\section{Laursen 2018}

Laursen RP, Hojsak I. Probiotics for respiratory tract infections in children attending day care centers - a systematic review. European Journal of Paediatrics 2018;177(7):979-94. [DOI: 10.1007/s00431-018-3167-1]

\section{Lefebvre 2011}

Lefebvre C, Manheimer E, Glanville J. Chapter 6: Searching for studies. In: Higgins JP, Green S, editor(s). Cochrane Handbook for Systematic Reviews of Interventions Version 5.1.0 (updated March 2011). The Cochrane Collaboration, 2011. Available from handbook.cochrane.org.

\section{Marteau 2002}

Marteau PR. Probiotics in clinical conditions. Clinical Reviews in Allergy and Immunology 2002;22(3):255-73.

\section{McCullough 2017}

McCullough AR, Pollack AJ, Plejdrup Hansen M, Glasziou PP, Looke DF, Britt HC, et al. Antibiotics for acute respiratory infections in general practice: comparison of prescribing rates with guideline recommendations. Medical Journal of Australia 2017;207(2):65-9.

\section{Moher 2009}

Moher D, Liberati A, Tetzlaff J, Altman DG, The PRISMA Group. Preferred reporting items for systematic reviews and metaanalyses: The PRISMA Statement. BMJ 2009;339:2535.

\section{Monasta 2012}

Monasta L, Ronfani L, Marchetti F, Montico M, Vecchi Brumatti L, Bavcar A, et al. Burden of disease caused by otitis media: systematic review and global estimates. PLOS ONE 2012;7(4):e36226.

\section{Niittynen 2012}

Niittynen L, Pitkaranta A, Korpela R. Probiotics and otitis media in children. International Journal of Otorhinolaryngology 2012;76(4):465-70.

\section{Norhayati 2017}

Norhayati MN, Ho JJ, Azman MY. Influenza vaccines for preventing acute otitis media in infants and children. Cochrane Database of Systematic Reviews 2017, Issue 10. [DOI: 10.1002/14651858.CD010089.pub3]

\section{O'Neill 2014}

O'Neill J, Davies S, Rex J. Antimicrobial resistance: tackling a crisis for the health and wealth of nations. https://amrreview.org/sites/default/files/AMR\%20Review\%20Paper\%20\%20Tackling\%20a\%20crisis\%20for\%20the\%20health\%20and \%20wealth\%20of\%20nations_1.pdf (accessed 7 March 2017).

\section{Pichichero 2016}

Pichichero ME. Ten-year study of the stringently defined otitisprone child in Rochester, NY. Pediatric Infectious Disease Journal 2016;35(9):1033-9.

\section{Pirozzo 2000}

Pirozzo S, Del Mar C. Chapter 27: Otitis media. Evidence Based Pediatrics and Child Health. London: BMJ Books, 2000. 


\section{RevMan 2014 [Computer program]}

Nordic Cochrane Centre, The Cochrane Collaboration. Review Manager 5 (RevMan 5). Version 5.3. Copenhagen: Nordic Cochrane Centre, The Cochrane Collaboration, 2014.

\section{Roos 2001b}

Roos K, Hakansson EG, Holm S. Effect of recolonisation with "interfering" alpha streptococci on recurrences of acute and secretory otitis media in children: randomised placebo controlled trial. BMJ 2001;322:1-4.

\section{Rovers 2006}

Rovers MM, Glasziou P, Appelman CL, Burke P, McCormick DP, Damoiseaux RA, et al. Antibiotics for acute otitis media: a meta-analysis with individual patient data. Lancet 2006;368(9545):1429-35.

\section{Stool 1989}

Stool SE, Field MJ. The impact of otitis media. Pediatric Infectious Disease Journal 1989;8(Suppl 1):11-4.

\section{Tamir 2017}

Tamir SO, Sibbald A, Rupa V, Marchisio P, Homoe P, Daniel SJ, et al. Gudelines for the treatment of acute otitis media: why are there worldwide differences?. Current Otorhinolaryngology Reports 2017;5(2):101-7.

\section{Venekamp 2015}

Venekamp RP, Sanders SL, Glasziou PP, Del Mar CB, Rovers MM. Antibiotics for acute otitis media in children. Cochrane Database of Systematic Reviews 2015, Issue 6. [DOI: 10.1002/14651858.CD000219.pub4]

\section{CHARACTERISTICS OF STUDIES}

Characteristics of included studies [ordered by study ID]

\section{Vouloumanou 2009}

Vouloumanou EK, Makris GC, Karageorgopoulos DE, Falagas ME. Probiotics for the prevention of respiratory tract infections: a systematic review. International Journal of Antimicrobial Agents 2009;34(3):197.e1-10.

\section{Wang 2016}

Wang Y, Li X, Ge T, Xiao Y, Liao Y, Cui Y, et al. Probiotics for prevention and treatment of respiratory tract infections in children. Medicine 2016;95(31):e4509.

\section{Xu 2016}

Xu Q, Casey JR, Newman E, Pichichero ME. Otitis-prone children have immunologic deficiencies in naturally acquired nasopharyngeal mucosal antibody response after Streptococcus pneumoniae colonization. Pediatric Infectious Disease Journal 2016;35(1):54-60.

\section{References to other published versions of this review Crosby 2004}

Crosby Z, Williamson I, Del Mar C, Little P. Probiotics for the prevention of acute otitis media in children. Cochrane Database of Systematic Reviews 2004, Issue 4. [DOI: 10.1002/14651858.CD004978.pub2]

\section{Scott 2018}

Scott AM, Beller EM, Clark J, Roos K, Grimwood K, Little P, et al. Probiotics for preventing acute otitis media in children. Cochrane Database of Systematic Reviews 2018, Issue 1. [DOI: 10.1002/14651858.CD012941]

Cohen 2013a

Methods

Study design: 2-arm, placebo-controlled, randomised clinical study

Method of randomisation: centralised randomisation without stratification was used with the Trial Balance programme on an Internet-based server to assign participants to groups

Blinding: double-blind

Duration: 12 months

Exclusions postrandomisation: 236 randomised, 12 declined postrandomisation, 224 enrolled

Losses to follow-up:

Stage 1: probiotic group: 11 dropouts due to non-compliance with overall follow-up; control group: 11 dropouts due to non-compliance with overall follow-up

Subsequently: probiotic group: 18 ( 8 due to non-compliance with treatment, 4 for personal reasons, 1 adenoidectomy scheduled, 1 adenoidectomy, 2 unknown, 5 adverse events); control group: 18 (9 noncompliance with treatment, 6 personal reasons, 1 adenoidectomy, 1 ichthyosis, 1 unknown, 1 tympanostomy)

Participants

Country: France

Setting: children were enrolled by paediatricians 
Age (mean +/- SD): $10.2+/-1.7$ months

Inclusion criteria: healthy infants, 7 to 13 months old, full-term birth, weight $\geq 6 \mathrm{~kg}$ at enrolment, AOM at the pre-inclusion visit treated with an antibiotic based on French guidelines and able to tolerate oral formula of $300 \mathrm{~mL}$ per day, at high risk of AOM (exposed to other children via day-care centre attendance or with $\geq 2$ siblings), history of at least 1 episode of AOM before the current one

Exclusion criteria: twins, children with underlying chronic disease, allergy to cow's milk protein, or participating in another clinical study

Interventions

Treatment group: NAN 3 formula with probiotic (Streptococcus thermophilus nCC 2496, Streptococcus salivarius dSM 13084, Lactobacillus rhamnosus IPr CgMCC 1.3724) and preB (raftilose/raftiline). Dose: $S$ thermophilus: $1 \times 10^{7} \mathrm{CFU} / \mathrm{g}$, S salivarius: $2.5 \times 10^{7} \mathrm{CFU} / \mathrm{g}$, L rhamnosus: $1 \times 10^{7} \mathrm{CFU} / \mathrm{g}$; aiming for 300 to $630 \mathrm{~mL}$ of formula consumed per day, for 12 months

Comparator group: NAN 3 formula alone (placebo); aiming for 300 to $630 \mathrm{~mL}$ consumed per day, for 12 months

\begin{tabular}{ll}
\hline Outcomes & Primary outcome(s): incidence of AOM in each group in the 12 months \\
& Secondary outcome(s): URTI incidence, LRTI incidence, number of antibiotic treatment courses, num- \\
ber of children without a new episode of AOM, number of children with recurring AOM (3 episodes in 6 \\
months or 4 episodes in 12 months)
\end{tabular}

Notes Authors' COIs: 1 of the authors employed by study funder

Funding: financial support provided by Nestle. Role of the funder in design, collection, analysis, interpretation of data, the writing of the manuscript, decision to submit the manuscript was not reported.

\section{Risk of bias}

\begin{tabular}{lll}
\hline Bias & Authors' judgement & Support for judgement \\
\hline $\begin{array}{l}\text { Random sequence genera- } \\
\text { tion (selection bias) }\end{array}$ & Low risk & $\begin{array}{l}\text { Centralised randomisation without stratification was used with the Trial Bal- } \\
\text { ance programme to assign participants to groups. }\end{array}$ \\
\hline $\begin{array}{l}\text { Allocation concealment } \\
\text { (selection bias) }\end{array}$ & Unclear risk & NR \\
\hline $\begin{array}{l}\text { Blinding of participants } \\
\text { and personnel (perfor- } \\
\text { mance bias) } \\
\text { All outcomes }\end{array}$ & Low risk & Study described as "double blind". \\
\hline $\begin{array}{l}\text { Blinding of outcome as- } \\
\text { sessment (detection bias) } \\
\text { All outcomes }\end{array}$ & Unclear risk & NR \\
\hline $\begin{array}{l}\text { Incomplete outcome data } \\
\text { (attrition bias) } \\
\text { All outcomes }\end{array}$ & Low risk & Attrition reported for both arms, with reasons provided. \\
\hline $\begin{array}{l}\text { Selective reporting (re- } \\
\text { porting bias) }\end{array}$ & Unclear risk & All outcomes reported except incidence of URTIs (a secondary outcome). \\
\hline $\begin{array}{l}\text { Other bias } \\
\text { High risk }\end{array}$ & 1 of the authors employed by study funder. \\
\hline
\end{tabular}


Other authors state no conflicts of interest or other funding to disclose.

\section{Corsello 2017}

\section{Methods}

Study design: 2-arm, placebo-controlled, randomised clinical study

Method of randomisation: randomisation was based on a list with consecutive numbers with an allocation ratio of $1: 1$ between groups

Blinding: double-blind

Duration: 90 days

Exclusions postrandomisation: no child refused to participate after randomisation, and all of the children received the allocated intervention

Losses to follow-up: probiotic 7 (reasons NR); placebo 13 (reasons NR)

\section{Country: Italy}

Setting: children in the Italian public health system; recruited by paediatricians

Number of participants: 146 randomised: 73 treatment group; 73 comparator group

Age (mean +/-SD): $33+/-9$ months

Inclusion criteria: healthy children aged 12 to 48 months who were attending day care or preschool at least 5 days a week and who were regularly checked by the paediatricians involved in the trial were considered for the study, and were consecutively contacted during scheduled medical examinations at the paediatrician's office

Exclusion criteria: age $<12$ months or $>48$ months, concomitant chronic infections, chronic systemic diseases, chronic inflammatory bowel diseases, autoimmune diseases, immunodeficiency, malignancy, metabolic diseases, chronic respiratory tract diseases including respiratory allergies and cystic fibrosis, malformations of gastrointestinal or urinary or respiratory tract, history of respiratory or gastrointestinal or urinary tract surgery, congenital cardiac defects, functional bowel disorders, suspected or challenge-proven food allergy, food intolerances, severe malnutrition (Z-score for weight-for-height $<3$ SD scores), and use of antibiotics or pre/pro/synbiotics or immune-stimulating products in the 2 weeks before study enrolment. Siblings of participants enrolled in the study were not allowed to participate in the trial.
Treatment group: $7 \mathrm{~g}$ cow's skim milk fermented with Lactobacillus paracasei (CBA L74), daily, for 90 days

Comparator group: placebo (maltodextrins, with an energy content similar to that of the fermented milk), daily, for 90 days

\section{Outcomes}

Primary outcome(s): the rate of children experiencing at least 1 episode of common infectious disease

Secondary outcome(s): total number of common infectious diseases, use of medications (antibiotics, antipyretics, corticosteroids), emergency department medical examinations, hospitalisations, days of work lost by the parents, days of school lost by the children, faecal levels of $\alpha$ - and $\beta$-defensins, cathelicidin (LL-37), and secretory immunoglobulin A (slgA), adverse events 
Funding: unrestricted grant from Heinz Italia (affiliate of Kraft Heinz Company). The funder had no influence on design, collection, analysis, interpretation of data, the writing of the manuscript, or the decision to submit the manuscript.

The trialled probiotic was manufactured by Heinz Italia SpA.

Note regarding meta-analysis: the study reports separate numbers for rhinitis, pharyngitis, laryngitis, tracheitis, otitis, for "common infectious diseases observed during the study period". For the 'difference in other infections' (ARIs) outcome, we reported the numbers for rhinitis only so as not to double count participants; when the numbers of all ARIs (rhinitis, pharyngitis, laryngitis, tracheitis, AOM) were added, they exceeded the number of children in the group, suggesting that at least some of the children had more than 1 ARI during the study.

\section{Risk of bias}

\begin{tabular}{|c|c|c|}
\hline Bias & Authors' judgement & Support for judgement \\
\hline $\begin{array}{l}\text { Random sequence genera- } \\
\text { tion (selection bias) }\end{array}$ & Low risk & $\begin{array}{l}\text { The study is described as randomised; baseline characteristics appear similar } \\
\text { (Table 2). }\end{array}$ \\
\hline $\begin{array}{l}\text { Allocation concealment } \\
\text { (selection bias) }\end{array}$ & Unclear risk & Not clearly reported \\
\hline $\begin{array}{l}\text { Blinding of participants } \\
\text { and personnel (perfor- } \\
\text { mance bias) } \\
\text { All outcomes }\end{array}$ & Low risk & $\begin{array}{l}\text { The investigators were blinded to the treatment at all times. Intervention and } \\
\text { control were in similar packaging, and products appeared the same. }\end{array}$ \\
\hline $\begin{array}{l}\text { Blinding of outcome as- } \\
\text { sessment (detection bias) } \\
\text { All outcomes }\end{array}$ & Low risk & $\begin{array}{l}\text { A biostatistician blinded to the treatment allocation performed the statistical } \\
\text { analysis. }\end{array}$ \\
\hline $\begin{array}{l}\text { Incomplete outcome data } \\
\text { (attrition bias) } \\
\text { All outcomes }\end{array}$ & Low risk & $\begin{array}{l}\text { Attrition was reported for both arms, but no reasons provided. As attrition was } \\
\text { less than } 20 \% \text { in both arms, we judged the risk of bias to be low. }\end{array}$ \\
\hline $\begin{array}{l}\text { Selective reporting (re- } \\
\text { porting bias) }\end{array}$ & Unclear risk & Emergency department visits (secondary outcome) not reported \\
\hline Other bias & Low risk & $\begin{array}{l}\text { Authors' COIs: the authors declare they have no conflict of interest. } \\
\text { Funding: unrestricted grant from Heinz Italia (affiliate of Kraft Heinz Company). } \\
\text { The funder had no influence on design, collection, analysis, interpretation of } \\
\text { data, the writing of the manuscript, decision to submit the manuscript. } \\
\text { The trialled probiotic was manufactured by Heinz Italia SpA. }\end{array}$ \\
\hline
\end{tabular}

\section{Di Nardo 2014}

Study design: 2-arm, placebo-controlled, randomised clinical study
Method of randomisation: allocation schedule was computer generated, using a random permuted
blocks algorithm
Blinding: double-blinded
Duration: 6 months
Exclusions postrandomisation: none


Di Nardo 2014 (Continued)

Losses to follow-up: 1 discontinued in placebo group (consent withdrawn)

\begin{tabular}{|c|c|}
\hline \multirow[t]{6}{*}{ Participants } & Country: Italy \\
\hline & Setting: Dept of Paediatrics, University of Rome "La Sapienza" \\
\hline & Number of participants: 61 randomised; 30 probiotic, 31 placebo \\
\hline & Age (mean +/- SD): NR. Median: 17.5 years; range: 6 to 29 years \\
\hline & $\begin{array}{l}\text { Inclusion criteria: patients with cystic fibrosis, FEV1 > 70\%; no inhaled or systemic corticosteroids; no } \\
\text { anti-inflammatory drugs, antileukotrienes, and mast cell membrane stabilisers; and no serious organ } \\
\text { involvement. (Although this study technically meets the exclusion criteria as it involves patients with } \\
\text { cystic fibrosis, we have included this study because the study only included those with mild disease, } \\
\text { who had limited respiratory impairment, and had not had a recent change in treatment.) }\end{array}$ \\
\hline & $\begin{array}{l}\text { Exclusion criteria: history of pulmonary exacerbation or upper respiratory infection in the previous } 2 \\
\text { months; changes in medications in the last } 2 \text { months; history of haemoptysis in the last } 2 \text { months; and } \\
\text { colonisation with Burkholderia cepacia or mycobacteria }\end{array}$ \\
\hline \multirow[t]{2}{*}{ Interventions } & Treatment group: probiotic Lactobacillus reuteri ATCC55730; 5 drops per day ( $\left.10^{10} \mathrm{CFU}\right)$ for 6 months \\
\hline & $\begin{array}{l}\text { Comparator group: the placebo was packed in identical bottles, had the same colour, weight, smell, } \\
\text { and taste of the probiotic formulation; } 5 \text { drops per day for } 6 \text { months }\end{array}$ \\
\hline \multirow[t]{2}{*}{ Outcomes } & $\begin{array}{l}\text { Primary outcome(s): number of episodes of pulmonary exacerbations; number and duration of hospital } \\
\text { admissions made for pulmonary exacerbations; number of GI and upper respiratory tract infections }\end{array}$ \\
\hline & $\begin{array}{l}\text { Secondary outcome(s): change in qualitative and quantitative bacteria present in the sputum; FEV1; } \\
\text { change in faecal calprotectin concentration; IL-8 and TNF-a levels in plasma and induced sputum }\end{array}$ \\
\hline \multirow[t]{2}{*}{ Notes } & Authors' COIs: the authors report that they have no conflicts of interest \\
\hline & $\begin{array}{l}\text { Funding: intervention and placebo supplied by Italchimici (Pomezia, Italy), which had no role in the } \\
\text { conception, design, conduct of the study, or in the analysis and interpretation of the data }\end{array}$ \\
\hline
\end{tabular}

\section{Risk of bias}

Bias Authors' judgement Support for judgement

Random sequence genera- Low risk Randomised; no significant differences in baseline characteristics between the tion (selection bias) 2 groups

$\begin{aligned} & \text { Allocation concealment } \\ & \text { (selection bias) }\end{aligned} \quad$ Low risk $\quad$ Allocation schedule computer generated and fully concealed from doctors.

Blinding of participants Low risk Study described as double-blind; doctors and participants blinded.
and personnel (perfor-
mance bias)
All outcomes

\begin{tabular}{lll}
\hline $\begin{array}{l}\text { Blinding of outcome as- } \\
\text { sessment (detection bias) }\end{array}$ & Low risk & $\begin{array}{l}\text { Outcome measures of efficacy were recorded by investigators completely un- } \\
\text { aware of group assignment; unblinding procedures were performed after the } \\
\text { sll outcomes }\end{array}$ \\
\hline
\end{tabular}

Incomplete outcome data Low risk Attrition reported for both arms, with reasons.

(attrition bias)

All outcomes 
Di Nardo 2014 (Continued)

Selective reporting (reporting bias)

Other bias

Low risk
All outcomes reported.

Intervention and placebo supplied by Italchimici (Pomezia, Italy), who had no role in the conception, design, conduct of the study, or in the analysis and interpretation of the data.

The authors reported that they had no conflicts of interest.

\section{Di Pierro 2016}

\begin{tabular}{|c|c|}
\hline \multirow[t]{6}{*}{ Methods } & Study design: 2-arm, controlled, randomised clinical study \\
\hline & Method of randomisation: individuals were randomised into groups by toss of a coin \\
\hline & Blinding: unblinded \\
\hline & Duration: 180 days \\
\hline & Exclusions postrandomisation: NR \\
\hline & Losses to follow-up: the authors state that "none of the children were withdrawn from the study" \\
\hline \multirow[t]{6}{*}{ Participants } & Country: Italy \\
\hline & Setting: unclear \\
\hline & Number of participants: 222 randomised; 111 treatment group, 111 placebo \\
\hline & $\begin{array}{l}\text { Age (mean +/- SD): treated group males: } 36+/-3.2 \text { months, females: } 34+/-3 \text { months; untreated group } \\
\text { males: } 35+/-3 \text { months, females: } 35+/-3.6 \text { months }\end{array}$ \\
\hline & $\begin{array}{l}\text { Inclusion criteria: children around } 3 \text { years of age and soon to attend the first year of kindergarten; free } \\
\text { of streptococcal disease, as established by a rapid throat swab test for group A streptococcus; none } \\
\text { were clinically ill on enrolment }\end{array}$ \\
\hline & $\begin{array}{l}\text { Exclusion criteria: immunocompromised children; had undergone tonsillectomy or had an indication } \\
\text { for adeno-tonsillectomy; had a history of rheumatic disorders, bronchospasm, and/or a diagnosis of } \\
\text { asthma and/or allergy; a diagnosed respiratory or significant systemic disorder; were either undergoing } \\
\text { current pharmacological therapies to prevent recurrent respiratory infections or presented with con- } \\
\text { ditions that could favour the development of AOM, including severe atopy, acquired or congenital im- } \\
\text { munodeficiency, cleft palate, a chronically ruptured eardrum, craniofacial abnormalities or obstructive } \\
\text { adenoids, sleep apnoea syndrome, or placement of tympanostomy tubes }\end{array}$ \\
\hline
\end{tabular}

Interventions

Treatment group: Streptococcus salivarious K12 (i.e. BLIS K12) probiotic strain, formulated as slowly dissolving oral tablets; containing no less than 1 billion CFU/tablet of S salivarious K12, 1 tablet/day, dissolved slowly in the mouth after brushing teeth/immediately before going to sleep, for 180 consecutive days

Comparator group: untreated

Outcomes

Primary/secondary outcome(s): not specified, but the study states that it aimed to evaluate the following: (1) the onset of side effects or symptoms of toxicity while the product was being administered; (2) the efficacy of BLIS K12 in the prevention of Streptococcus pyogenes infections (pharyngo-tonsillitis and scarlet fever) during 6 months of treatment and a 3-month follow-up period; (3) the efficacy of BLIS K12 in reducing the occurrence of $\mathrm{AOM}$

Notes

Authors' COIs: first author is the main formulator of the tested product and is involved in the Scientific Council of the company (Omeopiacenza) trading the tested product. The other authors report no conflicts of interest. 


\section{Funding: NR}

Note regarding meta-analysis: this study only reports "pharyngo-tonsillitis" rather than ARIs generally (as other studies do in this analysis); we included these data in the analysis of the 'difference in other infections' outcome.

\section{Risk of bias}

\begin{tabular}{|c|c|c|}
\hline Bias & Authors' judgement & Support for judgement \\
\hline $\begin{array}{l}\text { Random sequence genera- } \\
\text { tion (selection bias) }\end{array}$ & Low risk & "Randomised by tossed coin"; Table 1 suggests randomisation worked \\
\hline $\begin{array}{l}\text { Allocation concealment } \\
\text { (selection bias) }\end{array}$ & Unclear risk & NR \\
\hline $\begin{array}{l}\text { Blinding of participants } \\
\text { and personnel (perfor- } \\
\text { mance bias) } \\
\text { All outcomes }\end{array}$ & High risk & $\begin{array}{l}\text { Untreated group did not receive any treatment (i.e. unlikely patients/doctors } \\
\text { blinded) }\end{array}$ \\
\hline $\begin{array}{l}\text { Blinding of outcome as- } \\
\text { sessment (detection bias) } \\
\text { All outcomes }\end{array}$ & Unclear risk & NR \\
\hline $\begin{array}{l}\text { Incomplete outcome data } \\
\text { (attrition bias) } \\
\text { All outcomes }\end{array}$ & Low risk & "None of the children were withdrawn from the study" \\
\hline $\begin{array}{l}\text { Selective reporting (re- } \\
\text { porting bias) }\end{array}$ & Low risk & All outcomes reported. \\
\hline Other bias & High risk & $\begin{array}{l}\text { Authors' COIs: first author is the main formulator of the tested product and is } \\
\text { involved in the Scientific Council of the company (Omeopiacenza) trading the } \\
\text { tested product. The other authors report no conflicts of interest. } \\
\text { Funding for the trial and the role of the funder: NR }\end{array}$ \\
\hline
\end{tabular}

\section{Hatakka 2001a}

\section{Methods}

Study design: 2-arm, placebo-controlled, randomised clinical study

Method of randomisation: computer-generated, blocked randomisation list; block size of 4, stratified according to age ( $<3$ years, and 3 years and over) and day-care centre ( 18 centres)

Blinding: double-blinded

Duration: 7 months

Exclusions postrandomisation: discontinued before intervention: probiotic 14, placebo 9

Losses to follow-up: probiotic 30 (9 moving away from the area, 2 sickness, 8 other reasons, 11 unknown); placebo 28 (11 moving away from the area, 3 non-compliance, 3 sickness, 4 other reasons, 7 unknown)

$\begin{array}{ll}\text { Participants } & \text { Country: Finland } \\ & \text { Setting: day-care centres in Helsinki }\end{array}$


Hatakka 2001a (Continued)

Number of participants: randomised 594; probiotic 296, control 298

Age (mean, range): probiotic 4.6 (1.3 to 6.8 ) years, control 4.4 (1.3 to 6.7) years

Inclusion criteria: healthy children aged 1 to 6 years, attending municipal day-care centres

Exclusion criteria: children with allergy to cow's milk, lactose intolerance, severe food allergy, and other severe chronic diseases

Interventions

Treatment group: Lactobacillus milk (Gefilus, Valio, Riihimäki, Finland) containing $1 \%$ fat and 5 to 10 $x 10^{5}$ CFU/mL of strain Lactobacillus rhamnosus GG (ATCC 53103); 3 times a day, 5 days a week, for 7 months over the course of the winter

Comparator group: control milk had the same composition asLactobacillus milk, but did not contain Lactobacillus; 3 times a day, 5 days a week, for 7 months over the course of the winter

Outcomes Primary outcome(s): the number of days with respiratory and gastrointestinal symptoms or days with any illness; absences from day-care centre because of illness; number of children with URTIs with complications (AOM and sinusitis) and LRTIs (acute bronchitis and pneumonia) as diagnosed by a doctor; antibiotic treatments during the 7-month intervention

Secondary outcome(s): correlation between the amount of milk consumed and the number of days with symptoms; symptom score (measuring the overall burden of symptoms)

\section{Notes}

Authors' COIs: KH (first author) has been employed by Valio Research Centre (manufacturer of the trialled probiotic) for 2 of the past 5 years. MS and RK are employed by Valio Research Centre. ES has given 2 educational presentations on Lactobacillus GG for Valio, and TP has received consulting fees from Valio.

Funding: Valio Research and Development, Helsinki, Finland. The University of Helsinki and the City of Helsinki participated in the funding by providing supervision and technical help. Role of the funders in design, collection, analysis, interpretation of data, the writing of the manuscript, decision to submit the manuscript not reported.

Note regarding meta-analysis: for the 'difference in other infections (ARI)' outcome, we used data reporting "all infections together" (context suggests these were only respiratory infections) having first subtracted the number of children with AOM from this number.

\section{Risk of bias}

\begin{tabular}{lll}
\hline Bias & Authors' judgement & Support for judgement \\
\hline $\begin{array}{l}\text { Random sequence genera- } \\
\text { tion (selection bias) }\end{array}$ & Low risk & Randomly allocated using a computer-generated randomisation list \\
\hline $\begin{array}{l}\text { Allocation concealment } \\
\text { (selection bias) }\end{array}$ & Unclear risk & NR \\
\hline $\begin{array}{l}\text { Blinding of participants } \\
\text { and personnel (perfor- } \\
\text { mance bias) }\end{array}$ & Low risk & $\begin{array}{l}\text { Day-care staff, parents, children, and investigators were unaware of which milk } \\
\text { carton contained Lactobacillus until the intention-to-treat analysis was per- } \\
\text { formed. }\end{array}$ \\
\hline $\begin{array}{l}\text { Blinding of outcome as- } \\
\text { sessment (detection bias) } \\
\text { All outcomes }\end{array}$ & Unclear risk & Not clear whether outcome assessors were blinded \\
\hline $\begin{array}{l}\text { Incomplete outcome data } \\
\text { (attrition bias) } \\
\text { All outcomes }\end{array}$ & Low risk & Attrition reported in both arms, with reasons. \\
\hline
\end{tabular}


Hatakka 2001a (Continued)

Selective reporting (reporting bias)

Other bias
Low risk

All outcomes reported.

High risk

\begin{abstract}
Authors' COIs: KH (first author) has been employed by Valio Research Centre (manufacturer of the trialled probiotic) for 2 of the past 5 years. MS and RK are employed by Valio Research Centre. ES has given 2 educational presentations on Lactobacillus GG for Valio, and TP has received consulting fees from Valio.

Funding: Valio Research and Development, Helsinki, Finland. The University of Helsinki and the City of Helsinki participated in the funding by providing supervision and technical help. Role of the funders in design, collection, analysis, interpretation of data, the writing of the manuscript, decision to submit the manuscript not reported.
\end{abstract}

\title{
Hatakka 2007a
}

Methods Study design: 2-arm, placebo-controlled, randomised clinical study

Method of randomisation: computer-generated blocked randomisation list drawn up by a statistician; block size of 4 , stratified by gender, age ( $<3$ years old, $\geq 3$ years old), and care type (home or smallgroup care or day care)

Blinding: double-blinded

Duration: 6 months

Exclusions postrandomisation: none

Losses to follow-up: probiotic 20 (4 sickness, 5 non-compliance, 5 personal reasons, 5 unknown, 1 adverse events); placebo 20 ( 3 sickness, 8 non-compliance, 0 personal reasons, 7 unknown, 2 tympanostomy)

Country: Finland
Setting: NR
Number of participants: 309 randomised; probiotic 155, placebo 154
Age (mean, range): probiotic group: 2.4 (0.8 to 6.0) years, placebo: 2.4 (0.9 to 5.6) years
Inclusion criteria: at least 4 episodes of AOM during the preceding 12 months, or at least 3 episodes dur-
ing the preceding 6 months
Exclusion criteria: children on regular medication, with chronic illnesses, Down's syndrome, lip or
palatal cleft, otitis media with effusion, or who were scheduled for tympanostomy or adenoidectomy
during the study were excluded; those who had undergone tympanostomy or adenoidectomy during
the preceding 6 months were also excluded unless they had suffered at least 3 episodes of AOM since
the operations
nosus GG, ATCC 53103; L rhamnosus LC 705; Bifidobacterium breve 99; Propionibacterium freudenreichii subsp. shermanii) 8 to $9 \times 10^{9} \mathrm{CFU} /$ capsule of each strain, 1 capsule daily for 6 months

Comparator group: capsule containing cellulose microcrystalline (identical looking to active intervention), 1 capsule daily for 6 months 
Secondary outcome(s): frequency of pathogen carriage, the occurrence of recurrent URTIs, and the number of antimicrobial treatments

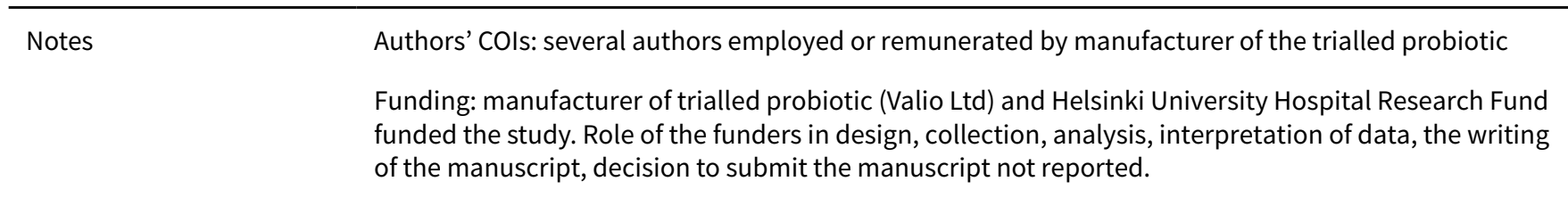

\section{Risk of bias}

\begin{tabular}{|c|c|c|}
\hline Bias & Authors' judgement & Support for judgement \\
\hline $\begin{array}{l}\text { Random sequence genera- } \\
\text { tion (selection bias) }\end{array}$ & Low risk & Computer-generated blocked randomisation list drawn by the statistician. \\
\hline $\begin{array}{l}\text { Allocation concealment } \\
\text { (selection bias) }\end{array}$ & Unclear risk & NR \\
\hline $\begin{array}{l}\text { Blinding of participants } \\
\text { and personnel (perfor- } \\
\text { mance bias) } \\
\text { All outcomes }\end{array}$ & Low risk & $\begin{array}{l}\text { Investigators, parents, and children were all unaware of which treatment } \\
\text { group each child was in until the statistical analysis was performed; capsules } \\
\text { were delivered in coded containers. }\end{array}$ \\
\hline $\begin{array}{l}\text { Blinding of outcome as- } \\
\text { sessment (detection bias) } \\
\text { All outcomes }\end{array}$ & Unclear risk & NR \\
\hline $\begin{array}{l}\text { Incomplete outcome data } \\
\text { (attrition bias) } \\
\text { All outcomes }\end{array}$ & Low risk & Attrition reported for both arms, reasons provided. \\
\hline $\begin{array}{l}\text { Selective reporting (re- } \\
\text { porting bias) }\end{array}$ & Low risk & All outcomes reported. \\
\hline \multirow[t]{2}{*}{ Other bias } & High risk & $\begin{array}{l}\text { Authors' COIs: several authors employed or remunerated by manufacturer of } \\
\text { the trialled probiotic }\end{array}$ \\
\hline & & $\begin{array}{l}\text { Funding: manufacturer of trialled probiotic (Valio Ltd) and Helsinki University } \\
\text { Hospital Research Fund funded the study. Role of the funders in design, collec- } \\
\text { tion, analysis, interpretation of data, the writing of the manuscript, decision to } \\
\text { submit the manuscript not reported. }\end{array}$ \\
\hline
\end{tabular}

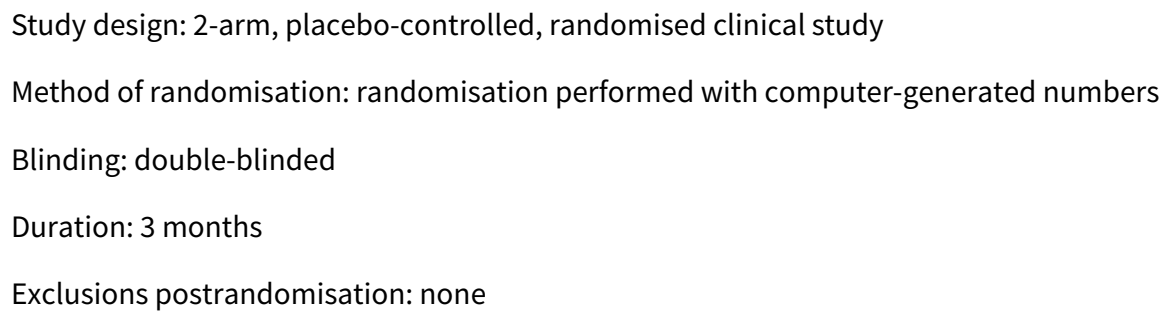

Losses to follow-up: probiotic 12 (8 did not want to drink product anymore, 4 did not like the taste of product); placebo 15 (9 did not want to drink product anymore, 6 did not like the taste of product) 
Hojsak 2010a (Continued)
Participants
Country: Croatia
Setting: day-care centres in Zagreb
Number of participants: 281 randomised; 139 probiotic, 142 placebo
Age (mean, range): probiotic 51.9 (13 to 86 ) months; placebo 53.6 (13 to 83 ) months
Inclusion criteria: children whose parents or legal guardians provided written informed consent and who did not meet any of the exclusion criteria
Exclusion criteria: children with cow's milk allergy (probiotics were given in a fermented cow's milk product); those who were receiving probiotic or prebiotic products, or both prior to or at the time of en- rolment; those who had a neoplasm, other chronic severe illness, or immunodeficiency; and children who disliked fermented milk products

Interventions

Treatment group: Lactobacillus rhamnosus strain GG (LGG strain from Valio) administered in $100 \mathrm{~mL}$ of a fermented milk product at a dose of $1 \times 10^{9} \mathrm{CFU}$, once daily during the 3-month intervention period (19 November 2007 to 20 February 2008)

Comparator group: placebo was the same postpasteurised fermented milk product $(100 \mathrm{~mL})$ without LGG, once daily during the 3-month intervention period (19 November 2007 to 20 February 2008)

Outcomes Primary outcome(s): (1) number of children with GI infections; (2) number of children with respiratory tract infections confirmed by physician

Secondary outcome(s): (1) number of children with vomiting episodes; (2) number of children with diarrhoeal episodes; (3) number of GI infections lasting longer than 2 days; (4) number of children with URTI, including rhinitis, pharyngitis, sinusitis, otitis, and the common cold; (5) number of children with LRTIs, including pneumonia, bronchitis, and bronchiolitis; (6) number of respiratory tract infections lasting longer than 3 days; (7) total number of days with respiratory and GI symptoms; and (8) number of days absent from day-care centre due to infections

Notes

Authors' COIs: the authors report that before, during, or after the study, none of the authors received any funds for their work, which was exclusively voluntary, and the authors state that they have no conflict of interest

Funding: probiotic and placebo supplied by Dukat Dairy Industry (dairy company in Croatia), who had no role in the conception, design, or conduct of the study or in the analysis or interpretation of the data

Note regarding meta-analysis: this study reports the number of children with LRTIs and the number of children with URTIs separately. To report this outcome in the analysis of difference in other infections, we added the number of children with LRTI and URTI and subtracted from this number the number of children with AOM.

\section{Risk of bias}

\begin{tabular}{lll}
\hline Bias & Authors' judgement & Support for judgement \\
\hline $\begin{array}{l}\text { Random sequence genera- } \\
\text { tion (selection bias) }\end{array}$ & Low risk & Randomisation procedure performed with computer-generated numbers. \\
\hline $\begin{array}{l}\text { Allocation concealment } \\
\text { (selection bias) }\end{array}$ & Unclear risk & NR \\
\hline $\begin{array}{l}\text { Blinding of participants } \\
\text { and personnel (perfor- } \\
\text { mance bias) } \\
\text { All outcomes }\end{array}$ & Low risk & $\begin{array}{l}\text { Study described as double-blind; neither research staff nor children were } \\
\text { aware of the real nature of the product. Probiotic and placebo were packed in } \\
\text { identical bottles, and were of the same colour, weight, smell, and taste. }\end{array}$ \\
\hline
\end{tabular}


Hojsak 2010a (Continued)

Blinding of outcome as- Low risk Unblinding procedure was performed after the study was completed and after sessment (detection bias)

All outcomes the statistical analyses were finalised.

\begin{tabular}{|c|c|c|}
\hline Incomplete outcome data & Low risk & Attrition reported for both arms, with reasons. \\
\hline
\end{tabular}

All outcomes

Selective reporting (re- Low risk All outcomes reported.

porting bias)

Other bias Low risk

Authors' COIs: the authors report that before, during, or after the study, none of the authors received any funds for their work, which was exclusively voluntary, and the authors state that they have no conflict of interest

Funding: probiotic and placebo supplied by Dukat Dairy Industry (dairy company in Croatia), who had no role in the conception, design, or conduct of the study or in the analysis or interpretation of the data

Hojsak 2016

Study design: 2-arm, placebo-controlled, randomised clinical study
Method of randomisation: used Random Allocation Software, in which every patient got a number and
received the preparation successively; randomisation in blocks of 6
Blinding: double-blinded
Duration: 90 days
Exclusions postrandomisation: none
Losses to follow-up: probiotic 5 (5 discontinued product use); placebo 7 (7 discontinued product use)

Participants

Country: Croatia

Setting: day cares in Zagreb, Croatia

Number of participants: 210 randomised; 104 probiotic, 106 placebo

Age (mean, range): probiotic 4.49 (1.43 to 7.48 ) years; placebo 4.44 (1.44 to 6.79$)$ years

Inclusion criteria: children who attended day-care centres in 3 separate locations in the Zagreb area were eligible for the study, whose parents or legal guardians signed written informed consent, and who did not meet any of the exclusion criteria were included into the study

Exclusion criteria: children receiving probiotic or prebiotic products, or both 2 weeks prior to or at the time of enrolment; those who had any severe chronic illness, including neoplasm and immunodeficiency

Treatment group: a sachet containing $1 \mathrm{~g}$ of powder (maltodextrin with BB-12 at a dose of $10^{9} \mathrm{CFU}$; the powder was mixed in about $20 \mathrm{~mL}$ of milk, water, cordial, or drinking yogurt or spread on a spoon of yogurt and consumed immediately thereafter, at home in the evening together with a meal. Once daily for 90 days (starting 23 January 2013).

Comparator group: a sachet containing $1 \mathrm{~g}$ of powder (maltodextrin); the powder was mixed in about $20 \mathrm{~mL}$ of milk, water, cordial, or drinking yogurt or spread on a spoon of yogurt and consumed immediately thereafter, at home in the evening together with a meal. Once daily for 90 days (starting 23 January 2013). 
Hojsak 2016 (Continued)

Outcomes
Primary outcome(s): number of children with common GI and respiratory infections. GI infections included diarrhoea, vomiting, both; ARIs included pharyngitis, otitis, common cold, pneumonia, bronchitis, and bronchiolitis diagnosed by physician.

Secondary outcome(s): duration of symptoms of common infections (GI and ARIs); number of children with GI infections; number of children with ARIs; absence from day-care centre due to infections; use of antibiotics
Authors' COls: the article states "none declared"

Funding: Chr. Hansen, Denmark (manufacturer of the probiotic). The role of the funder in the conception, design, or conduct of the study or in the analysis or interpretation of the data was not reported.

Note regarding meta-analysis: for the 'difference in other infections' outcome, we have reported the numbers of children with ARIs but subtracted from those the number of children with AOM so as not to double count

\section{Risk of bias}

\begin{tabular}{|c|c|c|}
\hline Bias & Authors' judgement & Support for judgement \\
\hline $\begin{array}{l}\text { Random sequence genera- } \\
\text { tion (selection bias) }\end{array}$ & Low risk & Randomised using Random Allocation Software \\
\hline $\begin{array}{l}\text { Allocation concealment } \\
\text { (selection bias) }\end{array}$ & Low risk & $\begin{array}{l}\text { "To ensure allocation concealment, an independent person prepared the ran- } \\
\text { domisation schedule." }\end{array}$ \\
\hline $\begin{array}{l}\text { Blinding of participants } \\
\text { and personnel (perfor- } \\
\text { mance bias) } \\
\text { All outcomes }\end{array}$ & Low risk & $\begin{array}{l}\text { All study personnel, parents, and guardians were unaware of the group assign- } \\
\text { ments. Products were of the same taste, colour, and smell, and were packed in } \\
\text { identical sachets. The real nature of the product was not revealed to research } \\
\text { staff and participants. }\end{array}$ \\
\hline $\begin{array}{l}\text { Blinding of outcome as- } \\
\text { sessment (detection bias) } \\
\text { All outcomes }\end{array}$ & Low risk & $\begin{array}{l}\text { Statistical plan and complete statistical analysis was performed prior to un- } \\
\text { blinding, and all analyses were performed according to a written statistical } \\
\text { analysis plan. }\end{array}$ \\
\hline $\begin{array}{l}\text { Incomplete outcome data } \\
\text { (attrition bias) } \\
\text { All outcomes }\end{array}$ & Low risk & Attrition reported for both arms, with reasons. \\
\hline $\begin{array}{l}\text { Selective reporting (re- } \\
\text { porting bias) }\end{array}$ & Low risk & All outcomes reported. \\
\hline Other bias & High risk & $\begin{array}{l}\text { Authors' COIs: the article states "none declared" } \\
\text { Funding: Chr. Hansen, Denmark (manufacturer of the probiotic). The role of } \\
\text { the funder in the conception, design, or conduct of the study or in the analysis } \\
\text { or interpretation of the data was not reported. }\end{array}$ \\
\hline
\end{tabular}

Karpova 2015

Study design: 2-arm, controlled, randomised clinical study
Method of randomisation: the article states that it used "simple randomisation" (further details NR)
Blinding: none (open)
Duration: 30 days


Exclusions postrandomisation: probiotics 15 ( 3 allergic reaction, 12 reasons not provided); control 19 (reasons not provided). 3 participants with allergic reaction were transferred to the control group and analysed as part of the control group.

Losses to follow-up: none

Country: Russia
Setting: children attending organised children's groups
Number of participants: 250 children; 128 probiotic, 122 control; the study reports on 113 probiotic, 106
control
Age: mean NR. Median NR. Range: 6 to 7 years old
Inclusion criteria: children attending organised children's groups, aged 6 to 7 years, who had clinical
signs of chronic adenoiditis
Exclusion criteria: intolerance to flavouring components that make up the probiotic complex; presence
of concomitant diseases that change the natural course of the disease, affect the result of therapy, and/
or disrupt the possibility of subjective assessment of the symptoms of the disease (psychoneurological
pathology, diabetes mellitus, blood diseases, oncological diseases, immunodeficiency conditions, gas-
trointestinal tract diseases, etc.)

Interventions Treatment group: Streptococccus salivarius K12-based probiotic complex in combination with the nasal-douche, once daily at night for 30 days

Comparator group: nasal-douche alone, once daily at night for 30 days

Outcomes

Primary/secondary outcome(s): unclear. The following outcomes listed: frequency of diagnosed adenoiditis, the need for topical anti-inflammatory therapy, complications of adenoiditis (AOM and acute rhinosinusitis), the need for systemic antibacterial drugs, side effects

Notes Authors' COIs: NR

Funding: NR. The role of the funder (if any) in the conception, design, or conduct of the study or in the analysis or interpretation of the data was not reported.

Note regarding meta-analysis: for the analysis of difference in the use of antibiotics, we used the numbers reported in this study of children "prescribed antibiotics for AOM and acute rhinitis" (the numbers are reported collectively rather than individually by disease) in the 'use of antibiotics for AOM' subgroup rather than the 'use of antibiotics for any infection' subgroup as the former is a closer match.

For the analysis of difference in other infections, we have reported the numbers for children with acute rhinosinusitis, as those are the only reported numbers (unlike other studies, which report 'ARIs' more collectively).

\section{Risk of bias}

\begin{tabular}{|c|c|c|}
\hline Bias & Authors' judgement & Support for judgement \\
\hline $\begin{array}{l}\text { Random sequence genera- } \\
\text { tion (selection bias) }\end{array}$ & Unclear risk & $\begin{array}{l}\text { Study states that it is randomised, but method not reported; no baseline char- } \\
\text { acteristics provided to assess the result of randomisation. }\end{array}$ \\
\hline $\begin{array}{l}\text { Allocation concealment } \\
\text { (selection bias) }\end{array}$ & Unclear risk & NR \\
\hline $\begin{array}{l}\text { Blinding of participants } \\
\text { and personnel (perfor- } \\
\text { mance bias) } \\
\text { All outcomes }\end{array}$ & Unclear risk & NR \\
\hline
\end{tabular}


Karpova 2015 (Continued)

Blinding of outcome assessment (detection bias)

All outcomes

Incomplete outcome data Low risk $\quad$ Attrition reported for both arms, with reasons.
(attrition bias)

(attrition bias)

All outcomes

Selective reporting (re- Unclear risk Side effects are listed as one of the outcomes, but not reported.
porting bias)

Other bias High risk Authors' COIs: NR

Funding: NR. The role of the funder (if any) in the conception, design, or conduct of the study or in the analysis or interpretation of the data was not reported.

Maldonado 2012

Study design: 2-arm, placebo-controlled, randomised clinical study
Method of randomisation: computer-generated randomisation list
Blinding: double-blinded
Duration: 6 months
Exclusions postrandomisation: probiotic 0; placebo 7 ( 7 did not receive the formula due to mistake in
sending)
Losses to follow-up: probiotic 7 (1 moved out of study area, 4 discontinued intervention/did not attend
study visits, 2 excluded from analysis/incomplete data); placebo 13 (2 discontinued intervention, 6 dis-
continued intervention/did not attend study visits, 5 excluded from analysis/incomplete data)

Participants

Country: Spain

Setting: paediatric departments of 3 hospitals

Number of participants: 215 randomised; probiotic 117 , control 98

Age (mean +/- SD): probiotic 6.5 +/- 1.2 months; control 6.5 +/- 1.3 months

Inclusion criteria: healthy 6-month-old infants who were exclusively formula fed; live in proximity to the hospitals, child was delivered at the hospital and/or made regular visits to the paediatrician

Exclusion criteria: GI disorders (history of chronic diarrhoea or constipation, gastro-oesophageal reflux), GI surgery, cow's milk protein allergy, metabolic disorders (diabetes, lactose intolerance), immunodeficiency, antibiotic prescription 1 week before inclusion, and previous use of formula containing prebiotics or probiotics rent European Union regulations, supplemented with $(0.4 \mathrm{~g} / 100 \mathrm{~mL})$ galactooligosaccharide plus Lactobacillus fermentum CECT5716 ( $L$ fermentum Hereditum, Biosearch Life, Granada, Spain) at an average dose of $2 \times 10^{8} \mathrm{CFU} /$ day. The amount of formula per day was paediatrician-prescribed; duration was 6 months.

Comparator group: standard powdered formula with nutritional composition in accordance with current European Union regulations, supplemented with galactooligosaccharide only $(0.4 \mathrm{~g} / 100 \mathrm{~mL})$. The amount of formula per day was paediatrician-prescribed; duration was 6 months. 
Maldonado 2012 (Continued)

Outcomes

Primary outcome(s): incidence of infections (including GI, ARI, AOM, urinary, and other, less common infections)

Secondary outcome(s): evolution of weight, length, and head circumference, fever episodes, antibiotic prescriptions, and concentrations of short-chain fatty acids (SCFAs), immunoglobulin (Ig) A, and microbiota composition in faeces; the incidence of recurrent ( $\geq 3$ events) respiratory infections

Notes

Authors' COIs: the article states that "the authors report no conflict of interest" (NB: corresponding author lists affiliation with Puleva Food SL, which manufactured the formulas used in the trial)

Funding: Puleva Food SL (manufacturer of the formulas; provided the formulas)

The role of the funder (if any) in the conception, design, or conduct of the study or in the analysis or interpretation of the data was not reported.

\section{Risk of bias}

\begin{tabular}{|c|c|c|}
\hline Bias & Authors' judgement & Support for judgement \\
\hline $\begin{array}{l}\text { Random sequence genera- } \\
\text { tion (selection bias) }\end{array}$ & Low risk & Computer-generated randomisation list (SIGESMU, Madrid, Spain) \\
\hline $\begin{array}{l}\text { Allocation concealment } \\
\text { (selection bias) }\end{array}$ & Unclear risk & NR \\
\hline $\begin{array}{l}\text { Blinding of participants } \\
\text { and personnel (perfor- } \\
\text { mance bias) } \\
\text { All outcomes }\end{array}$ & Low risk & $\begin{array}{l}\text { Study described as double blind; "to ensure blinding, both formulas submitted } \\
\text { to a sensorial test by an expert panel that finds both products to be identical" }\end{array}$ \\
\hline $\begin{array}{l}\text { Blinding of outcome as- } \\
\text { sessment (detection bias) } \\
\text { All outcomes }\end{array}$ & Low risk & Data were analysed with STATA by a blinded statistician. \\
\hline $\begin{array}{l}\text { Incomplete outcome data } \\
\text { (attrition bias) } \\
\text { All outcomes }\end{array}$ & Low risk & Attrition reported for both arms, with reasons. \\
\hline $\begin{array}{l}\text { Selective reporting (re- } \\
\text { porting bias) }\end{array}$ & Low risk & All outcomes reported. \\
\hline \multirow[t]{3}{*}{ Other bias } & High risk & $\begin{array}{l}\text { Authors' COIs: the article states that "the authors report no conflict of inter- } \\
\text { est" (NB: corresponding author lists affiliation with Puleva Food SL, which } \\
\text { manufactured the formulas used in the trial) }\end{array}$ \\
\hline & & $\begin{array}{l}\text { Funding: Puleva Food SL (manufacturer of the formulas; provided the formu- } \\
\text { las). }\end{array}$ \\
\hline & & $\begin{array}{l}\text { The role of the funder (if any) in the conception, design, or conduct of the } \\
\text { study or in the analysis or interpretation of the data was not reported. }\end{array}$ \\
\hline
\end{tabular}

Maldonado 2015

Study design: 2-arm, placebo-controlled, randomised clinical study
Method of randomisation: computer-generated randomisation list
Blinding: double-blinded

Probiotics for preventing acute otitis media in children (Review) 
Maldonado 2015 (Continued)

Duration: this is a 3-year follow-up of Maldonado 2012 (see above)

Exclusions postrandomisation: 121 assessed for eligibility; 5 not located, 6 declined to participate; 110 included

Losses to follow-up: probiotic 10 (did not attend medical visits); placebo 9 (did not attend medical visits)

Country: Spain
Setting: children who completed the initial trial (Maldonado 2012)
Number of participants: 110 included; probiotic 55 , control 55
Age (mean +/- SD): probiotic: $3.02+/-0.1$ years; control: $3.02+/-0.1$ years
Inclusion criteria: infants who had completed the previous trial (Maldonado 2012)
Exclusion criteria: NR

Interventions

Treatment group (Maldonado 2012): standard powdered formula with nutritional composition in accordance with current European Union regulations, supplemented with $(0.4 \mathrm{~g} / 100 \mathrm{~mL})$ galactooligosaccharide plus Lactobacillus fermentum CECT5716 ( $L$ fermentum Hereditum, Biosearch Life, Granada, Spain) at an average dose of $2 \times 10^{8} \mathrm{CFU} /$ day. The amount of formula per day was paediatrician-prescribed; duration was 6 months.

Comparator group (Maldonado 2012): standard powdered formula with nutritional composition in accordance with current European Union regulations, supplemented with galactooligosaccharide only $(0.4 \mathrm{~g} / 100 \mathrm{~mL})$. The amount of formula per day was paediatrician-prescribed; duration was 6 months.

\section{Outcomes}

Primary outcome(s): anthropometric values including weight, length, and head circumference at 3 years of age

Secondary outcome(s): incidence of non-acquired diseases (allergies and metabolic diseases), hospitalisations and surgical procedures, incidence of infections measured during the final year of the study

Notes Authors' COIs: MG, JM, MVR, KF, and ELH acknowledge no conflict of interest of personal interest/gain
in any company/organisation, or having received any financial support from any industry-related or-
ganisation in the preparation of this article. ADV, JF, and MO work for Biosearch, owner of the patent of
Lactobacillus fermentum CECT5716. FLV works for Lactalis Puleva. JML is the recipient of a fellowship
from the Fundación Universidad-Empresa (Universidad de Granada, Spain).
Funding: the study was funded by HiPP GmbH \& Co Vertrieb KG, Pfaffenhofen (Germany) and Lactalis
Puleva, Granada (Spain). Study sponsors participated in the study design and the writing of the report.

\section{Risk of bias}

\begin{tabular}{lll}
\hline Bias & Authors' judgement & Support for judgement \\
\hline $\begin{array}{l}\text { Random sequence genera- } \\
\text { tion (selection bias) }\end{array}$ & Low risk & Randomised in the original study (Maldonado 2012) \\
\hline $\begin{array}{l}\text { Allocation concealment } \\
\text { (selection bias) }\end{array}$ & Unclear risk & NR \\
\hline $\begin{array}{l}\text { Blinding of participants } \\
\text { and personnel (perfor- } \\
\text { mance bias) }\end{array}$ & Unclear risk & $\begin{array}{l}\text { Original study described as double-blind; not clear if the 2-year follow-up was } \\
\text { all outcomes }\end{array}$ \\
\hline
\end{tabular}


Maldonado 2015 (Continued)
Blinding of outcome as-
Unclear risk
NR sessment (detection bias)
All outcomes

\begin{tabular}{lll}
\hline $\begin{array}{l}\text { Incomplete outcome data } \\
\text { (attrition bias) } \\
\text { All outcomes }\end{array}$ & Low risk & Attrition reported for both arms, with reasons. \\
\hline $\begin{array}{l}\text { Selective reporting (re- } \\
\text { porting bias) }\end{array}$ & Low risk & All outcomes reported.
\end{tabular}

Other bias High risk

\begin{abstract}
Authors' COIs: MG, JM, MVR, KF, and ELH acknowledge no conflict of interest of personal interest/gain in any company/organisation, or having received any financial support from any industry-related organisation in the preparation of this article. ADV, JF, and MO work for Biosearch, owner of the patent of Lactobacillus fermentum CECT5716. FLV works for Lactalis Puleva. JML is the recipient of a fellowship from the Fundación Universidad-Empresa (Universidad de Granada, Spain).

Funding: the study was funded by HiPP GmbH \& Co Vertrieb KG, Pfaffenhofen (Germany) and Lactalis Puleva, Granada (Spain). Study sponsors participated in the study design and the writing of the report.
\end{abstract}

Marchisio 2015

Study design: 2-arm, placebo-controlled, randomised controlled trial
Method of randomisation: using a random number generator, in a 1:1 ratio
Blinding: double-blinded
Duration: 3 months
Exclusions postrandomisation: none

Losses to follow-up: probiotic 0 ; placebo 3 (refused to continue study after first treatment period)

Participants

Country: Italy

Setting: Paediatric Highly Intensive Care Unit, Dept of Pathophysiology \& Transplantation, University of Milan

Number of participants: 100 randomised; 50 probiotic, 50 placebo

Age (mean +/- SD): probiotic: $2.7+/-1.1$ years; placebo: $3.1+/-1.2$ years

Inclusion criteria: children aged 1 to 5 years with histories of recurrent AOM (defined as at least 3 episodes in the preceding 6 months or at least 4 episodes in the preceding 12 months with the most recent episode within the previous 2 to 8 weeks) who were regularly followed up by the outpatient section of the Paediatric Highly Intensive Care Unit. The minimum number of episodes of AOM for inclusion in the otitis-prone group had to be diagnosed by pneumatic otoscopy performed by a trained investigator and documented by medical records, and at least 2 episodes had to be supported by tympanometric findings. At the time of enrolment, the children had to be free of AOM but could be experiencing otitis media with effusion.

Exclusion criteria: all factors that could favour the development of AOM, including severe atopy, acquired or congenital immunodeficiency, cleft palate, a chronically ruptured eardrum, craniofacial abnormalities or obstructive adenoids, sleep apnoea syndrome, or the placement of tympanostomy tubes. 
Marchisio 2015 (Continued)

Interventions
Treatment group: Streptococcus salivarius 24SMB preparation (suspension of S salivarius 24SMB consisting of a minimum of $100 \times 10^{9} \mathrm{CFU} / \mathrm{mL}$ in $5 \mathrm{~mL}$ of saline); delivered with a nasal spray that provided $5 \times 10^{9}$ CFU to each nostril; twice per day, 5 days each month for 3 consecutive months

Comparator group: the placebo was based on saline with a colour and taste that were indistinguishable from the preparation containing $S$ salivarius. The placebo was administered with the same nasal spray and provided the same saline dose; twice per day, 5 days each month for 3 consecutive months.

\section{Outcomes}

Primary/secondary outcome(s): not clearly identified. The article states: "Three types of outcome were considered, i.e., the total number of AOM episodes and the numbers of complicated and uncomplicated episodes."
Authors' COIs: the author(s) declare that they have no competing interests

Funding: this study was supported by a grant obtained from DMG Italia S.r.l. The role of the funder (if any) in the conception, design, or conduct of the study or in the analysis or interpretation of the data was not reported.

\section{Risk of bias}

\begin{tabular}{|c|c|c|}
\hline Bias & Authors' judgement & Support for judgement \\
\hline $\begin{array}{l}\text { Random sequence genera- } \\
\text { tion (selection bias) }\end{array}$ & Low risk & Randomised by "a random number generator" \\
\hline $\begin{array}{l}\text { Allocation concealment } \\
\text { (selection bias) }\end{array}$ & Unclear risk & NR \\
\hline $\begin{array}{l}\text { Blinding of participants } \\
\text { and personnel (perfor- } \\
\text { mance bias) } \\
\text { All outcomes }\end{array}$ & Low risk & $\begin{array}{l}\text { Study described as double-blinded; paediatricians were blinded to treatment } \\
\text { assignments. Both groups' sprays were labelled with randomisation codes. }\end{array}$ \\
\hline $\begin{array}{l}\text { Blinding of outcome as- } \\
\text { sessment (detection bias) } \\
\text { All outcomes }\end{array}$ & Unclear risk & $\begin{array}{l}\text { Sprays' randomisation codes were revealed only to the staff of the data moni- } \\
\text { toring centre. }\end{array}$ \\
\hline $\begin{array}{l}\text { Incomplete outcome data } \\
\text { (attrition bias) } \\
\text { All outcomes }\end{array}$ & Low risk & Attrition reported for both arms, with reasons. \\
\hline $\begin{array}{l}\text { Selective reporting (re- } \\
\text { porting bias) }\end{array}$ & Unclear risk & $\begin{array}{l}\text { Outcomes not clearly identified as primary or secondary. Lists } 3 \text { outcomes } \\
\text { (AOM episodes, complicated AOM episodes, uncomplicated episodes), all of } \\
\text { which are reported, but the number of children treated with antibiotics is also } \\
\text { reported in the results. }\end{array}$ \\
\hline Other bias & High risk & $\begin{array}{l}\text { Authors' COIs: the author(s) declare that they have no competing interests } \\
\text { Funding: this study was supported by a grant obtained from DMG Italia S.r.l. } \\
\text { The role of the funder (if any) in the conception, design, or conduct of the } \\
\text { study or in the analysis or interpretation of the data was not reported. }\end{array}$ \\
\hline
\end{tabular}

Nocerino 2017

Study design: 3-arm, placebo-controlled, randomised clinical study
Method of randomisation: computer-generated randomisation list


Nocerino 2017 (Continued)

Blinding: double-blinded

Duration: 3 months

Exclusions postrandomisation: probiotic in milk: 3 refused to participate after randomisation; probiotic in rice: 21 refused to participate after randomisation; placebo: 17 refused to participate after randomisation

Losses to follow-up: probiotic in milk (4); probiotic in rice (5); placebo (5)

Participants
Setting: family paediatricians in the Italian Public Health System
Number of participants: randomised 432: probiotic in milk: 144; probiotic in rice 144; placebo 144
Age (mean +/- SD): probiotic in milk: $32+/-30$ months; probiotic in rice: $31+/-11$ months; placebo: 34
$+/-9$ months
Inclusion criteria: consecutive healthy children (12 to 48 months of age) attending day care or
preschool at least 5 days a week
Exclusion criteria: age $\leq 12$ months or $\geq 48$ months, concomitant chronic systemic diseases, congeni-
tal cardiac defects, gastrointestinal or urinary or respiratory tract surgery, active tuberculosis, autoim-
mune diseases, immunodeficiency, chronic inflammatory bowel diseases, cystic fibrosis, metabol-
ic diseases, history of suspected or challenge-proved food allergy, lactose intolerance, malignancy,
chronic pulmonary diseases, malformations of gastrointestinal or urinary or respiratory tract, severe
malnutrition (Z score for weight-for-height $<3$ SD scores); use of pre/pro/synbiotics, antibiotics, or im-
mune-stimulating products in the 2 weeks before study enrolment

Interventions

Probiotic in milk: cow's milk fermented with Lactobacillus paracasei CBA L74. $7 \mathrm{~g} /$ day of study product diluted in maximum $150 \mathrm{~mL}$ of cow's milk or water. Daily for 3 months during the winter season.

Probiotic in rice: rice fermented with $L$ paracasei CBA $L 74.7 \mathrm{~g} /$ day of study product diluted in maximum $150 \mathrm{~mL}$ of cow's milk or water. Daily for 3 months during the winter season.

Comparator group: placebo consisting of maltodextrins with similar energy content of fermented milk and rice products. $7 \mathrm{~g} /$ day of study product diluted in maximum $150 \mathrm{~mL}$ of cow's milk or water. Daily for 3 months during the winter season.

Outcomes Primary outcome(s): the proportion of children experiencing at least 1 episode of common infectious disease

Secondary outcome(s): proportion of children with recurrent common infectious diseases (i.e. 3 episodes), total number of common infectious diseases, use of medications (antipyretics, antibiotics, or corticosteroids), emergency department visits, paediatric visits, hospitalisations

Notes Authors' COIs: the authors state that they have no financial relationships relevant to this article to disclose. The authors have no conflicts of interest that are directly relevant to the content of this paper.

Funding: this work was supported in part by the Italian Ministry of Health Grant PE-2011-02348447, and by an unrestricted grant from Heinz Italia SpA, Latina, Italy, an affiliate of H.J. Heinz Company, Pittsburgh, PA, USA, devoted to the Department of Translational Medical Science of the University of Naples "Federico II". However, neither the Italian Ministry of Health nor Heinz Italia SpA, Latina, Italy, an affiliate of H.J. Heinz Company, Pittsburgh, PA, USA had any influence on: 1) the study design, 2) the collection, analysis, and interpretation of data; 3) the writing of the manuscript; and 4) the decision to submit the manuscript for publication.

\section{Risk of bias}


Nocerino 2017 (Continued)

Random sequence genera- Low risk Randomised according to a computer-generated randomisation list tion (selection bias)

\begin{tabular}{|c|c|c|}
\hline $\begin{array}{l}\text { Allocation concealment } \\
\text { (selection bias) }\end{array}$ & Low risk & $\begin{array}{l}\text { The paediatricians assigned each child to the next available number on entry } \\
\text { into the trial. }\end{array}$ \\
\hline
\end{tabular}

\begin{tabular}{ll}
\hline $\begin{array}{l}\text { Blinding of participants } \\
\text { and personnel (perfor- }\end{array}$ & Low risk \\
ents, and children were not aware of the dietary treatment assigned.
\end{tabular}

mance bias)

All outcomes

Blinding of outcome as- $\quad$ Low risk $\quad$ Statistical analysis was blinded.
sessment (detection bias)
All outcomes

Incomplete outcome data $\quad$ Low risk $\quad$ Attrition reported for all 3 arms, with reasons.
(attrition bias)

All outcomes

\begin{tabular}{|c|c|c|}
\hline $\begin{array}{l}\text { Selective reporting (re- } \\
\text { porting bias) }\end{array}$ & Low risk & All outcomes reported. \\
\hline \multirow[t]{2}{*}{ Other bias } & Low risk & $\begin{array}{l}\text { Authors' COIs: the authors state that they have no financial relationships rel- } \\
\text { evant to this article to disclose. The authors have no conflicts of interest that } \\
\text { are directly relevant to the content of this paper. }\end{array}$ \\
\hline & & $\begin{array}{l}\text { Funding: this work was supported in part by the Italian Ministry of Health } \\
\text { Grant PE-2011-02348447, and by an unrestricted grant from Heinz Italia SpA, } \\
\text { Latina, Italy, an affiliate of H.J. Heinz Company, Pittsburgh, PA, USA, devoted } \\
\text { to the Department of Translational Medical Science of the University of Naples } \\
\text { "Federico II". However, neither the Italian Ministry of Health nor Heinz Italia } \\
\text { SpA, Latina, Italy, an affiliate of H.J. Heinz Company, Pittsburgh, PA, USA had } \\
\text { any influence on: 1) the study design, 2) the collection, analysis, and interpre- } \\
\text { tation of data; 3) the writing of the manuscript; and 4) the decision to submit } \\
\text { the manuscript for publication. }\end{array}$ \\
\hline
\end{tabular}

Rautava 2009

\begin{tabular}{|c|c|}
\hline Methods & $\begin{array}{l}\text { Study design: } 2 \text {-arm, placebo-controlled, randomised clinical study } \\
\text { Method of randomisation: block randomisation with individual codes } \\
\text { Blinding: double-blinded } \\
\text { Duration: } 10 \text { to } 12 \text { months (infants < } 2 \text { months old were recruited and followed until they were } 12 \\
\text { months old) } \\
\text { Exclusions postrandomisation: none } \\
\text { Losses to follow-up: probiotic } 2 \text {; placebo } 1 \\
\text { Non-adherence to protocol: probiotic } 9 \text { ( } 4 \text { discontinued, } 2 \text { GI complaints, } 2 \text { inconvenience of powdered } \\
\text { formula, } 1 \text { arduousness of study); placebo } 4 \text { ( } 2 \text { discontinued, } 1 \text { Gl complaints, } 1 \text { arduousness of study) }\end{array}$ \\
\hline
\end{tabular}


Rautava 2009 (Continued)

Age (mean age in days at start of intervention): probiotics 38 (6 to 65), placebo 35 (2 to 59)

Inclusion criteria: need for infant formula before the age of 2 months

Exclusion criteria: infants with chronic disease

\begin{tabular}{|c|c|}
\hline \multirow[t]{2}{*}{ Interventions } & $\begin{array}{l}\text { Treatment group: } 1 \times 10^{10} \text { CFU of both Lactobacillus rhamnosus (Lactobacillus GG, American type cul- } \\
\text { ture collection 53103; Valio Ltd, Helsinki, Finland) and Bifidobacterium lactis Bb-12 (Chr. Hansen A/S, } \\
\text { Hoersholm, Denmark) in capsule, the contents of which were supplemented to infant formula given at } \\
1 \text { feeding. Once daily, until the age of } 12 \text { months. }\end{array}$ \\
\hline & $\begin{array}{l}\text { Comparator group: placebo capsule (microcrystalline cellulose) in capsule, the contents of which were } \\
\text { supplemented to infant formula given at } 1 \text { feeding. Once daily, until the age of } 12 \text { months. }\end{array}$ \\
\hline \multirow[t]{2}{*}{ Outcomes } & $\begin{array}{l}\text { Primary outcome(s): incidence of early ARIs, doctor-diagnosed AOM, GIs occurring before the age of } 7 \\
\text { months }\end{array}$ \\
\hline & Secondary outcome(s): incidence of recurrent $(3+)$ respective infections during the first year of life \\
\hline \multirow[t]{2}{*}{ Notes } & Authors' COIs: NR \\
\hline & $\begin{array}{l}\text { Funding: Lactobacillus GG was acquired without cost from Valio Ltd, and Chr. Hansen A/S provided } B \\
\text { lactis Bb-12 and manufactured the probiotic and placebo capsules without cost. The infant formula } \\
\text { was provided without cost by Mead Johnson Nutrition. The study was funded by the Microbes and Man } \\
\text { research programme, the Academy of Finland, and the Bristol-Myer Squibb Mead Johnson Founda- } \\
\text { tion Unrestricted Research Grant. The funding sources had no involvement in study design, collection, } \\
\text { analysis, and interpretation of data, writing of the report, or the decision to submit the paper for publi- } \\
\text { cation. }\end{array}$ \\
\hline
\end{tabular}

Risk of bias

\begin{tabular}{lll}
\hline Bias & Authors' judgement & Support for judgement \\
\hline $\begin{array}{l}\text { Random sequence genera- } \\
\text { tion (selection bias) }\end{array}$ & Low risk & Randomised by block randomisation with individual codes \\
\hline $\begin{array}{l}\text { Allocation concealment } \\
\text { (selection bias) }\end{array}$ & Unclear risk & $\begin{array}{l}\text { The random allocation was generated independently from the investigators by } \\
\text { the manufacturer of the capsules (Chr. Hansen A/S). }\end{array}$ \\
\hline
\end{tabular}

\begin{tabular}{|c|c|c|}
\hline $\begin{array}{l}\text { Blinding of participants } \\
\text { and personnel (perfor- }\end{array}$ & Low risk & $\begin{array}{l}\text { Study was double-blind; the code was opened after all the infants had com- } \\
\text { pleted the study and data had been edited. }\end{array}$ \\
\hline
\end{tabular}

mance bias)

All outcomes

\begin{tabular}{|c|c|c|}
\hline $\begin{array}{l}\text { Blinding of outcome as- } \\
\text { sessment (detection bias) } \\
\text { All outcomes }\end{array}$ & Unclear risk & Not clear who performed the assessment or whether or not they were blinded \\
\hline $\begin{array}{l}\text { Incomplete outcome data } \\
\text { (attrition bias) } \\
\text { All outcomes }\end{array}$ & Low risk & Attrition reported for both arms, with reasons. \\
\hline $\begin{array}{l}\text { Selective reporting (re- } \\
\text { porting bias) }\end{array}$ & Low risk & All outcomes reported. \\
\hline Other bias & Unclear risk & $\begin{array}{l}\text { Lactobacillus GG was acquired without cost from Valio Ltd, and Chr. Hansen } \\
\text { A/S provided B lactis Bb-12 and manufactured the probiotic and placebo cap- } \\
\text { sules without cost. The infant formula was provided without cost by Mead } \\
\text { Johnson Nutrition. The study was funded by the Microbes and Man research } \\
\text { programme, the Academy of Finland, and the Bristol-Myer Squibb Mead John- }\end{array}$ \\
\hline
\end{tabular}


Rautava 2009 (Continued)

son Foundation Unrestricted Research Grant. The funding sources had no involvement in study design, collection, analysis, and interpretation of data, writing of the report, or the decision to submit the paper for publication. Author COls not reported.

Method of randomisation: randomisation was undertaken by a technician with no access to information on the participants or doctors; no further details provided

Blinding: double-blinded

Duration: 3 months

Exclusions postrandomisation: not clear, of 132 children included, 108 (82\%) were eligible for analysis of efficacy (53 in the probiotic group and 55 in the placebo group) and 126 (95\%) for analysis of adverse events

Losses to follow-up: not reported by assigned group; main reasons for not being eligible for the efficacy analysis were withdrawal from the study or refusal to start spray treatment ( 8 children), inadequate handling of spray (4), and antibiotic treatment being received for reasons other than AOM (3). The other 5 participants were either lost to follow-up (2), allergic to penicillin (1), or it was not possible to determine whether a recurrence had occurred because they were treated by another doctor during the study (2).

\section{Participants}

Country: Sweden

Setting: ENT specialists at Lundby Hospital

Number of participants: 130 randomised; 108 eligible for efficacy analysis (53 in probiotic group, 55 in placebo group)

Age (mean, range): 23 months ( 6 months to 6 years)

Inclusion criteria: had had recurrent AOM and who had been either referred by their general practitioner or a paediatrician to the open care unit of the ear, nose, and throat department at Lundby Hospital or were directly seeking medical advice for ear pain; had had at least 2 episodes of AOM during the past 6 months or 5 episodes during the past year; at the next occurrence of ear pain the children were examined, and those with a red or pale, bulging, thickened tympanic membrane were included in the study

Exclusion criteria: penicillin allergy, serious underlying disease, immunological deficiency, a valvular heart defect, major lesions in the mouth or nose, a grommet in the ear, or chronic otitis media

Interventions

Treatment group: streptococcal spray (2 strains of Streptococcus sanguis, 2 strains of S mitis, 1 strain of S oralis), freeze-dried in skim milk, reconstituted in $0.9 \%$ sodium chloride immediately prior to use; corresponding to a suspension of $5 \times 10^{8} \mathrm{CFU} / \mathrm{mL}$. Children with no recurrences during the last month received phenoxymethylpenicillin $(n=22)$, and those with a recurrence within 1 month received amoxicillin-clavulanic acid $(n=86)$, both twice a day for 10 days. Streptococcal spray was then sprayed into the nose for 10 days ( 3 puffs into each nostril, twice daily). At day 60 , the same spray was administered for another 10 days (3 puffs into each nostril, twice daily).

Comparator group: placebo comprised of skim milk powder (with the same texture and colour as the spray). Children with no recurrences during the last month received phenoxymethylpenicillin $(n=22)$, and those with recurrence within 1 month received amoxicillin-clavulanic acid $(n=86)$, both twice a day for 10 days. Placebo spray was then sprayed into the nose for 10 days ( 3 puffs into each nostril, twice daily). At day 60 , the same spray was administered for another 10 days ( 3 puffs into each nostril, twice daily). 
Roos 2001a (Continued)

Outcomes
Primary outcome(s): recurrence of AOM during follow-up; normal tympanic membrane at the last valid visit

Secondary outcome(s): unclear

Authors' COIs: the authors of this study have been co-operating for over 15 years in the study of recurrent infections in the upper respiratory tract, and the present study is a continuation of earlier studies on bacterial interference done by the authors. The Medical Products Agency in Uppsala approved the design and suggested minor changes.

Funding: Swedish National Board for Industrial and Technical Development; Teknikbro Foundation; Samariten Foundation. The role of the funder (if any) in the conception, design, or conduct of the study or in the analysis or interpretation of the data was not reported.

\section{Risk of bias}

\begin{tabular}{|c|c|c|}
\hline Bias & Authors' judgement & Support for judgement \\
\hline $\begin{array}{l}\text { Random sequence genera- } \\
\text { tion (selection bias) }\end{array}$ & Low risk & $\begin{array}{l}\text { Randomisation was performed by a technician with no access to information } \\
\text { on participants or doctors. }\end{array}$ \\
\hline $\begin{array}{l}\text { Allocation concealment } \\
\text { (selection bias) }\end{array}$ & Unclear risk & NR \\
\hline $\begin{array}{l}\text { Blinding of participants } \\
\text { and personnel (perfor- } \\
\text { mance bias) } \\
\text { All outcomes }\end{array}$ & Low risk & $\begin{array}{l}\text { Study described as "double blind"; placebo powder was the same texture and } \\
\text { colour as the intervention. }\end{array}$ \\
\hline $\begin{array}{l}\text { Blinding of outcome as- } \\
\text { sessment (detection bias) } \\
\text { All outcomes }\end{array}$ & Unclear risk & NR \\
\hline $\begin{array}{l}\text { Incomplete outcome data } \\
\text { (attrition bias) } \\
\text { All outcomes }\end{array}$ & Low risk & Attrition reported for both arms, with reasons provided. \\
\hline $\begin{array}{l}\text { Selective reporting (re- } \\
\text { porting bias) }\end{array}$ & Low risk & All outcomes reported. \\
\hline Other bias & Unclear risk & $\begin{array}{l}\text { Authors' COIs: the authors of this study have been co-operating for over } 15 \\
\text { years in the study of recurrent infections in the upper respiratory tract, and } \\
\text { the present study is a continuation of earlier studies on bacterial interference } \\
\text { done by the authors. The Medical Products Agency in Uppsala approved the } \\
\text { design and suggested minor changes. } \\
\text { Funding: Swedish National Board for Industrial and Technical Development; } \\
\text { Teknikbro Foundation; Samariten Foundation. The role of the funder (if any) in } \\
\text { the conception, design, or conduct of the study or in the analysis or interpreta- } \\
\text { tion of the data was not reported. }\end{array}$ \\
\hline
\end{tabular}

\section{Stecksen-Blicks 2009}

Methods Study design: 2-arm, placebo-controlled, cluster-randomised clinical study

Method of randomisation: clusters (different day cares) were randomly allocated to the intervention or control regimen by a staff member at the local dairy by coin toss 
Stecksen-Blicks 2009 (Continued)

Blinding: double-blinded

Duration: 21 months

Exclusions postrandomisation: none

Losses to follow-up:

Before 12 months: probiotic 23 ( 22 children moved to school after 3 months, 1 child changed unit); control 39 ( 36 children moved to school after 3 months; 3 milk intolerance)

After 12 months but before 21 months: probiotic 26 (moved to school after 15 months); control 31 (moved to school after 15 months)

Country: Sweden
Setting: day-care centres
Number of participants: randomised 27 units $(\mathrm{n}=248)$; probiotic 16 units $(\mathrm{n}=133)$, control 11 units ( $\mathrm{n}=$
$115)$
Age (mean $+/$ - SD at baseline): probiotic $42.9+/-16.5$ months; control $42.4+/-13.8$ months
Inclusion criteria: children 1 to 5 years old, from 14 day-care centres located in Nordmaling and Hörne-
fors
Exclusion criteria: severe chronic diseases, milk intolerance, or with a fluoride concentration in piped
drinking water exceeding $0.5 \mathrm{mg} / \mathrm{L}$ were excluded

Interventions

Treatment group: $150 \mathrm{~mL}$ medium-fat milk (1.5\%) at lunch; the milk was prepared by the day-care staff by adding 1 colour-coded capsule $(10 \mathrm{~mL})$ to each litre of milk. The capsules were kept frozen and contained fluoride and probiotic bacteria in skim milk to give a final concentration of $2.5 \mathrm{mg} / \mathrm{L}$ fluoride and $10^{7} \mathrm{CFU} / \mathrm{mL}$ Lactobacillus rhamnosus LB21 in the intervention group. The milk was served only on weekdays and not during weekends, holidays, or vacation periods; once daily for 21 months.

Comparator group: children were served $150 \mathrm{~mL}$ medium-fat milk (1.5\%) at lunch. Before serving, the milk was prepared by the day-care staff by adding 1 colour-coded capsule $(10 \mathrm{~mL})$ to each litre of milk. The capsules in the control group contained only skimmed milk and were identical in appearance except in colour code. The intervention milk was served only on weekdays and not during weekends, holidays, or vacation periods; once daily for 21 months.

Primary outcome(s): caries increment
Secondary outcome(s): "measures of general health"
Authors' COIs: NR
Funding: the probiotic strain was provided by Essum AB, Umeå, Sweden. The fluoride solution was pre-
pared at the university biochemical laboratory, and the capsules were produced at the local dairy (Nor-
rmejerier, Umeå, Sweden). The study was supported financially by the County Council of Västerbotten
(TUA) and the Borrow Foundation, UK. Norrmejerier Ekonomisk Förening, Umeå, Sweden supported
the study by preparation and distribution of the milk. The role of the funder (if any) in the conception,
design, or conduct of the study or in the analysis or interpretation of the data was not reported.

\section{Risk of bias}

\begin{tabular}{lll}
\hline Bias & Authors' judgement & Support for judgement \\
\hline $\begin{array}{l}\text { Random sequence genera- } \\
\text { tion (selection bias) }\end{array}$ & Low risk & $\begin{array}{l}\text { Day-care units were randomly allocated by a staff member at the local dairy by } \\
\text { means of coin tossing. }\end{array}$ \\
\hline
\end{tabular}


Stecksen-Blicks 2009 (Continued)

Allocation concealment Low risk The units were referred to as blue or yellow units in order to conceal their al(selection bias) location. The code was kept by an independent monitor and was not unveiled until all data were computerised.
Neither the researchers nor the clinicians, personnel, or families at the daycare centres knew whether the children had received control or intervention milk during the course of the study. and personnel (perfor-

Low risk mance bias)

All outcomes
NR

Blinding of outcome as-

Unclear risk sessment (detection bias) All outcomes Attrition reported for both arms, with reasons provided.

Incomplete outcome data Low risk (attrition bias)

All outcomes

Selective reporting (re- Low risk All outcomes reported.
porting bias)

Other bias High risk Authors' COls: NR

Funding: the probiotic strain was provided by Essum AB, Umeå, Sweden. The fluoride solution was prepared at the university biochemical laboratory, and the capsules were produced at the local dairy (Norrmejerier, Umeå, Sweden). The study was supported financially by the County Council of Västerbotten (TUA) and the Borrow Foundation, UK. Norrmejerier Ekonomisk Förening, Umeå, Sweden supported the study by preparation and distribution of the milk. The role of the funder (if any) in the conception, design, or conduct of the study or in the analysis or interpretation of the data was not reported.

\section{Taipale 2011}

Methods

Study design: 2-arm, placebo-controlled, randomised clinical study

Method of randomisation: computer-generated randomisation list; blocks of 3

Blinding: double-blinded

Duration: approximately 7 months (from age 1 to 2 months to 8 months)

Exclusions postrandomisation: none

Losses to follow-up: probiotic group: 17 did not receive tablet; control group: 17 did not receive tablet

Non-adherence to protocol: probiotic group 4 ( $2 \mathrm{Gl}$ complaints, 2 arduousness of study); control group 2 ( 1 atopic eczema, 1 arduousness of study)
Participants
Country: Finland
Setting: recruited via pamphlets at well-baby clinic
Number of participants: randomised 109; probiotic 55, control 54
Age: not reported, but participants were "1 month old infants"
Inclusion criteria: (1) the child was healthy, (2) the parents were willing to use the novel slow-release pacifier, and (3) the child started receiving the tablet before the age of 2 months. In cases where the 
Taipale 2011 (Continued)

child did not start using the pacifier but the parents were motivated to remain in the study, they were offered the possibility of delivering the crushed tablet to the child using a spoon.

Exclusion criteria: NR

Interventions

Treatment group: the probiotic bacterium used was BB-12 (DSM 15 954; Chr. Hansen A/S, Hoersholm, Denmark). 2 probiotic tablets per day via a novel slow-release pacifier (pacifier contains a pouch in which the tablet is inserted); each tablet contained 5 billion CFU of BB-12. Until 6 to 8 months of age, the children received the tablet via a small pacifier, thereafter via a larger pacifier. The tablet in the small pacifier contained $100 \mathrm{mg} x y$ litol; the tablet in the larger pacifier contained $300 \mathrm{mg}$ xylitol, both in addition to BB-12. Duration: from age 1 to 2 months to 8 months.

Comparator group: the control tablets contained xylitol alone. Duration: from age 1 to 2 months to 8 months.

Outcomes Primary outcome(s): reported cumulative incidence of ARIs and doctor-diagnosed AOM occurring be-
fore the age of 8 months

Secondary outcome(s): successful intestinal passage of BB-12 (Bifidobacterium animalis subsp. lactis)

Notes Authors' COls: 1 author (TT) states "no conflict of interest". 1 author (CL) lists an affiliation with Chr. Hansen (which donated the BB-12 probiotics) in the author affiliations, but this is not noted in the COI. No information on COIs of the remaining authors.

Funding: TT had no conflicts of interest. He was supported by personal grants from the Emil Aaltonen and Sohlberg Foundations, Finnish Dental Society Apollonia, and the Finnish Dental Association. The funding sources had no involvement in study design, interpretation of data, writing of the paper, or the decision to submit the paper for publication. Chr. Hansen A/S (Hoersholm, Denmark) donated the BB-12 for the probiotic tablets and helped in carrying out the faecal analysis of BB-12. The tablets were manufactured by Oy Karl Fazer Ab (Vantaa, Finland). The pacifiers were manufactured by Mekalasi Oy (Konnevesi, Finland). Neither Hansen, Fazer, or Mekalasi provided financial support for this clinical study.

\section{Risk of bias}

\begin{tabular}{|c|c|c|}
\hline Bias & Authors' judgement & Support for judgement \\
\hline $\begin{array}{l}\text { Random sequence genera- } \\
\text { tion (selection bias) }\end{array}$ & Low risk & $\begin{array}{l}\text { Study described as randomised; baseline characteristics appear similar be- } \\
\text { tween groups. }\end{array}$ \\
\hline $\begin{array}{l}\text { Allocation concealment } \\
\text { (selection bias) }\end{array}$ & Unclear risk & NR \\
\hline $\begin{array}{l}\text { Blinding of participants } \\
\text { and personnel (perfor- } \\
\text { mance bias) } \\
\text { All outcomes }\end{array}$ & Low risk & $\begin{array}{l}\text { All of the study personnel and participants were blinded to the treatment as- } \\
\text { signment for the duration of the study. }\end{array}$ \\
\hline $\begin{array}{l}\text { Blinding of outcome as- } \\
\text { sessment (detection bias) } \\
\text { All outcomes }\end{array}$ & Low risk & $\begin{array}{l}\text { Only } 1 \text { of the authors (ES) had the code, but this author did not participate in } \\
\text { producing or analysing the data at any stage of the trial and had no contact } \\
\text { with the study participants. }\end{array}$ \\
\hline $\begin{array}{l}\text { Incomplete outcome data } \\
\text { (attrition bias) } \\
\text { All outcomes }\end{array}$ & Low risk & Attrition reported for both arms, with reasons provided. \\
\hline $\begin{array}{l}\text { Selective reporting (re- } \\
\text { porting bias) }\end{array}$ & Low risk & All outcomes reported. \\
\hline
\end{tabular}


Taipale 2011 (Continued)

Other bias
TT had no conflicts of interest. He was supported by personal grants from the Emil Aaltonen and Sohlberg Foundations, Finnish Dental Society Apollonia, and the Finnish Dental Association. The funding sources had no involvement in study design, interpretation of data, writing of the paper, or the decision to submit the paper for publication. Chr. Hansen A/S (Hoersholm, Denmark) donated the BB-12 for the probiotic tablets and helped in carrying out the faecal analysis of BB-12. The tablets were manufactured by Oy Karl Fazer Ab (Vantaa, Finland). The pacifiers were manufactured by Mekalasi Oy (Konnevesi, Finland). Neither Hansen, Fazer, or Mekalasi provided financial support for this clinical study. 1 author (TT) states "no conflict of interest". 1 author (CL) lists an affiliation with Chr. Hansen (which donated the BB-12 probiotics) in the author affiliations, but this is not noted in the COI. No information on COls of the remaining authors.

Taipale 2016

\section{Methods}

NB: this study reports the results of a 2-year follow-up of the participants in Taipale 2011 (see above)

Study design: 2-arm, placebo-controlled, randomised clinical study

Method of randomisation: computer-generated randomisation list; blocks of 3 (see Taipale 2011)

Blinding: double-blinded

Duration: 2-year follow-up of participants in Taipale 2011

Exclusions postrandomisation: none

Losses to follow-up: probiotic group: 17 did not receive tablet; control group: 17 did not receive tablet

Non-adherence to protocol: probiotic group 6 ( $2 \mathrm{GI}$ complaints, 4 arduousness of study); control group 2 ( 1 atopic eczema, 1 arduousness of study)

Participants

Country: Finland

Setting: originally recruited via pamphlets at well-baby clinics

Number of participants: randomised 109; probiotic 55, control 54 in original trial; this study reports on those participants who completed the 2-year follow up: 32 probiotics, 35 control

Age: NR

Inclusion criteria: the inclusion criteria of the Taipale 2011 trial were that: (1) the child was healthy, (2) the parents agreed to use the novel slow-release pacifier, and (3) the child started to use the pacifier before the age of 2 months. In cases where the child did not start using the pacifier but the parents were motivated to remain in the study, they were offered the possibility of delivering the crushed tablet to the child using a spoon. Reasons for not participating in the trial included moving out of the area, miscarriage, and lack of interest in the trial.

Exclusion criteria: NR

Interventions

Treatment group: each probiotic tablet contained 5 billion CFU of Bifidobacterium animalis subsp. lactis BB-12, in addition to bulking agent xylitol. The smaller tablet contained $100 \mathrm{mg}$ xylitol, whilst the larger tablet contained $300 \mathrm{mg}$ xylitol. Test tablets were administered from the age of 1 to 2 months with a novel slow-release pacifier which contained a pouch in which the tablet was inserted. The children received the tablets twice a day via a small pacifier (volume $120 \mu \mathrm{L}$ ) until 6 to 8 months of age, thereafter via a larger pacifier (volume $250 \mu \mathrm{L}$ ) until the age of 2 years.

Comparator group: the placebo tablet contained xylitol (the smaller tablet contained $100 \mathrm{mg} x y$ litol, whilst the larger tablet contained $300 \mathrm{mg}$ xylitol). The children received the tablets twice a day via a 
Taipale 2016 (Continued)

small pacifier (volume $120 \mu \mathrm{L}$ ) until 6 to 8 months of age, thereafter via a larger pacifier (volume $250 \mu \mathrm{L}$ ) until the age of 2 years.

\begin{tabular}{|c|c|}
\hline \multirow[t]{2}{*}{ Outcomes } & $\begin{array}{l}\text { Primary outcome(s): prevalence of overall acute infections occurring before the age of } 2 \text { years (ARTIs, } \\
\text { AOM, GI, fever episodes) }\end{array}$ \\
\hline & Secondary outcome(s): successful intestinal passage of BB-12 \\
\hline \multirow[t]{2}{*}{ Notes } & $\begin{array}{l}\text { Authors' COIs: TJT was supported by a personal grant from Finnish Dental Society Apollonia. Disclo- } \\
\text { sures: the authors declare that there are no conflicts of interest. }\end{array}$ \\
\hline & $\begin{array}{l}\text { Funding: Chr. Hansen A/S (Hoersholm, Denmark) donated the BB-12 and carried out the faecal analyses } \\
\text { of BB-12. Oy Karl Fazer Ab (Vantaa, Finland) manufactured the tablets and Mekalasi Oy (Konnevesi, Fin- } \\
\text { land) manufactured the pacifiers. Neither Hansen, Fazer, or Mekalasi provided financial support for this } \\
\text { study. The role of the funder (if any) in the conception, design, or conduct of the study or in the analysis } \\
\text { or interpretation of the data was not reported. }\end{array}$ \\
\hline
\end{tabular}

\section{Risk of bias}

\begin{tabular}{|c|c|c|}
\hline Bias & Authors' judgement & Support for judgement \\
\hline $\begin{array}{l}\text { Random sequence genera- } \\
\text { tion (selection bias) }\end{array}$ & Low risk & Computer-generated randomisation list; blocks of 3 \\
\hline $\begin{array}{l}\text { Allocation concealment } \\
\text { (selection bias) }\end{array}$ & Unclear risk & NR \\
\hline $\begin{array}{l}\text { Blinding of participants } \\
\text { and personnel (perfor- } \\
\text { mance bias) } \\
\text { All outcomes }\end{array}$ & Low risk & $\begin{array}{l}\text { All study personnel and participants were blinded to treatment assignment for } \\
\text { the duration of the study. }\end{array}$ \\
\hline
\end{tabular}

Blinding of outcome as- Low risk Data were analysed with SPSS by a blinded statistician (KP).

sessment (detection bias)

All outcomes

Incomplete outcome data Low risk $\quad$ Attrition reported for both arms, with reasons provided.
(attrition bias)

All outcomes

\begin{tabular}{|c|c|c|}
\hline $\begin{array}{l}\text { Selective reporting (re- } \\
\text { porting bias) }\end{array}$ & Low risk & All outcomes reported. \\
\hline \multirow[t]{2}{*}{ Other bias } & Unclear risk & $\begin{array}{l}\text { Authors' COIs: TJT was supported by a personal grant from Finnish Dental So- } \\
\text { ciety Apollonia. Disclosures: the authors declare that there are no conflicts of } \\
\text { interest. }\end{array}$ \\
\hline & & $\begin{array}{l}\text { Funding: Chr. Hansen A/S (Hoersholm, Denmark) donated the BB-12 and car- } \\
\text { ried out the faecal analyses of BB-12. Oy Karl Fazer Ab (Vantaa, Finland) man- } \\
\text { ufactured the tablets and Mekalasi Oy (Konnevesi, Finland) manufactured the } \\
\text { pacifiers. Neither Hansen, Fazer, or Mekalasi provided financial support for this } \\
\text { study. The role of the funder (if any) in the conception, design, or conduct of } \\
\text { the study or in the analysis or interpretation of the data was not reported. }\end{array}$ \\
\hline
\end{tabular}

Tano 2002

Methods Study design: 2-arm, placebo-controlled, randomised clinical study


Tano 2002 (Continued)

Method of randomisation: randomisation performed by a technician with no access to information about the included participants or the doctor involved; further details not reported

Blinding: double-blinded

Duration: 4 months

Exclusions postrandomisation: none

Losses to follow-up: probiotic: 3 did not complete the scheduled 4-month treatment; placebo: 1 did not complete the scheduled 4-month treatment

Non-adherence to protocol: probiotic: 2 excluded due to freezer with alpha-haemolytic streptococci (AHS) suspension inadvertently being thawed; control: 1 excluded due to freezer with AHS suspension inadvertently being thawed

Country: Sweden
Setting: children referred to ENT department due to recurrent AOM
Number of participants: 43 "included" (not clear if this is the number randomised); probiotic 21, place-
bo 22
Age (mean, range): probiotic: 21.5 months (range 9 to 42), placebo: 20.7 months (range 4 to 46 )
Inclusion criteria: children referred to the ENT department in Boden and Umea because of recur-
rent AOM; aged 3 years and younger, and with a history of at least 3 episodes of AOM during the last 6
months or 6 episodes of AOM; aerated middle ears
Exclusion criteria: patients with secretory otitis media in 1 or both ears; severe underlying diseases
such as immunological deficiencies, valvular heart diseases, or wounds in the nose or mouth

Interventions

Treatment group: a suspension of $10 \%$ skim milk and $0.9 \% \mathrm{CFU} / \mathrm{mL}$ was used; strains included: 2 strains of Streptococcus sanguis, 2 strains of $S$ mitis, 1 strain of $S$ oralis in equal proportions. Spray once daily (1 puff $50 \mu \mathrm{L}$ in each nostril) for 4 months.

Comparator group: skim milk with $0.9 \%$ sodium chloride was used as a placebo control and was kept frozen until thawed and used. Spray once daily (1 puff $50 \mu \mathrm{L}$ in each nostril) for 4 months.

\begin{tabular}{ll}
\hline Outcomes & Primary outcome(s): a reduction in AOM episodes (NB: this is not made explicit) \\
& Secondary outcome(s): not clear. Other outcomes reported in the article: URI episodes, AOM episodes, \\
otalgia, serous otitis media (SOM), adverse events. & Authors' COIs: NR \\
Notes & Funding: the present study was supported by the County Council of Norrbotten, the Joint Com- \\
mittee North Medical Care Region ('Visare Norr'), and the Swedish Medical Research Council (No. \\
K2001-73x-06578-19A). Essum AB prepared the bottles with nasal spray. The role of the funder (if any) in \\
the conception, design, or conduct of the study or in the analysis or interpretation of the data was not \\
reported.
\end{tabular}

\section{Risk of bias}

\begin{tabular}{lll}
\hline Bias & Authors' judgement & Support for judgement \\
\hline $\begin{array}{l}\text { Random sequence genera- } \\
\text { tion (selection bias) }\end{array}$ & Low risk & $\begin{array}{l}\text { Randomised by a technician with no access to information about included par- } \\
\text { ticipants or doctor involved; baseline characteristics appear similar for both } \\
\text { groups }\end{array}$ \\
\hline $\begin{array}{l}\text { Allocation concealment } \\
\text { (selection bias) }\end{array}$ & Unclear risk & $\mathrm{NR}$ \\
\hline \hline
\end{tabular}


Tano 2002 (Continued)

Blinding of participants Low risk Both the investigator (KT) and the parents were blinded to the drug. and personnel (performance bias)

All outcomes

\begin{tabular}{|c|c|c|}
\hline $\begin{array}{l}\text { Blinding of outcome as- } \\
\text { sessment (detection bias) } \\
\text { All outcomes }\end{array}$ & Unclear risk & NR \\
\hline $\begin{array}{l}\text { Incomplete outcome data } \\
\text { (attrition bias) } \\
\text { All outcomes }\end{array}$ & Low risk & Attrition reported for both arms, with reasons provided. \\
\hline $\begin{array}{l}\text { Selective reporting (re- } \\
\text { porting bias) }\end{array}$ & Unclear risk & Outcomes not clearly identified. \\
\hline Other bias & High risk & $\begin{array}{l}\text { Authors' COIs: NR } \\
\text { Funding: the present study was supported by the County Council of Norrbot- } \\
\text { ten, the Joint Committee North Medical Care Region ('Visare Norr'), and the } \\
\text { Swedish Medical Research Council (No. K2001-73x-06578-19A). Essum AB pre- } \\
\text { pared of the bottles with nasal spray. The role of the funder (if any) in the con- } \\
\text { ception, design, or conduct of the study or in the analysis or interpretation of } \\
\text { the data was not reported. }\end{array}$ \\
\hline
\end{tabular}

AOM: acute otitis media

ARI: acute respiratory infection

CFU: colony-forming units

COI: conflict of interest

ENT: ear, nose, and throat

FEV1: forced expiratory volume in one second

GI: gastrointestinal

IL-8: interleukin-8

LRTI: lower respiratory tract infection

NR: not reported

SD: standard deviation

SOM: serous otitis media

TNF: tumour necrosis factor

URI: upper respiratory infection

URTI: upper respiratory tract infection

Characteristics of excluded studies [ordered by study ID]

\begin{tabular}{ll}
\hline Study & Reason for exclusion \\
\hline Agustina 2012 & Wrong outcomes \\
\hline Ahanchian 2016 & Wrong outcomes \\
\hline Arvola 1999 & Wrong outcomes \\
\hline Aryayev 2012 & Wrong outcomes \\
\hline Auinger 2013 & Wrong population \\
\hline Bellomo 1980 & Wrong outcomes \\
\hline
\end{tabular}




\begin{tabular}{|c|c|}
\hline Study & Reason for exclusion \\
\hline Canani 2016 & Wrong outcomes \\
\hline Cazzola 2010 & Wrong outcomes \\
\hline Cobo 2006 & Wrong outcomes \\
\hline Collet 1993 & Wrong intervention \\
\hline Corsello 2016 & Wrong outcomes \\
\hline Coulthard 2004 & Wrong study type \\
\hline Cáceres 2010 & Wrong outcomes \\
\hline Dekker 2017 & Wrong outcomes \\
\hline Di Pierro 2012 & Wrong study type \\
\hline Garaiova 2015 & Wrong outcomes \\
\hline Gerasimov 2012 & Wrong outcomes \\
\hline Gerasimov 2016 & Wrong outcomes \\
\hline Guillemard 2010 & Wrong population \\
\hline Gutierrez-Castrellon 2014 & Wrong outcomes \\
\hline Hatakka 2001b & Wrong study type \\
\hline He 2005 & Wrong outcomes \\
\hline Hojsak 2009a & Wrong outcomes \\
\hline Hojsak 2009b & Wrong outcomes \\
\hline Hojsak 2010b & Wrong outcomes \\
\hline Hojsak 2015 & Wrong outcomes \\
\hline ISCTRN 2004 & $\begin{array}{l}\text { Clinical trial record only, picked up in literature searches; no publications } \\
\text { resulting from this trial }\end{array}$ \\
\hline Ito 2017 & Wrong intervention \\
\hline Jespersen 2015 & Wrong population \\
\hline Kaplan 1968 & Wrong study type \\
\hline Kloster 2008 & Wrong outcomes \\
\hline
\end{tabular}




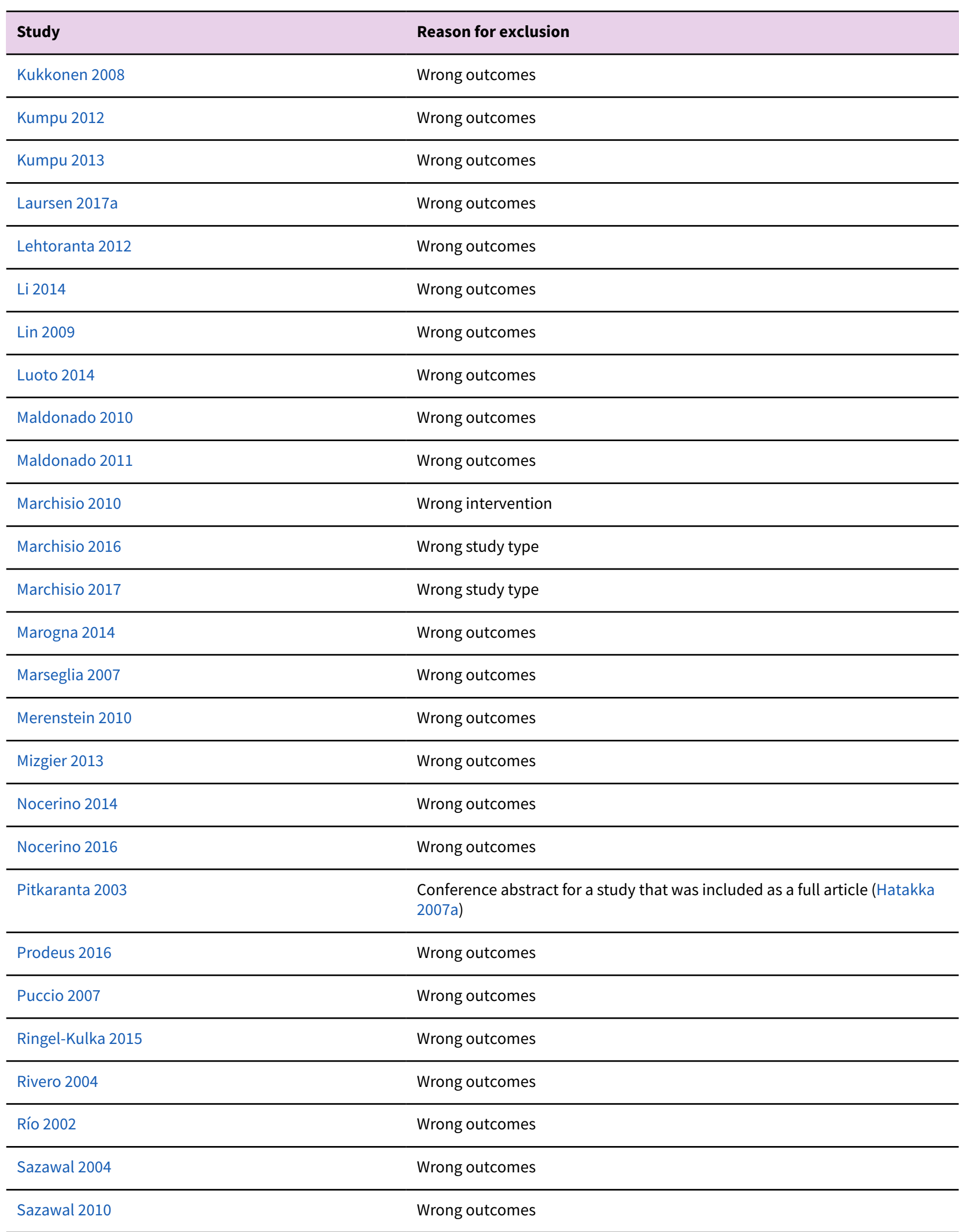




\begin{tabular}{|c|c|}
\hline Study & Reason for exclusion \\
\hline Schrezenmeir 2004 & Wrong outcomes \\
\hline Skovbjerg 2009 & Wrong outcomes \\
\hline Smith 2016 & Wrong outcomes \\
\hline Stojkovic 2016 & Wrong study type \\
\hline Timby 2015 & Wrong intervention \\
\hline Vlieger 2009 & Wrong outcomes \\
\hline Weizman 2006 & Wrong outcomes \\
\hline West 2008 & Wrong outcomes \\
\hline Wright 2009 & Wrong population \\
\hline
\end{tabular}

Characteristics of ongoing studies [ordered by study ID]

\section{ACTRN12618000130268}

Trial name or title

Trial name or title

\section{Methods}

Participants
A randomised placebo controlled trial of the effect of BLIS probiotic, S. salivarius (K12) on otitis media (ear infections) and upper respiratory tract infections amongst 6-24 month old children, as measured by medical record events

Quadruple-blind (participant, individuals administering treatment, outcome assessors, outcome analysts), placebo-controlled, randomised clinical trial with 2 arms
Interventions

Outcomes

Starting date

Infants 6 months old; both genders

Probiotic (Streptococcus salivarius K12), isomalt, maltodextrin, and natural flavour; placebo

The primary outcome will be rate of doctor-recorded AOM in the 18 months the child takes part in the trial.

Not yet started; recruitment anticipated to start February 2018, actual start date not listed

Contact information

Prof Julian Crane, julian.crane@otago.ac.nz

\section{Trial ID}

ACTRN12618000130268

Trial name or title

\section{BLIS-OM}

\section{Notes}

\section{EUCTR2017-000820-83-FI}

\begin{tabular}{ll}
\hline Trial name or title & Otitis media and nasopharyngeal microbiome in children \\
\hline Methods & Open, randomised clinical trial with 2 arms
\end{tabular}


EUCTR2017-000820-83-FI (Continued)

\begin{tabular}{ll} 
Participants & Age 1 to 6 years, in day-care centre in the city of Oulu, Finland \\
\hline Interventions & Streptococcus salivarius K12 strain (oral powder in sachet); no treatment \\
\hline Outcomes & $\begin{array}{l}\text { Primary endpoint is the positive S salivarius quantitative 16S RNA PCR result in time points } 1 \text { and } \\
2 \text { months, e.g. after the } 1 \text { month use of the product and } 1 \text { month after that. Hence we are mea- } \\
\text { suring the rate of } S \text { salivarius colonisation, or the microbiological efficiency of the different prod- } \\
\text { ucts. Samples are to be taken from controls as well since we do not know if the bacteria are able to } \\
\text { transmit among children, and for how long the desired result lasts. }\end{array}$ \\
\hline Starting date & Unclear. Current status: ongoing \\
\hline Contact information & Oulu University Hospital, phone: +35883152011 \\
\hline Trial ID & EUCTR2017-000820-83-FI \\
\hline Trial name or title & -
\end{tabular}

\section{ISRCTN53286030}

\begin{tabular}{ll}
\hline Trial name or title & A controlled trial of probiotics in the prevention of episodes of otitis media in general practice \\
\hline Methods & Blinding NR, randomised, placebo-controlled trial \\
\hline Participants & Children 6 to 11 months old, both genders \\
\hline Interventions & Probiotics (Lactobacillus and bifidobacteria); placebo \\
\hline Outcomes & $\begin{array}{l}\text { Primary outcome: reported episodes of recurrent significant otalgia difference in proportions over } \\
\text { 3 months }\end{array}$ \\
\hline Starting date & September 2003 \\
\hline Contact information & Dr lan Williamson, University of Southampton; igw@soton.ac.uk \\
\hline Trial ID & ISRCTN53286030 \\
\hline Trial name or title & PIPO \\
\hline Notes & -
\end{tabular}

\begin{tabular}{ll} 
NCT01724203 & $\begin{array}{l}\text { Effect of 12-week probiotic supplementation on bacterial and viral infections in infants aged } 6 \text { to } 12 \\
\text { months }\end{array}$ \\
\hline Methods & Double-blind (participant, investigator), placebo-controlled, randomised clinical trial with 3 arms \\
\hline Participants & Children aged 6 to 12 months, both genders \\
\hline
\end{tabular}


NCT01724203 (Continued)

Interventions

Arm 1: Lactobacillus rhamnosus HN001; arm 2: Bifidobacterium animalis subsp. lactis; arm 3: placebo

\begin{tabular}{ll}
\hline Outcomes & $\begin{array}{l}\text { Primary outcome: proportion of participants with } 1 \text { or more of confirmed bacterial or viral infec- } \\
\text { tions at any time during the study }\end{array}$ \\
\hline Starting date & December 2012 \\
\hline Contact information & $\begin{array}{l}\text { Dr Xiaoyang Sheng, Xinhua Hospital, Shanghai Jiao Tong University School of Medicine (email/ } \\
\text { phone not provided) }\end{array}$
\end{tabular}

Trial ID NCT01724203

Trial name or title

Notes

NCT01909128

Trial name or title $\quad$ Fermented milk and fermented rice on the appearance of respiratory and gastrointestinal symptoms

\begin{tabular}{ll}
\hline Methods & $\begin{array}{l}\text { Quadruple-blind (participant, care provider, investigator, outcomes assessor), placebo-controlled, } \\
\text { randomised clinical trial with } 3 \text { arms }\end{array}$ \\
\hline Participants & Children aged 12 to 48 months, both genders \\
\hline Interventions & Arm 1: fermented milk with probiotic; arm 2: fermented rice with probiotic; arm 3: placebo \\
\hline Outcomes & Primary outcome: common respiratory and gastrointestinal infections \\
\hline Starting date & February 2013 \\
\hline Contact information & Roberto Berni Canani, MD, PhD, Federico II University (email/phone not provided) \\
\hline Trial ID & NCT01909128 \\
\hline Trial name or title & - \\
\hline Notes & Included as Nocerino 2017 \\
\hline
\end{tabular}

\section{NCT02221687}

\begin{tabular}{ll}
\hline Trial name or title & $\begin{array}{l}\text { Evaluation of the efficacy and safety of an infant formula containing synbiotics and its effects on } \\
\text { the incidence of infectious diseases in the infant gut: a double-blind, randomised, controlled inter- } \\
\text { ventional study }\end{array}$ \\
\hline Methods & $\begin{array}{l}\text { Triple-blind (participant, care provider, investigator), placebo-controlled, randomised clinical trial } \\
\text { with } 3 \text { arms }\end{array}$ \\
\hline Participants & Children up to 5 weeks old, both genders \\
\hline
\end{tabular}


NCT02221687 (Continued)

Interventions

Synbiotic formula (standard formula enriched with prebiotic + probiotic); control formula (standard formula); no intervention (breast fed group)

\begin{tabular}{ll}
\hline Outcomes & $\begin{array}{l}\text { Primary outcome: cumulative number of infectious diarrhoea episodes per child during the first } \\
\text { year of life }\end{array}$ \\
\hline Starting date & August 2014 \\
\hline Contact information & Hugues Piloquet, Paediatrician (email/phone not provided) \\
\hline Trial ID & NCT02221687 \\
\hline Trial name or title & GOLFIII \\
\hline Notes & - \\
\hline
\end{tabular}

\section{NCT02802059}

\begin{tabular}{ll}
\hline Trial name or title & E. coli Nissle 1917 - suspension for infection prophylaxis \\
\hline Methods & Double-blind (participant, investigator), placebo-controlled, randomised clinical trial with 2 arms \\
\hline Participants & Age at inclusion: maximum 120 hours after birth, both genders \\
\hline Interventions & Escherichia coli strain Nissle 1917 (EcN-Suspension) probiotic bacteria; placebo \\
\hline Outcomes & Primary outcome: number of infections confirmed by a medical doctor \\
\hline Starting date & October 2015 \\
\hline Contact information & Corinna Wolff, Dipl-Biophys; corinna.wolff@ardeypharm.de \\
\hline Trial ID & NCT02802059 \\
\hline Trial name or title & RONi \\
\hline Notes & - \\
\hline
\end{tabular}

\section{NCT03516409}

\begin{tabular}{ll}
\hline Trial name or title & Bio-Kult Infantis in AAD prevention in infants \\
\hline Methods & Open, placebo-controlled, randomised clinical trial with 2 arms \\
\hline Participants & Children 6 months to 35 months old, both genders \\
\hline Interventions & Bio-Kult Infantis (a multistrain probiotic formula); placebo (maltodextrin DE19) \\
\hline Outcomes & Primary outcome: incidence of antibiotic-associated diarrhoea \\
\hline Starting date & April 2018 \\
\hline
\end{tabular}


NCT03516409 (Continued)

Contact information Dr Salvatore Tripodi, UOC Paediatric Hospital "Sandro Pertini" (email/phone not provided)

\begin{tabular}{ll}
\hline Trial ID & NCT03516409 \\
\hline Trial name or title & - \\
\hline Notes & - \\
\hline
\end{tabular}

\section{NCT03614117}

\begin{tabular}{ll}
\hline Trial name or title & Effect of a new probiotic strain on recurrent acute otitis media in children \\
\hline Methods & $\begin{array}{l}\text { Quadruple-blind (participant, care provider, investigator, outcomes assessor), placebo-controlled, } \\
\text { randomised clinical trial with } 3 \text { arms }\end{array}$ \\
\hline Participants & $\begin{array}{l}\text { Children } 1 \text { to } 4 \text { years old with recurrent AOM, and presence of AOM at the time of inclusion in the } \\
\text { study }\end{array}$ \\
\hline Interventions & $\begin{array}{l}\text { Arm 1: Lactobacillus salivarius PS7 for } 6 \text { months; arm 2: } L \text { salivarius PS 7 + placebo for 3 months } \\
\text { each; arm 3: placebo supplement }\end{array}$ \\
\hline Outcomes & Primary outcome: number of AOM episodes \\
\hline Starting date & October 2018 \\
\hline Contact information & Susana Manzano; susana.manzano@probisearch.com \\
\hline Trial ID & NCT03614117 \\
\hline Trial name or title & PROMAR \\
\hline Notes & -
\end{tabular}

AAD: antibiotic-associated diarrhoea

AOM: acute otitis media

NR: not reported

PCR: polymerase chain reaction

RNA: ribonucleic acid

\section{DATA AND ANALYSES}

\section{Comparison 1. Probiotics versus placebo or usual care}

\begin{tabular}{lllll}
\hline Outcome or subgroup title & No. of studies & $\begin{array}{l}\text { No. of partici- } \\
\text { pants }\end{array}$ & Statistical method & Effect size \\
\hline $\begin{array}{l}\text { 1 Proportion of children with AOM } \\
\text { (overall) }\end{array}$ & 16 & 2961 & $\begin{array}{l}\text { Risk Ratio (M-H, Random, } \\
95 \% \mathrm{Cl})\end{array}$ & $0.77[0.63,0.93]$ \\
\hline
\end{tabular}




\begin{tabular}{|c|c|c|c|c|}
\hline Outcome or subgroup title & No. of studies & $\begin{array}{l}\text { No. of partici- } \\
\text { pants }\end{array}$ & Statistical method & Effect size \\
\hline $\begin{array}{l}2 \text { Proportion of children with AOM (by } \\
\text { health status) }\end{array}$ & 16 & 2961 & $\begin{array}{l}\text { Risk Ratio (M-H, Random, } \\
95 \% \mathrm{Cl} \text { ) }\end{array}$ & $0.77[0.63,0.93]$ \\
\hline 2.1 Children prone to otitis media & 5 & 734 & $\begin{array}{l}\text { Risk Ratio (M-H, Random, } \\
95 \% \mathrm{Cl} \text { ) }\end{array}$ & $0.97[0.85,1.11]$ \\
\hline 2.2 Children not prone to otitis media & 11 & 2227 & $\begin{array}{l}\text { Risk Ratio (M-H, Random, } \\
95 \% \mathrm{Cl} \text { ) }\end{array}$ & $0.64[0.49,0.84]$ \\
\hline $\begin{array}{l}3 \text { Proportion of children with AOM (by } \\
\text { probiotic strain) }\end{array}$ & 16 & 2961 & $\begin{array}{l}\text { Risk Ratio (M-H, Random, } \\
95 \% \mathrm{Cl})\end{array}$ & $0.77[0.63,0.93]$ \\
\hline 3.1 Lactobacillus-containing & 10 & 2055 & $\begin{array}{l}\text { Risk Ratio (M-H, Random, } \\
95 \% \mathrm{Cl} \text { ) }\end{array}$ & $0.72[0.54,0.98]$ \\
\hline 3.2 Streptococcus-containing & 6 & 906 & $\begin{array}{l}\text { Risk Ratio (M-H, Random, } \\
95 \% \mathrm{Cl} \text { ) }\end{array}$ & $0.78[0.60,1.02]$ \\
\hline 4 Adverse events & 4 & 395 & $\begin{array}{l}\text { Odds Ratio (M-H, Random, } \\
95 \% \mathrm{Cl})\end{array}$ & $1.54[0.60,3.94]$ \\
\hline 5 Difference in the use of antibiotics & 8 & 1768 & $\begin{array}{l}\text { Risk Ratio (M-H, Random, } \\
95 \% \mathrm{Cl} \text { ) }\end{array}$ & $0.66[0.51,0.86]$ \\
\hline 5.1 Use of antibiotic for AOM & 3 & 597 & $\begin{array}{l}\text { Risk Ratio (M-H, Random, } \\
95 \% \mathrm{Cl} \text { ) }\end{array}$ & $0.63[0.30,1.32]$ \\
\hline $\begin{array}{l}5.2 \text { Use of antibiotic for other infec- } \\
\text { tions }\end{array}$ & 5 & 1171 & $\begin{array}{l}\text { Risk Ratio (M-H, Random, } \\
95 \% \mathrm{Cl} \text { ) }\end{array}$ & $0.65[0.45,0.92]$ \\
\hline 6 Time off school for the child (days) & 5 & 1280 & $\begin{array}{l}\text { Mean Difference (IV, Random, } \\
95 \% \mathrm{CI} \text { ) }\end{array}$ & $-0.95[-2.47,0.57]$ \\
\hline $\begin{array}{l}7 \text { Difference in proportion of children } \\
\text { with other infections }\end{array}$ & 11 & 3610 & $\begin{array}{l}\text { Risk Ratio (M-H, Random, } \\
95 \% \mathrm{Cl} \text { ) }\end{array}$ & $0.75[0.65,0.87]$ \\
\hline 7.1 Acute respiratory infections & 10 & 2167 & $\begin{array}{l}\text { Risk Ratio (M-H, Random, } \\
95 \% \mathrm{Cl} \text { ) }\end{array}$ & $0.74[0.62,0.88]$ \\
\hline 7.2 Gastrointestinal infections & 8 & 1443 & $\begin{array}{l}\text { Risk Ratio (M-H, Random, } \\
95 \% \mathrm{Cl} \text { ) }\end{array}$ & $0.78[0.57,1.06]$ \\
\hline 8 Compliance with taking probiotics & 6 & 990 & $\begin{array}{l}\text { Risk Ratio (M-H, Random, } \\
95 \% \mathrm{Cl} \text { ) }\end{array}$ & $1.02[0.99,1.05]$ \\
\hline
\end{tabular}

\section{Analysis 1.1. Comparison 1 Probiotics versus placebo or usual care, Outcome 1 Proportion of children with AOM (overall).}

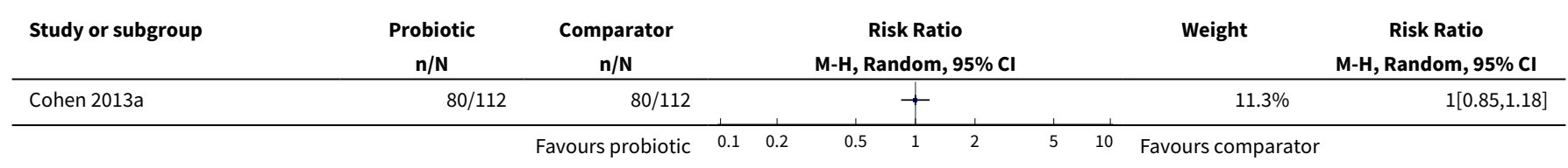




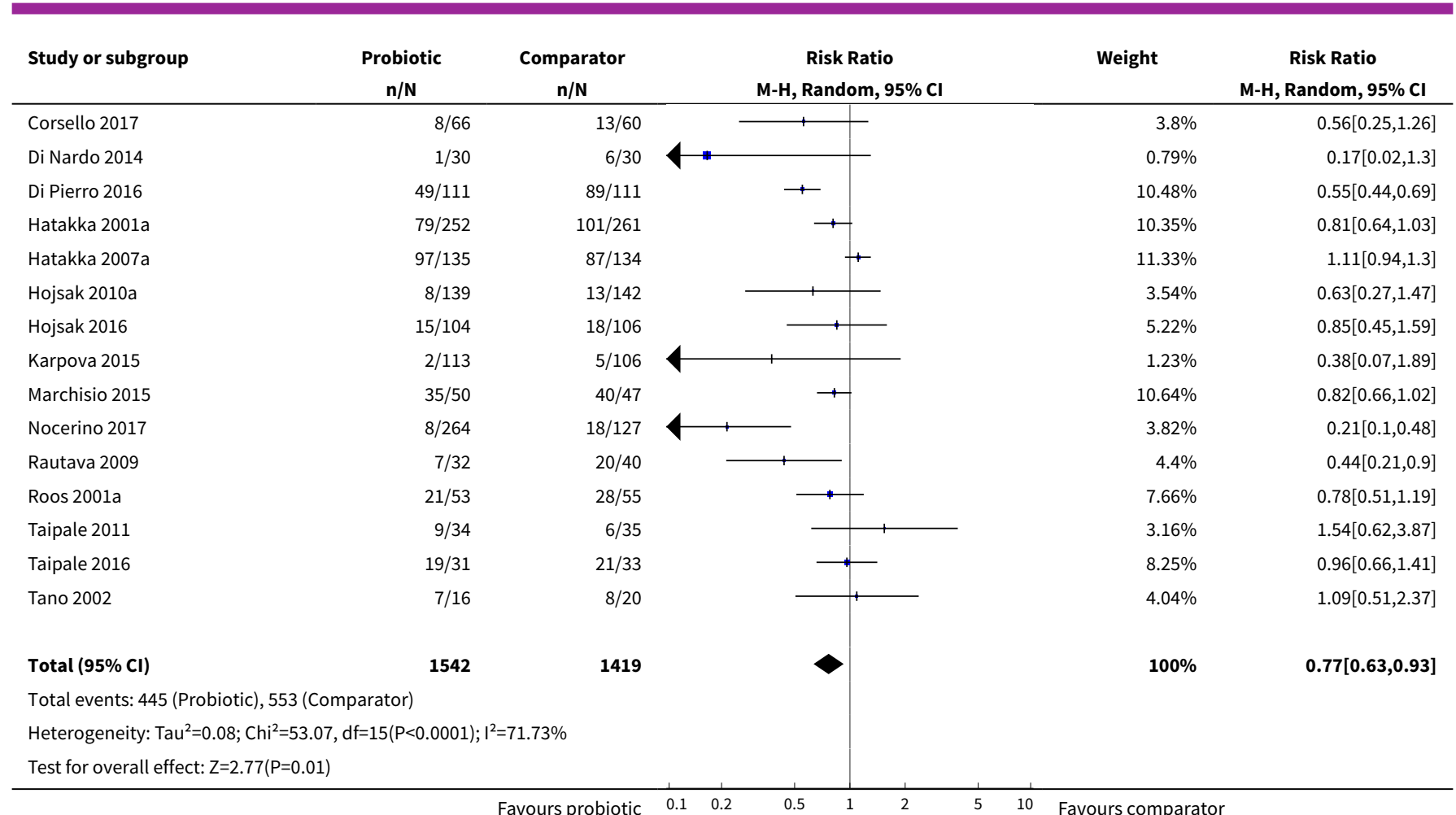

Analysis 1.2. Comparison 1 Probiotics versus placebo or usual care, Outcome 2 Proportion of children with AOM (by health status).

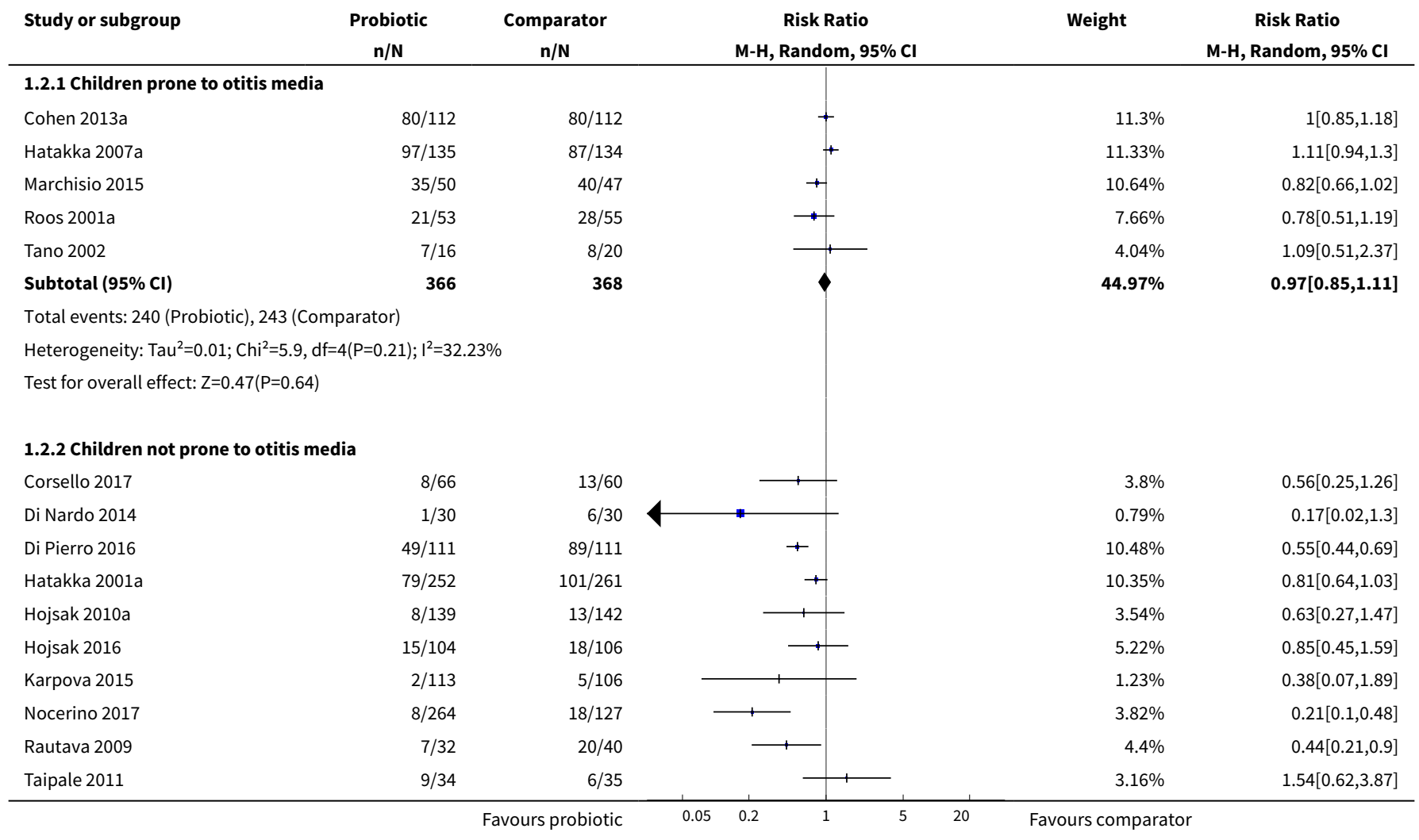




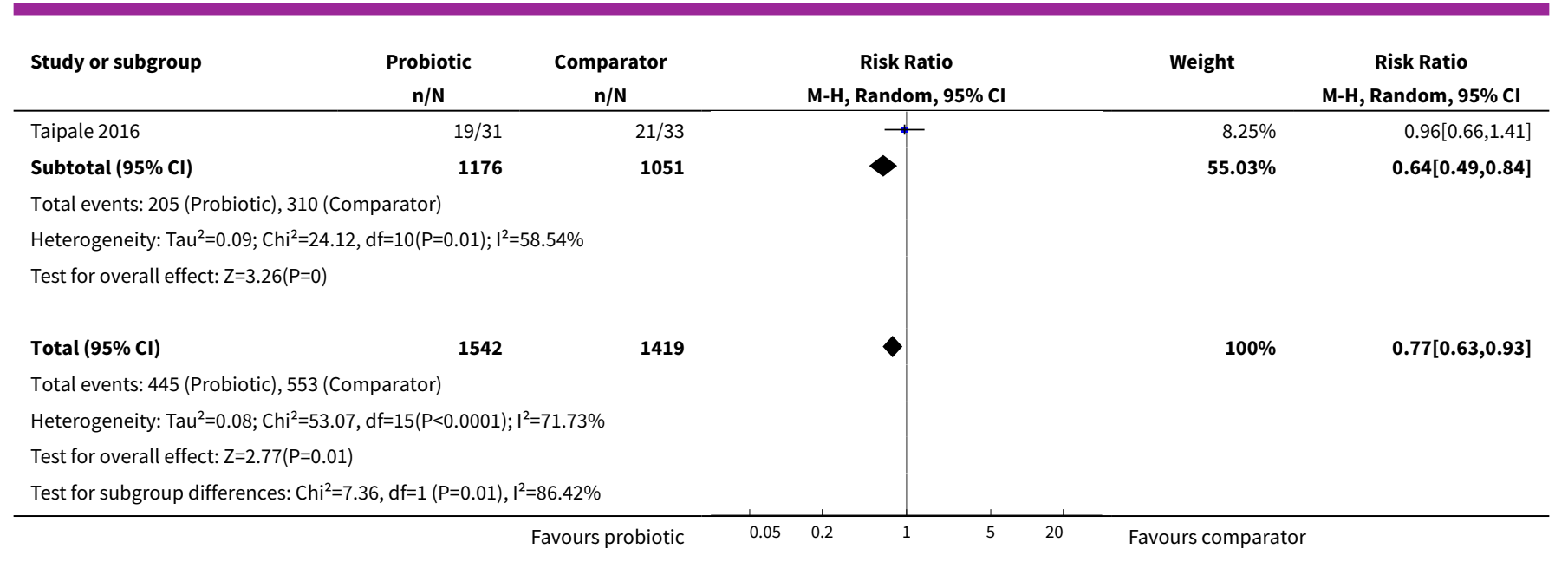

Analysis 1.3. Comparison 1 Probiotics versus placebo or usual care, Outcome 3 Proportion of children with AOM (by probiotic strain).

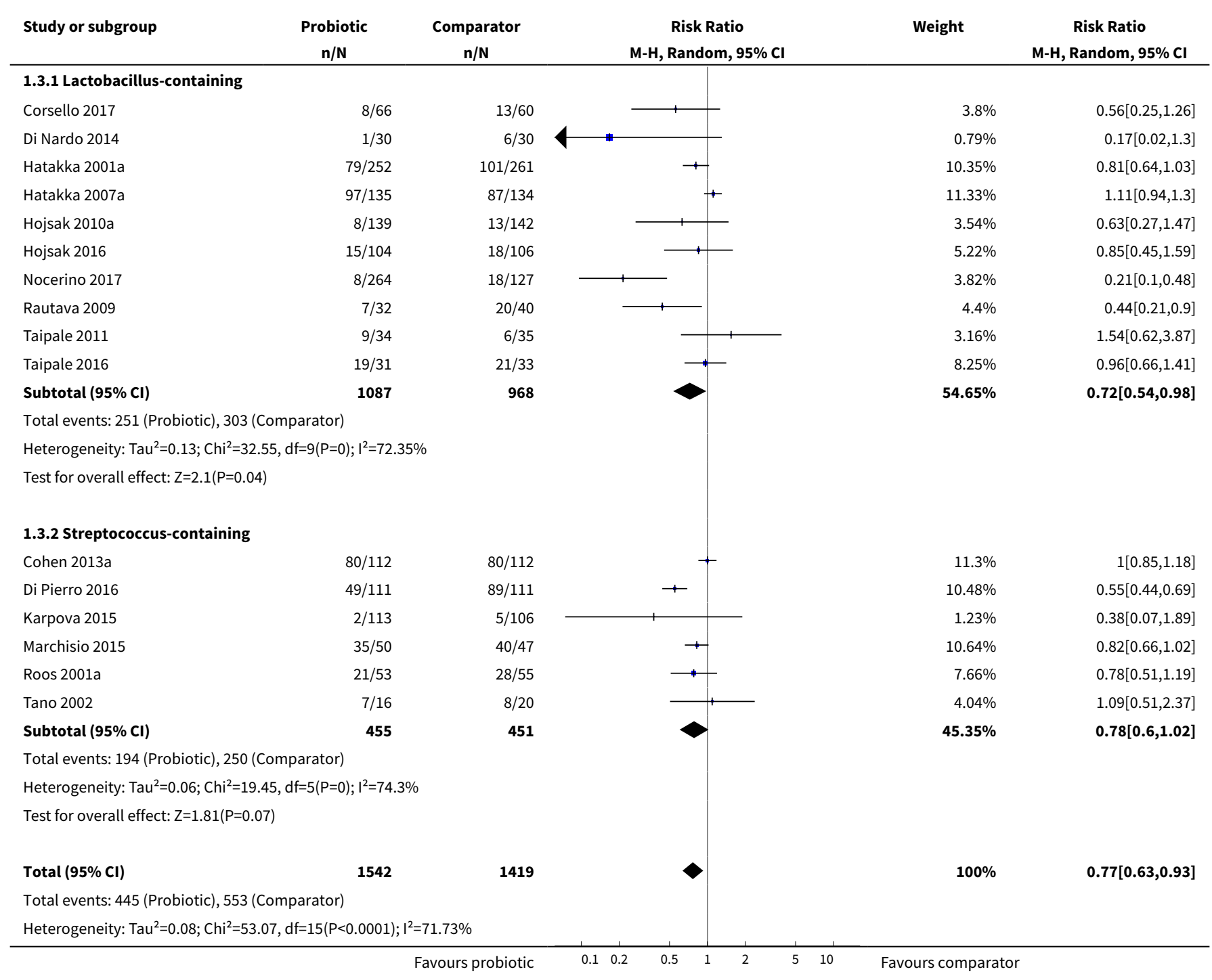




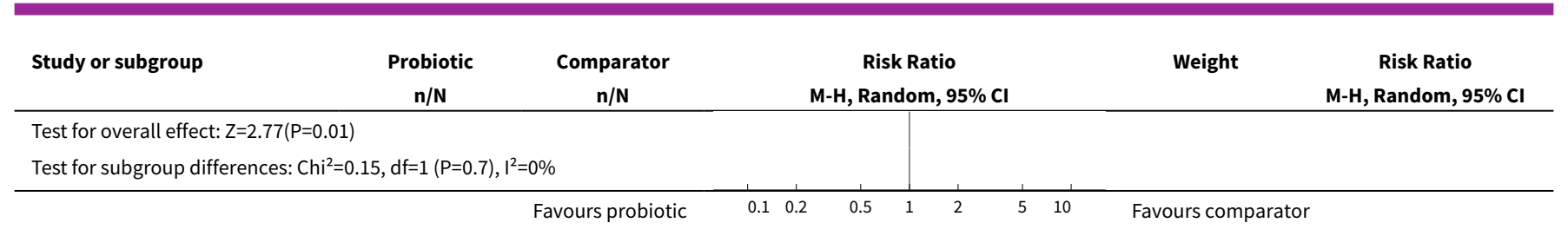

Analysis 1.4. Comparison 1 Probiotics versus placebo or usual care, Outcome 4 Adverse events.

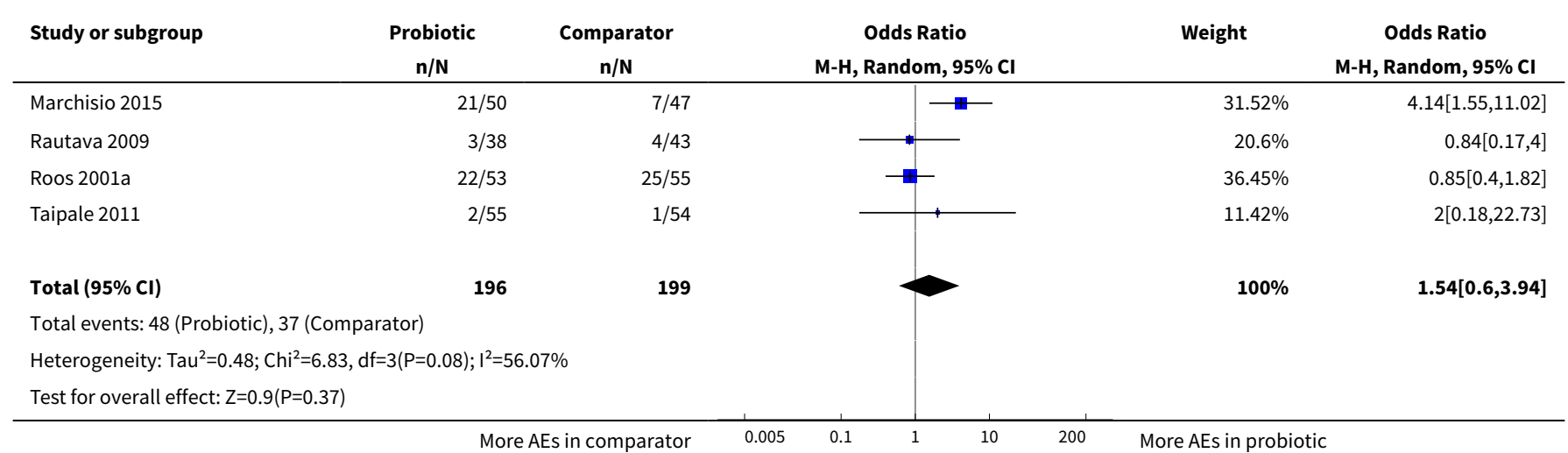

Analysis 1.5. Comparison 1 Probiotics versus placebo or usual care, Outcome 5 Difference in the use of antibiotics.

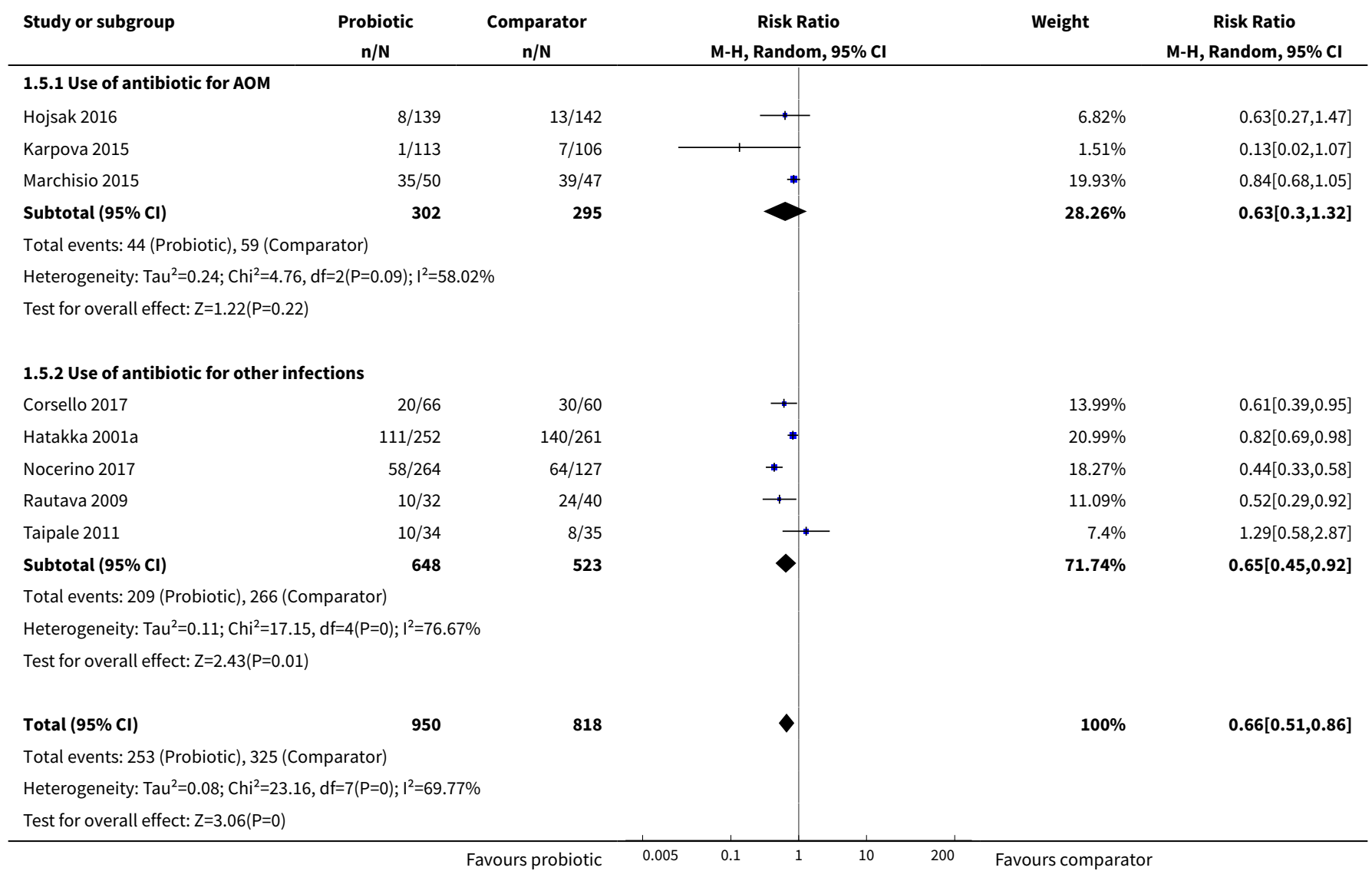




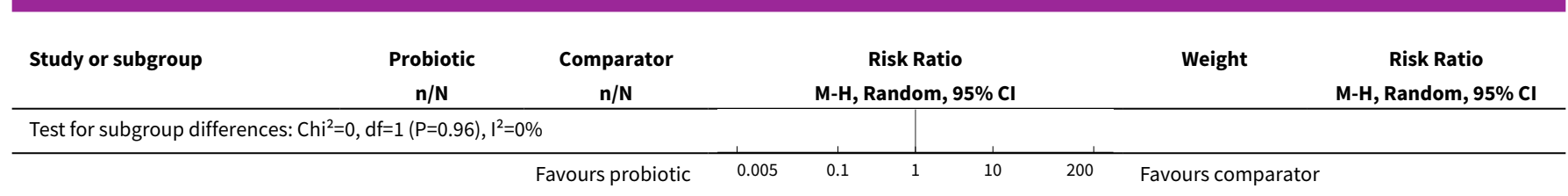

Analysis 1.6. Comparison 1 Probiotics versus placebo or usual care, Outcome 6 Time off school for the child (days).

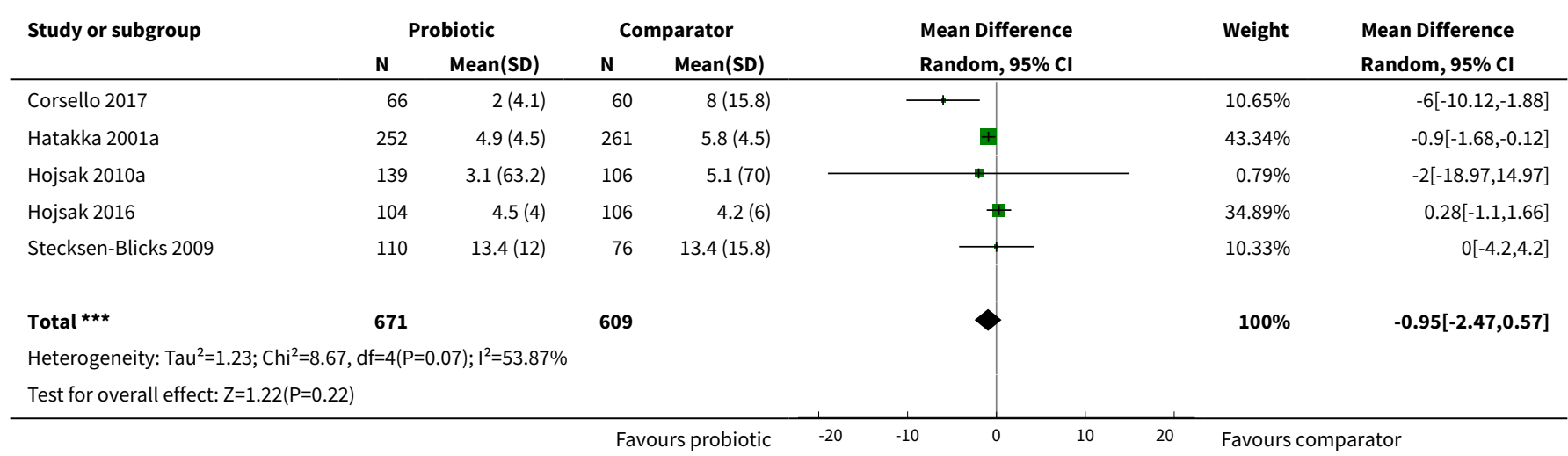

Analysis 1.7. Comparison 1 Probiotics versus placebo or usual care, Outcome 7 Difference in proportion of children with other infections.

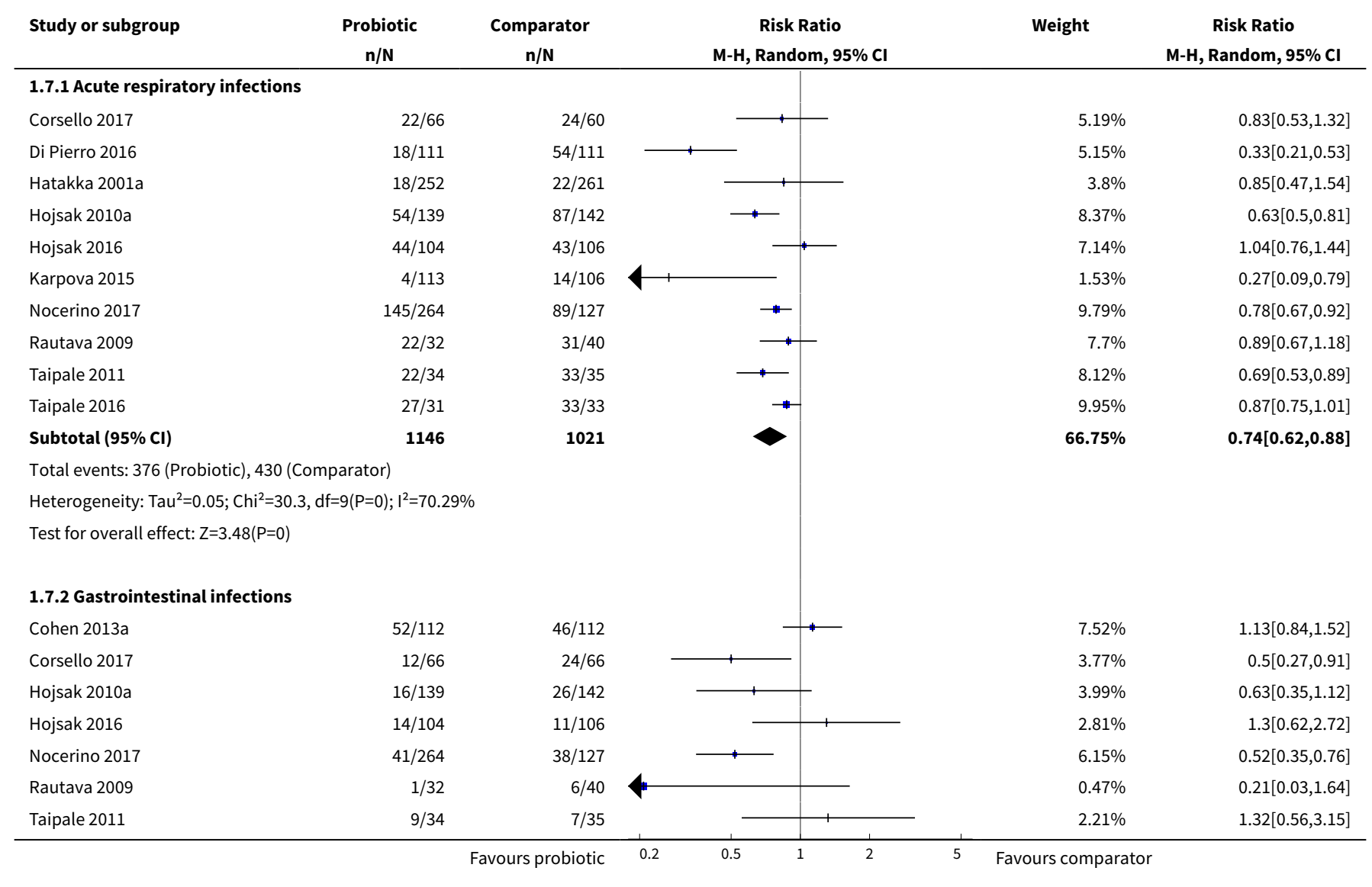




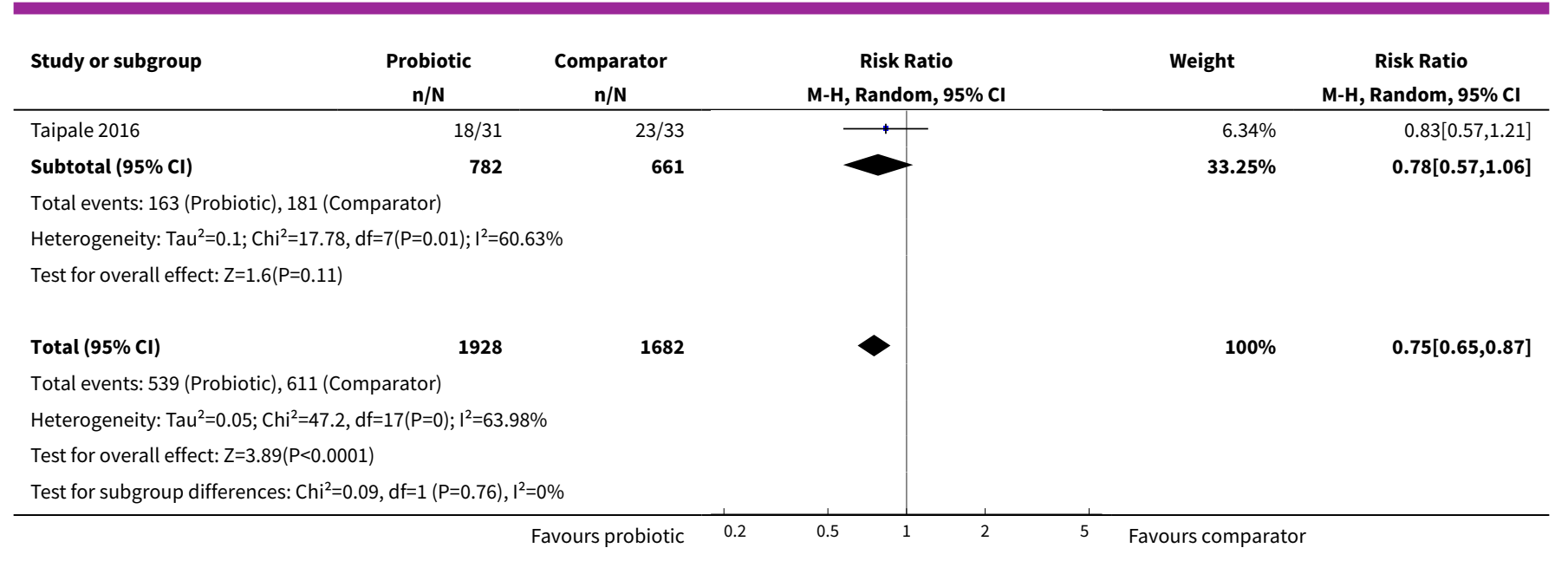

Analysis 1.8. Comparison 1 Probiotics versus placebo or usual care, Outcome 8 Compliance with taking probiotics.

\begin{tabular}{|c|c|c|c|c|c|}
\hline Study or subgroup & $\begin{array}{l}\text { Probiotics } \\
n / N\end{array}$ & $\begin{array}{c}\text { Comparator } \\
n / N\end{array}$ & $\begin{array}{c}\text { Risk Ratio } \\
\text { M-H, Random, 95\% Cl }\end{array}$ & Weight & $\begin{array}{c}\text { Risk Ratio } \\
\text { M-H, Random, } 95 \% \mathrm{Cl}\end{array}$ \\
\hline Cohen 2013a & $104 / 112$ & $103 / 112$ & 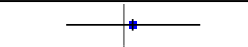 & $18.98 \%$ & $1.01[0.94,1.09]$ \\
\hline Hatakka 2007a & $51 / 53$ & $53 / 55$ & & $19.52 \%$ & $1[0.93,1.08]$ \\
\hline Hojsak 2010a & $127 / 139$ & $127 / 142$ & - & $18.42 \%$ & $1.02[0.95,1.1]$ \\
\hline Hojsak 2016 & $99 / 104$ & $99 / 106$ & 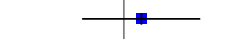 & $24.15 \%$ & $1.02[0.95,1.09]$ \\
\hline Marchisio 2015 & $50 / 50$ & $47 / 50$ & & $16.99 \%$ & $1.06[0.98,1.15]$ \\
\hline Taipale 2016 & $26 / 32$ & $28 / 35$ & & $1.94 \%$ & $1.02[0.8,1.28]$ \\
\hline Total $(95 \% \mathrm{Cl})$ & 490 & 500 & & $100 \%$ & $1.02[0.99,1.05]$ \\
\hline \multicolumn{6}{|c|}{ Total events: 457 (Probiotics), 457 (Comparator) } \\
\hline \multicolumn{6}{|c|}{ Heterogeneity: $\operatorname{Tau}^{2}=0 ; \mathrm{Chi}^{2}=1.44, \mathrm{df}=5(\mathrm{P}=0.92) ; \mathrm{I}^{2}=0 \%$} \\
\hline Test for overall effect & & & & & \\
\hline
\end{tabular}

\section{APPENDICES}

\section{Appendix 1. Bibliographic database search strategies}

\section{PubMed (National Library of Medicine)}

(Probiotics[Mesh] OR "Synbiotics"[Mesh] OR Lactobacillus[Mesh] OR Bifidobacterium[Mesh] OR Saccharomyces[Mesh] OR "Streptococcus thermophilus"[Mesh] OR "Cultured Milk Products"[Mesh] OR Antibiosis[Mesh] OR "Lactococcus"[Mesh] OR Probiotics[tiab] OR Probiotic[tiab] OR Synbiotics[tiab] OR Synbiotic[tiab] OR Lactobacillus[tiab] OR Lactobacilli[tiab] OR Bifidobacteria[tiab] OR Bifidobacterium[tiab] OR Saccharomyces[tiab] OR Saccharomyce[tiab] OR “Microbial dietary supplements"[tiab] OR Yoghurt[tiab] OR "Fermented milk"[tiab] OR "Cultured Milk"[tiab] OR "Fermented Dairy"[tiab] OR Acidophilus[tiab] OR Antibiosis[tiab] OR "Microbial Antagonism”[tiab] OR “Microbial Antagonisms"[tiab] OR "Bacterial Interferences”[tiab] OR "Bacterial Interference”[tiab] OR "Streptococcus thermophilus"[tiab] OR "Bacillus laterosporus"[tiab] OR "Pediococcus acidilactici”[tiab] OR Lactococcus[tiab] OR Lactis[tiab])

AND

("Respiratory Tract Infections"[Mesh] OR "Respiratory tract infection"[tiab] OR "Respiratory tract infections"[tiab] OR "Respiratory infection"[tiab] OR "Respiratory infections"[tiab] OR urti[tiab] OR uri[tiab] OR ari[tiab] OR "Otitis Media"[Mesh] OR "Otitis Media"[tiab] 
OR “Glue ear”[tiab] OR AOM[tiab] OR OME[tiab] OR (“Middle Ear”[tiab] AND (Infection[tiab] OR Infections[tiab] OR Inflammation[tiab] OR Inflammations[tiab])))

AND

((Randomized controlled trial[pt] OR controlled clinical trial[pt] OR randomized[tiab] OR randomised[tiab] OR placebo[tiab] OR "drug therapy"[sh] OR randomly[tiab] OR trial[tiab] OR groups[tiab])

NOT

(Animals[Mesh] not (Animals[Mesh] and Humans[Mesh])))

\section{CENTRAL (Cochrane Central Register of Controlled Trials)}

([mh Probiotics] OR [mh Synbiotics] OR [mh Lactobacillus] OR [mh Bifidobacterium] OR [mh Saccharomyces] OR [mh "Streptococcus thermophilus"] OR [mh "Cultured Milk Products"] OR [mh Antibiosis] OR [mh Lactococcus] OR Probiotics:ti,ab OR Probiotic:ti,ab OR Synbiotics:ti,ab OR Synbiotic:ti,ab OR Lactobacillus:ti,ab OR Lactobacilli:ti,ab OR Bifidobacteria:ti,ab OR Bifidobacterium:ti,ab OR Saccharomyces:ti,ab OR Saccharomyce:ti,ab OR "Microbial dietary supplements":ti,ab OR Yoghurt:ti,ab OR "Fermented milk":ti,ab OR "Cultured Milk":ti,ab OR "Fermented Dairy":ti,ab OR Acidophilus:ti,ab OR Antibiosis:ti,ab OR "Microbial Antagonism":ti,ab OR "Microbial Antagonisms":ti,ab OR "Bacterial Interferences":ti, ab OR "Bacterial Interference":ti,ab OR "Streptococcus thermophilus":ti,ab OR "Bacillus laterosporus":ti,ab OR "Pediococcus acidilactici":ti,ab OR Lactococcus:ti,ab OR Lactis:ti,ab)

AND

([mh "Respiratory Tract Infections"] OR "Respiratory tract infection":ti,ab OR "Respiratory tract infections":ti,ab OR "Respiratory infection":ti,ab OR "Respiratory infections":ti,ab OR urti:ti,ab OR uri:ti,ab OR ari:ti,ab OR [mh "Otitis Media"] OR "Otitis Media":ti,ab OR "Glue ear":ti,ab OR AOM:ti,ab OR OME:ti,ab OR ("Middle Ear":ti,ab AND (Infection:ti,ab OR Infections:ti,ab OR Inflammation:ti,ab OR Inflammations:ti,ab)))

\section{Embase (via Elsevier)}

('probiotic agent'/exp OR 'synbiotic agent'/exp OR 'Lactobacillus'/exp OR 'Bifidobacterium'/exp OR 'Saccharomyces'/exp OR 'Streptococcus thermophilus'/exp OR 'fermented milk product'/exp OR 'Antibiosis'/exp OR 'Lactococcus'/exp OR Probiotics:ti,ab OR Probiotic:ti,ab OR Synbiotics:ti,ab OR Synbiotic:ti,ab OR Lactobacillus:ti,ab OR Lactobacilli:ti,ab OR Bifidobacteria:ti,ab OR Bifidobacterium:ti,ab OR Saccharomyces:ti,ab OR Saccharomyce:ti,ab OR "Microbial dietary supplements":ti,ab OR Yoghurt:ti,ab OR "Fermented milk":ti,ab OR "Cultured Milk":ti,ab OR "Fermented Dairy":ti,ab OR Acidophilus:ti,ab OR Antibiosis:ti,ab OR "Microbial Antagonism":ti,ab OR "Microbial Antagonisms":ti,ab OR "Bacterial Interferences":ti,ab OR "Bacterial Interference":ti, ab OR "Streptococcus thermophilus":ti,ab OR "Bacillus laterosporus":ti,ab OR "Pediococcus acidilactici":ti,ab OR Lactococcus:ti,ab OR Lactis:ti,ab)

AND

('respiratory tract infection'/exp OR "Respiratory tract infection":ti,ab OR "Respiratory tract infections":ti,ab OR "Respiratory infection":ti,ab OR "Respiratory infections":ti,ab OR urti:ti,ab OR uri:ti,ab OR ari:ti,ab OR 'Otitis Media'/exp OR "Otitis Media":ti,ab OR "Glue ear":ti,ab OR AOM:ti,ab OR OME:ti,ab OR ("Middle Ear":ti,ab AND (Infection:ti,ab OR Infections:ti,ab OR Inflammation:ti,ab OR Inflammations:ti,ab)))

\section{AND}

(random* OR factorial OR crossover OR placebo OR blind OR blinded OR assign OR assigned OR allocate OR allocated OR 'crossover procedure'/exp OR 'double-blind procedure'/exp OR 'randomized controlled trial'/exp OR 'single-blind procedure'/exp NOT ('animal'/exp NOT ('animal'/exp AND 'human'/exp)))

AND

[embase]/lim

\section{CINAHL}

((MH "Probiotics+") OR (MH "Lactobacillus+") OR (MH "Bifidobacterium+") OR (MH "Saccharomyces+") OR (MH "Streptococcus+") OR (MH "Cultured Milk Products+") OR (MH "Antibiosis+") OR TI Probiotics OR AB Probiotics OR TI Probiotic OR AB Probiotic OR TI Synbiotics OR AB Synbiotics OR TI Synbiotic OR AB Synbiotic OR TI Lactobacillus OR AB Lactobacillus OR TI Lactobacilli OR AB Lactobacilli OR TI Bifidobacteria OR AB Bifidobacteria OR TI Bifidobacterium OR AB Bifidobacterium OR TI Saccharomyces OR AB Saccharomyces OR TI Saccharomyce OR AB Saccharomyce OR TI "Microbial dietary supplements" OR AB "Microbial dietary supplements" OR TI Yoghurt OR AB Yoghurt OR TI "Fermented milk" OR AB "Fermented milk" OR TI "Cultured Milk" OR AB "Cultured Milk" OR TI "Fermented Dairy" OR AB "Fermented Dairy" OR TI Acidophilus OR AB Acidophilus OR TI Antibiosis OR AB Antibiosis OR TI "Microbial Antagonism" OR AB "Microbial Antagonism" OR TI "Microbial Antagonisms" OR AB "Microbial Antagonisms" OR TI "Bacterial Interferences" OR AB "Bacterial Interferences" 
OR TI "Bacterial Interference" OR AB "Bacterial Interference" OR TI "Streptococcus thermophilus" OR AB "Streptococcus thermophilus" OR TI "Bacillus laterosporus" OR AB "Bacillus laterosporus" OR TI "Pediococcus acidilactici" OR AB "Pediococcus acidilactici" OR TI Lactococcus OR AB Lactococcus OR TI Lactis OR AB Lactis)

AND

((MH "Respiratory Tract Infections+") OR TI "Respiratory tract infection" OR AB "Respiratory tract infection" OR TI "Respiratory tract infections" OR AB "Respiratory tract infections" OR TI "Respiratory infection" OR AB "Respiratory infection" OR TI "Respiratory infections" OR AB "Respiratory infections" OR TI urti OR AB urti OR TI uri OR AB uri OR TI ari OR AB ari OR (MH "Otitis Media+") OR TI "Otitis Media" OR AB "Otitis Media" OR TI "Glue ear" OR AB "Glue ear" OR TI AOM OR AB AOM OR TI OME OR AB OME OR (TI "Middle Ear" OR AB "Middle Ear" AND (TI Infection OR AB Infection OR TI Infections OR AB Infections OR TI Inflammation OR AB Inflammation OR TI Inflammations OR $A B$ Inflammations)))

AND

((MH "Clinical Trials+") OR (MH "Quantitative Studies") OR TI placebo* OR AB placebo* OR (MH "Placebos") OR (MH "Random Assignment") OR TI random* OR AB random* OR TI ((singl* or doubl* or tripl* or trebl*) W1 (blind* or mask*)) OR AB ((singl* or doubl* or tripl* or trebl*) W1 (blind ${ }^{\star}$ or mask*)) OR TI clinic ${ }^{\star}$ trial $^{\star}$ OR AB clinic ${ }^{\star}$ trial* OR PT clinical trial)

\section{Web of Science}

(Probiotics OR Synbiotics OR Lactobacillus OR Bifidobacterium OR Saccharomyces OR "Streptococcus thermophilus" OR "Cultured Milk Products" OR Antibiosis OR Lactococcus OR Probiotics OR Probiotic OR Synbiotics OR Synbiotic OR Lactobacillus OR Lactobacilli OR Bifidobacteria OR Bifidobacterium OR Saccharomyces OR Saccharomyce OR "Microbial dietary supplements" OR Yoghurt OR "Fermented milk" OR "Cultured Milk" OR "Fermented Dairy" OR Acidophilus OR Antibiosis OR "Microbial Antagonism" OR "Microbial Antagonisms" OR "Bacterial Interferences" OR "Bacterial Interference" OR "Streptococcus thermophilus" OR "Bacillus laterosporus" OR "Pediococcus acidilactici" OR Lactococcus OR Lactis)

\section{AND}

("Respiratory Tract Infections" OR "Respiratory tract infection" OR "Respiratory tract infections" OR "Respiratory infection" OR "Respiratory infections" OR urti OR uri OR ari OR "Otitis Media" OR "Otitis Media" OR "Glue ear" OR AOM OR OME OR ("Middle Ear" AND (Infection OR Infections OR Inflammation OR Inflammations)))

AND

(TS=(random* or placebo ${ }^{\star}$ or allocat ${ }^{\star}$ or crossover ${ }^{\star}$ or "cross over" or ((singl* or doubl*) NEAR/1 blind $\left.\left.{ }^{\star}\right)\right)$ OR TI=(trial))

\section{LILACS}

(Probiotics OR Synbiotics OR Lactobacillus OR Bifidobacterium OR Saccharomyces OR "Streptococcus thermophilus" OR "Cultured Milk Products" OR Antibiosis OR Lactococcus OR Probiotics OR Probiotic OR Synbiotics OR Synbiotic OR Lactobacillus OR Lactobacilli OR Bifidobacteria OR Bifidobacterium OR Saccharomyces OR Saccharomyce OR "Microbial dietary supplements" OR Yoghurt OR "Fermented milk" OR "Cultured Milk" OR "Fermented Dairy" OR Acidophilus OR Antibiosis OR "Microbial Antagonism" OR "Microbial Antagonisms" OR "Bacterial Interferences" OR "Bacterial Interference" OR "Streptococcus thermophilus" OR "Bacillus laterosporus" OR "Pediococcus acidilactici" OR Lactococcus OR Lactis)

AND

("Respiratory Tract Infections" OR "Respiratory tract infection" OR "Respiratory tract infections" OR "Respiratory infection" OR "Respiratory infections" OR urti OR uri OR ari OR "Otitis Media" OR "Otitis Media" OR "Glue ear" OR AOM OR OME OR ("Middle Ear" AND (Infection OR Infections OR Inflammation OR Inflammations)))

AND

(random* or placebo* or allocat* or crossover* or "cross over" or blind* OR trial)

\section{Appendix 2. Trial registry search strategies}

\section{ClinicalTrials.gov}

(Probiotics OR Probiotic OR Synbiotics OR Synbiotic OR Lactobacillus OR Lactobacilli OR milk OR Acidophilus OR Yoghurt) AND ("Otitis Media" OR "Glue ear" OR AOM OR OME OR "Middle Ear Infection")

\section{WHO ICTRP}


Probiotics AND "Otitis Media" OR Probiotic AND "Otitis Media" OR Synbiotics AND "Otitis Media" OR Synbiotic AND "Otitis Media" OR Lactobacillus AND "Otitis Media" OR Lactobacilli AND "Otitis Media" OR milk AND "Otitis Media" OR Acidophilus AND "Otitis Media" OR Yoghurt AND "Otitis Media"

\section{CONTRIBUTIONS OF AUTHORS}

Draft the protocol: AMS, KG, Elaine Beller, KR, JC, PL, CDM

Develop the search strategy: JC

Run the search strategy: JC

Obtain copies of trials: JC

Select which trials to include: AMS, JC, FI, BJ

Extract data from trials: AMS, FI, BJ

Enter data into Review Manager 5: AMS

Carry out the analysis: AMS, CDM

Interpret the analysis: AMS, JC, BJ, FI, KR, KG, PL, CDM

Draft the final review: AMS, KG, CDM

Update the review: AMS, CDM

\section{DECLARATIONSOF INTEREST}

Anna M Scott: Salary funded by the Centre for Research Excellence in Minimising Antibiotic Resistance from Acute Respiratory Infections (CREMARA), which itself is funded by the National Health and Medical Research Council (NHMRC), Australia.

Justin Clark: Salary funded by the Centre for Research Excellence in Minimising Antibiotic Resistance from Acute Respiratory Infections (CREMARA), which itself is funded by the National Health and Medical Research Council (NHMRC), Australia.

Blair Julien: has no conflicts of interest to declare.

Farhana Islam: has no conflicts of interest to declare.

Kristian Roos: is a minor shareholder of a small biomedical company (ESSUM AB), which has for many years been performing research with probiotic bacteria. ESSUM AB has no patent in probiotic bacteria that might be used for acute otitis media, and ESSUM has no intention of conducting research into acute otitis media.

Keith Grimwood: has no conflicts of interest to declare.

Paul Little: A study for which PL was Chief Investigator had placebo and probiotic tablets provided by a commercial company that makes probiotic (Cultech).

Chris Del Mar: reports Centre for Research Excellence in Minimising Antibiotic Resistance from Acute Respiratory Infections (CREMARA) and Centre of Research in Minimising Antibiotic Resistance in the Community (CRE-MARC) institutional funding (National Health and Medical Research Council (NHMRC)); Cochrane Acute Respiratory Infections Group institutional funding (NHMRC); institutional and personal funding from the Australian Commission on Safety and Quality in Health Care for the development of patient decision aids; personal consulting funding for shared decision-making implementation (BUPA, UK); American College of Physicians (ACP) Journal Club editorial work; consultancy/providing advice to a pharmaceutical company about a proposed vaccine that might be effective against otitis media in children.

\section{SOURCES OF SUPPORT}

\section{Internal sources}

- There are no internal sources of support to report, Other.

\section{External sources}

- There are no external sources of support to report, Other.

\section{DIFFERENCES BETWEEN PROTOCOL AND REVIEW}

Differences from the protocol:

1. Study population: the protocol stated that the population of interest is children (aged $\leq 18$ years) diagnosed with acute otitis media (AOM) by a clinician. Because this review looks at the role of probiotics in preventing AOM, we broadened the population to include any children (aged $\leq 18$ years), still including children diagnosed with AOM. 
2. Electronic searches: the protocol stated that we would contact trial investigators for unpublished data. The status of trials categorised as 'ongoing studies' is as follows: not yet started or ongoing (five trials); contact information not available (two trials); already published (publication included in the present review) (one trial); awaiting response from investigators (one trial) (ISRCTN53286030).

3. Electronic searches: our protocol specified that we would use the 'similar articles' feature in PubMed and shared citation matcher in Web of Science. However, as forward and backward citation searches did not yield any additional included trials, we did not expect to find any additional included trials this way.

4. Subgroup analysis: we planned to carry out the following subgroup analyses: (1) child's age ( $\leq$ two years old), (2) type of probiotic, (3) children with severe AOM, (4) trials that included a co-intervention. (1) The first subgroup analysis was planned because the initial Population Intervention Comparison Outcome (PICO) stated that included trials will have as their population children diagnosed with $\mathrm{AOM}$, and there is no consensus on the benefit of antibiotics in $\mathrm{AOM}$ in children younger than two years old and guidelines recommend selective use of antibiotics for AOM in children older than two years old (Rovers 2006). As the population was amended to include all children, this subgroup analysis was omitted. (2) We did conduct an analysis by probiotic type (see Analysis 1.3). (3) We did not conduct a subgroup analysis by severity of AOM, as this outcome was reported by only one included trial. (4) We did not conduct a subgroup analysis by co-intervention because in only one trial all children (both groups) received a co-intervention (Roos 2001a).

5. Sensitivity analysis: we planned to carry out a sensitivity analysis on including versus excluding trials with two or more domains rated as at high risk of bias, however this was not performed as only one included study rated two domains as at high risk of bias.

6. Primary outcome was specified as 'incidence of AOM' in the protocol. This was reported as 'proportion of children with AOM' in the review due to variation in the time points at which studies reported the outcome.

7. Secondary outcome was specified as 'difference between probiotic and non-probiotic groups in use of antibiotics to treat AOM (e.g. dose, duration)' in the protocol. This was reported as 'difference in the use of antibiotics' in the review to more accurately refect the evidence available for meta-analyses.

8. 'Summary of findings' table: the protocol stated that we would create a 'Summary of findings' table using the following outcomes: incidence of AOM, severity of AOM, adverse events, median duration of AOM episodes, difference between groups in antibiotic use, time off school (child), time off work (parent or carer). Due to a paucity of data and change in how the primary outcome was reported (proportion of children with $A O M$ ), we instead reported the following outcomes: proportion of children with AOM, proportion of children with AOM among children not prone to AOM, proportion of children with AOM among children prone to AOM, severity of AOM, adverse events, time off school for child, difference in antibiotic use, difference in proportion of children with other infections.

9. Three subgroup analyses were not prespecified but were conducted because there were sufficient data available for pooling: difference in the use of antibiotics (subgroups: for AOM, for other infections); difference in other infections (subgroups: reduction in acute respiratory infections, reduction in gastrointestinal infections); and proportion of children with AOM (children prone to AOM, children not prone to $A O M$ ).

10.Authorship: one of the protocol authors (Elaine Beller) was not involved in the systematic review itself and is thus not listed as an author here.

\section{N DEX TERMS}

\section{Medical Subject Headings (MeSH)}

Acute Disease; Anti-Bacterial Agents [therapeutic use]; Disease Susceptibility; Otitis Media [epidemiology] [ ${ }^{*}$ prevention \& control]; Probiotics [adverse effects] [*therapeutic use]; Randomized Controlled Trials as Topic [statistics \& numerical data]

\section{MeSH check words}

Adolescent; Child; Child, Preschool; Humans; Infant 